GEAP-4495

AEC RESEARCH AND

DEVELOPMENT REPORT

MARCH, 1964

\title{
GENERAL CORROSION OF INCOLOY-80O IN SIMULATED SUPERHEAT REACTOR ENVIRONMENT
}

\author{
W.L. PEARL \\ E.G. BRUSH \\ G.G. GAUL \\ G.P. WOZADLO
}

U.S. ATOMIC ENERGY COMMISSION CONTRACT AT(04-3)- 189 PROJECT AGREEMENT 13

VALLECITOS ATOMIC LABORATORY GENERAL ELECTRIC 


\section{DISCLAIMER}

This report was prepared as an account of work sponsored by an agency of the United States Government. Neither the United States Government nor any agency Thereof, nor any of their employees, makes any warranty, express or implied, or assumes any legal liability or responsibility for the accuracy, completeness, or usefulness of any information, apparatus, product, or process disclosed, or represents that its use would not infringe privately owned rights. Reference herein to any specific commercial product, process, or service by trade name, trademark, manufacturer, or otherwise does not necessarily constitute or imply its endorsement, recommendation, or favoring by the United States Government or any agency thereof. The views and opinions of authors expressed herein do not necessarily state or reflect those of the United States Government or any agency thereof. 


\section{DISCLAIMER}

Portions of this document may be illegible in electronic image products. Images are produced from the best available original document. 


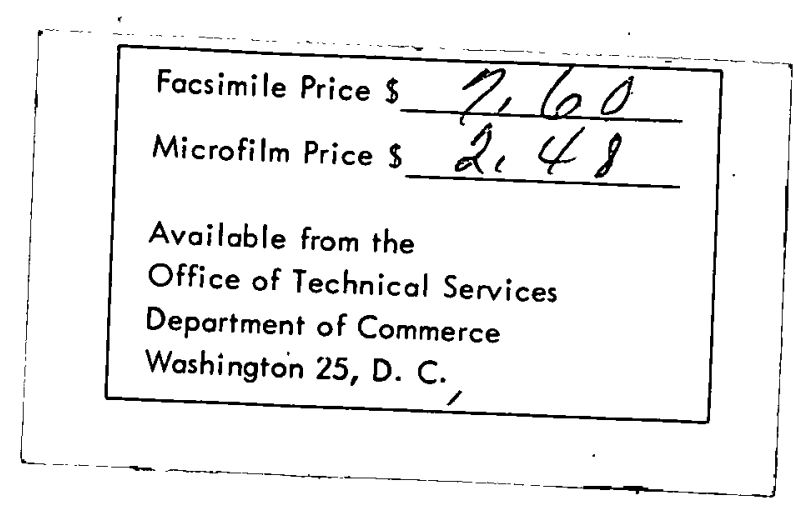

GEAP-4495

March, 1964

\section{GENERAL CORROSION OF \\ INCOLOY-800 IN SIMULATED \\ SUPERHEAT REACTOR ENVIRONMENT}

By

W. L. Pearl

E. G. Brush

G. G. Gaul

G. P. Wozadlo

Approved:

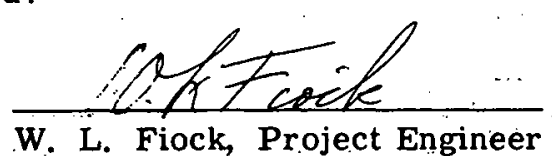

W. L. Fiock, Project Engineer Nuclear Super heat Project

\section{A. Kaynark}

S. Naymark Manager

Fuels and Materials Development

Prepared for the

U. S. Atomic Energy Commission

Contract No. A T(04-3)-189

Project Agreement No. 13

Printed in the U.S.A. Prom the Office of Technical Information, Department of Commerce,

Washington 25, D. C.

VALLECITOS atomic laboratoRy

GENERAL ELECTRIC

ATOMIC POWER EQUIPMENT DEPARTMENT

SAN JOSE, CALIFORNIA

1700-TIO-2

$80-5 / 64$ 


\section{LEGAL NOTICE}

This report was prepared as an account of Government sponsored work. Neither the United States, nor the Commission, nor any person acting on bebalf of the Commission:

A. Makes any warranty or representation, expressed or implied, with respect to the accuracy, completeness, or usefulness of the information contained in this report, or that the use of any information, apparatus, method, or process disclosed in this report may not infringe privately owned rights; or

B. Assumes any liabilities with respect to the use of, or for damages resulting from the use of any information, apparatus, method, or process disclosed in this report.

As used in the above, "person acting on bebalf of the Commission" includes any employee or contractor of the Commission, or employee of sucb contractor, to the extent that such employee or contractor of the Commission, or employee of such contractor prepares, disseminates, or provides access to, any information pursuant to bis employment or contract with the Commission, or bis emplovment with such contractor. 
TABLE OF CONTENTS

$\underline{\text { Page }}$

INTRODUCTION 1

CONCLUSIONS 2

MATERIATS 3

METHOD 5

CORROSION RESULTS 10

Heat Transfer 10

Isothermal 22

METALLURGICAL EVALUATION 27

Heat Transfer 27

Isother mal 31

Electron Microprobe Studies 35

DISCUSSION OF RESULTS 45

REFERENCES 49

ACKNOWLEDGMENT 51

APPENDIX A 53

DISTRIBUTION 


\section{LIST OF ILLUSTRATIONS*}

1 Superheat Corrosion Facility

2 Superheat Test Sheaths Temperature Gradients

3 Weight Loss with Heat Transfer Versus Time

4 Weight Loss with Heat Transfer Versus Time ${ }^{(1 / 2)}$

5 Weight Loss with Heat Transfer Versus Time ${ }^{(1 / 3)}$

6 Corrosion Rate as a Function of Temperature

7 Weight Loss Linear Response

8 Weight Loss Nonlinear Response

9 Incoloy-800 Oxidized in Superheated Steam

10 Corrosion of Incoloy-800 - Isother mal Exposures

11 Incoloy-800 Heat Transfer Specimens, 4078 Hours 28

12 Incoloy-800 Heat Transfer Specimens 29

13 Incoloy-800. Scale after 4078 Hours Exposure with Heat Transfer 30

14 Incoloy-800 Scale after 5266 Hours Isothermal Exposure in $1050^{\circ} \mathrm{F}$ Superheated Steam

15 Incoloy-800 Scale after 3067 Hours Isothermal Exposure in $1150^{\circ} \mathrm{F}$ Superheated Steam

16 Microstructure of Incoloy-800 after 5116 Hours Isothermal Exposure in $1050^{\circ} \mathrm{F}$ Superheated Steam

17 Microstructure of Incoloy-800 after 3067 Hours Isothermal Exposure in $1150^{\circ} \mathrm{F}$ Superheated Steam

18 Schematic Representation of Disturbed Alloy Layer Concentration Profiles

10 Electron Microprobe Traces of Incoloy-800 after 1000 Hours Isothermal Exposure at $1050^{\circ} \mathrm{F}$

20 Electron Microprobe Traces of Incoloy-800 after 5116 Hours Isothermal Exposure at $1050^{\circ} \mathrm{F}$

21 Linear Approximation for the Equilibrium Layer Thickness, $\dot{x}_{0(e)}$

Pictures reduced approximately 15 percent in printing. 


\section{LIST OF TABLES}

Table

$\underline{\text { Title }}$

$\underline{\text { Page }}$

I Composition of Incoloy-800 Materials

II Operating Conditions During Test

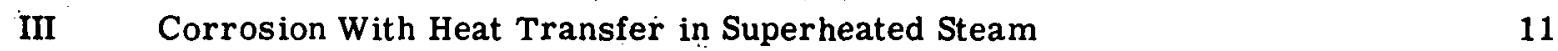

IV Predicted Three Year Corrosion Weight Lóss $\quad 22$

V Corrosion in Superheated Steam - Isothermal Exposures $\quad 23$

VI Weight Gain Measurements of Isothermal Exxposures $\quad 26$

VII Depth of Compositional Disturbance - Heat Transfer Specimens 31

VIII Depth of Compositional Disturbance - Isothermal Specimens 33

IX Electron Microprobe Evaluation $\quad 38$

X. Quantities Converted to Oxide $\quad 42$

XI Analysis of Scale After 18 Months Exposure 46 


\section{INTRODUCTION}

The 300 series stainless steels had been selected originally as the reference fuel cladding material for utilization in several superheat reactor (SHR) systems being built as part of the United States Atomic Energy Commission (USAEC) program. ${ }^{(1)}$ The adequacy of the general corrosion resistance of Type-304 stainless steel for superheat fuel cladding was confirmed in the Phase I portion of the study reported previously. ${ }^{(2)}$

Fuel jacket failures that occurred in Type-304 stainless clad fuel elements exposed in the Vallecitos boiling water reactor superheated steam loop (SADE) ${ }^{(3,4)}$ indicated the questionable dependability of such stainless steels for this SHR fuel cladding application.

A portion of the USAEC sponsored superheat program at the Atomic Power Equipment Department of the General Electric Company was oriented to study and reproduce the in-reactor intergranular failures in out-of-pile corrosion tests. The investigation was aimed at finding ways to eliminate the cause or using improved alloys that would be less susceptible to the effect. The work has been documented ${ }^{(5)}$ as a separate phase of the fuel cladding corrosion testing studies being performed in a SHR environment. A concurrent investigation was carried out in the simulated SHR environment facilities to evaluate the general corrosion properties of several commercially a vailable materials that could withstand the intergranular type of attack found in the SADE facility tests.

Early results of the program ${ }^{(6)}$ indicated that Incoloy-800* was a leading contender as an adequate cladding material for superheat fuel with its high temperature physical, mechanical, and chemical properties.

It is the purpose of this report to summarize the results of the general corrosion evaluations carried out to date with Incoloy-800 as part of the AEC sponsored superheat program.

* Registered trademark of the International Nickel Company, Incorporated 


\section{CONCLUSIONS}

The following conclusions are based on the out-of-pile general corrosion evaluations completed to date on Incoloy-800 as a fuel cladding for nuclear superheat applications :

1. The corrosion data from 4000-hour heat transfer tests indicate good corrosion resistance up to at least a $1300^{\circ} \mathrm{F}$ metal temperature. By use of a devised method of data treatment, the general corrosion for three-years exposure at $1300^{\circ} \mathrm{F}$ can be calculated to average 0.0016 inch with an upper 95 percent confidence limit of 0.0033 inch.

2. A compositionally-disturbed layer develops at the metal-oxide interface. The disturbed layer depth is a function of time and temperature of exposure. The most pessimistic interpretation of the growth rate with time would indicate a layer depth of 0.0017 inch after a three-years exposure at $1300^{\circ} \mathrm{F}$. The possible effects of such a layer on cyclic type exposures (i. e., cyclic strain, corrosion fatigue, etc) have not been evaluated.

3. The corrosion results indicate excellent corrosion resistance of Incoloy-800 when exposed isothermally to steam generated from a simulated BWR and superheated to $1150^{\circ} \mathrm{F}$. Corrosion rates of $3.6 \pm 1.2 \mathrm{mg} / \mathrm{dm}^{2}-\mathrm{mo}$ at $1050^{\circ} \mathrm{F}$ and $10 \pm 18$ $\mathrm{mg} / \mathrm{dm}^{2}-\mathrm{mo}$ at $1150^{\circ} \mathrm{F}$ are applicable in such exposures with a steam velocity of $20 \mathrm{ft} / \mathrm{sec}$.

4. The potential activity problem from metal-to-system losses increascs in significance with increase in metal temperature (especially above $1100^{\circ} \mathrm{F}$ ) and increase in exposure time. At least one-half of the oxide formed on metal operating at temperatures between 1200 and $1300^{\circ} \mathrm{F}$ will be carried downstream from the cladding.

5. Additional exposures of Incoloy-800 sheaths as heat transfer specimens at metal temperatures of $1200-1400^{\circ} \mathrm{F}$ are required to permit more accurate extrapolation of the higher temperature corrosion rate and corrosion-product-release rate data and to establish the ratio of alloy constituents lost to the system over time perlods of about three years. 


\section{MATERIALS}

The heat transfer specimens consisted of tubes, either welded or seamless, cold drawn, annealed and pickled. Each test sheath was 36-3/4 inches long by $9 / 16$-inch outside diameter by 0.500 -inch inside diameter. The ends of the sheaths were machined to 0.560 -inch outside diameter and the last $1 / 4$ inch on each end threaded. Two mils were centerless ground from the outside diameter of one set of Incoloy sheaths, (A) Table I, to remuve a layer of unknown composition believed to be caused by the annealing environment. The sheaths were marked, degreased in acetone; pickled for 10 minutes in a $130^{\circ} \mathrm{F}, 20$ percent, nitric acid bath, washed, dried and weighed.

Additional tubing, (B). Table I, to be tested was drawn from an ingot of Incoloy prepared with low aluminum and titanium content.

The coupons for isothermal testing were sheared from sheet and all edges were machined. They were given a uniform surface with " $O$ " grade paper, washed with soap, pickled for 20 minutes in a $130^{\circ} \mathrm{F}, 20$ percent nitric acid bath, rinsed, and acetone dried.

The chemical composition of the test materials are listed in Table I.

After test and prior to descaling, the tubes and test coupons were weighed and examined at magnifications up to $40 \times$ by means of a stereo-microscope. Descaling was performed in a solution of 20 percent sodium hydroxide and 3 percent potassium permanganate operated at $210^{\circ} \mathrm{F}$ up to $1-1 / 2$ hours. The time required for complete descaling increased with increasing temperature of exposure for both the heat transfer and isothermal specimens.

Nylon brushes and nylon wool were used to remove the rotted scale. Control pieces gave less than $2 \mathrm{mg} / \mathrm{dm}^{2}$ loss of base metal in the same time. The specimens were weighed and sectioned in selected areas for microscopic examination. 
TABLE I

COMPOSITION OF INCOLOY-800 MATERLALS

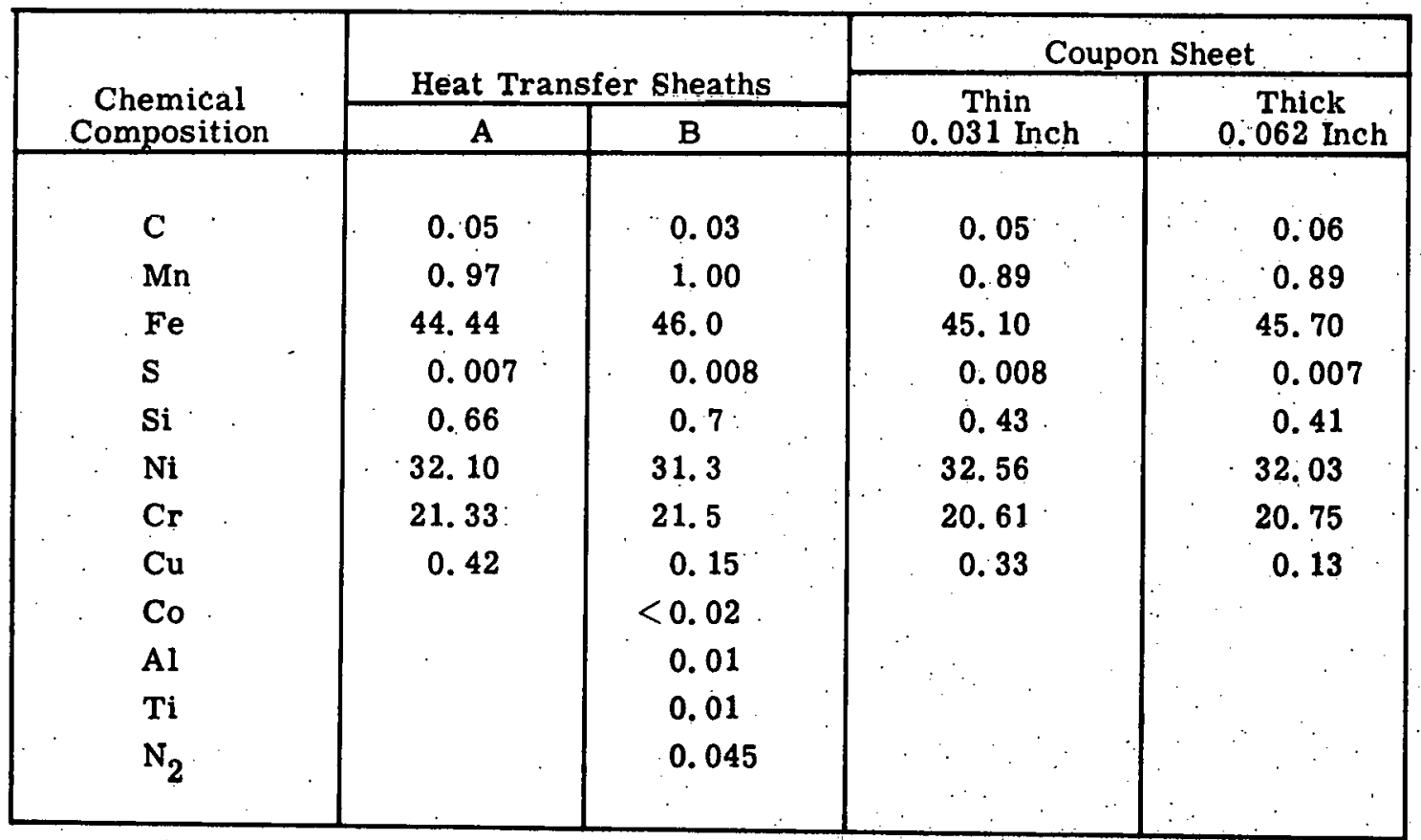




\section{METHOD}

The general corrosion tests were carried out in the modified CL-1 superheat corrosion facility shown in schematic diagram in Figure 1. The original CL-1 superheat facility, as previously described elsewhere, ${ }^{(7)}$ superheated the $546^{\circ} \mathrm{F}$ inlet saturated steam from the boiling

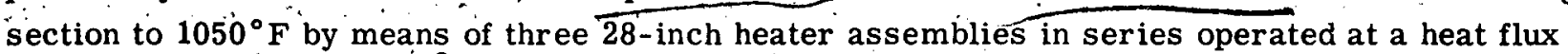
of about $175,000 \mathrm{Btu} / \mathrm{hr}-\mathrm{ft}^{2}$. The heat transfer was accomplished by use of an internal stainless steel heater electrically heated but electrically insulated from the sheath being tested. The calculated metal temperatures of the test sheaths was $800^{\circ} \mathrm{F}$ at the inlet to $1300^{\circ} \mathrm{F}$ at the outlet. The flow annulus was designed to pass $500 \mathrm{lb} / \mathrm{hr}$ of steam with an inlet velocity of about $110 \mathrm{ft} / \mathrm{sec}$ and outlet velocity of about $220 \mathrm{ft} / \mathrm{sec}$. The $1050^{\circ} \mathrm{F}$ steam was passed through a coupon section then desuperheated and condensed.

The facility was subsequently expanded to include an additional heat transfer test assembly to heat the $1050^{\circ} \mathrm{F}$ superheated steam to $1150^{\circ} \mathrm{F}$ with a corresponding calculated metal temperature of $1280^{\circ} \mathrm{F}$ at the inlet and $1410^{\circ} \mathrm{F}$ at the outlet with a heat flux of $125,000 \mathrm{Btu} / \mathrm{hr}-\mathrm{ft}^{2}$ across the 28 -inch heated length. The flow annulus was designed to give a resultant steam velocity of $130 \mathrm{ft} / \mathrm{sec}$ past the sheath. An additional coupon section was installed downstream of the new test section to permit the isothermal testing of coupons in $1150^{\circ} \mathrm{F}$ superheated steam. The calculated thermal gradients across the four sheath tests are represented in Figure 2. The test sheaths were extended outside the test housing, threaded, and a constant tensile force applied through attached end beams by means of air cylinders. The stresses on the three higher temperature sheaths were set to produce 0.1 percent elongation in 1000 hours.

The test coupons exposed in the $1050^{\circ} \mathrm{F}$ and $1150^{\circ} \mathrm{F}$ superheat coupon sections were mounted in the standard coupon holders ${ }^{(7)}$ with stainless steel bolts and separated by stainless steel spacers to result in a velocity of steam past the test specimens of about $20 \mathrm{ft} / \mathrm{sec}$.

The saturated steam generated in the boiling portion of the facility was maintained at $546^{\circ} \mathrm{F}$ and 1000 psig. A nominal level of $20 \mathrm{ppm}$ oxygen and $2.5 \mathrm{ppm}$ hydrogen was maintained in the steam, a condition representative of the oxygen and hydrogen formed in a boiling water reactor from radiolytic water decomposition.

Oxygen and hydrogen analyses of the condensed steam were performed by means of a gasstripper gas-chromatograph system described previously. ${ }^{(8)}$ The facility water was at neutral $\mathrm{pH}$ with no chemical additives. The water resistivity was maintained above 2 megohm-cm during the test runs by continuous cleanup of a portion of the flow. The facility operating conditions during the various test runs are summarized in Table $\Pi$.

At the start of the tests, after the assembled heaters and coupon holders were placed in position, demineralized aerated water was introduced into the loop. The boiling portion of the 
system was gradually brought to temperature and pressure. A steam blowdown was utilized for stripping out the dissolved gases. Approximately 2 hours elapsed from startup until the system was at boiling temperature and pressure and essentially deaerated. Power was then applied to the superheat heaters and to the electrolytic decomposer, and the system gradually brought to $1150^{\circ} \mathrm{F}$ exit-steam temperature in approximately 45 minutes. Because of the oxygen consumed in corrosion and/or hydrogen produced as a corrosion product, batch additions of oxygen were then made as needed to maintain the oxygen and hydrogen balance at the desired level. 


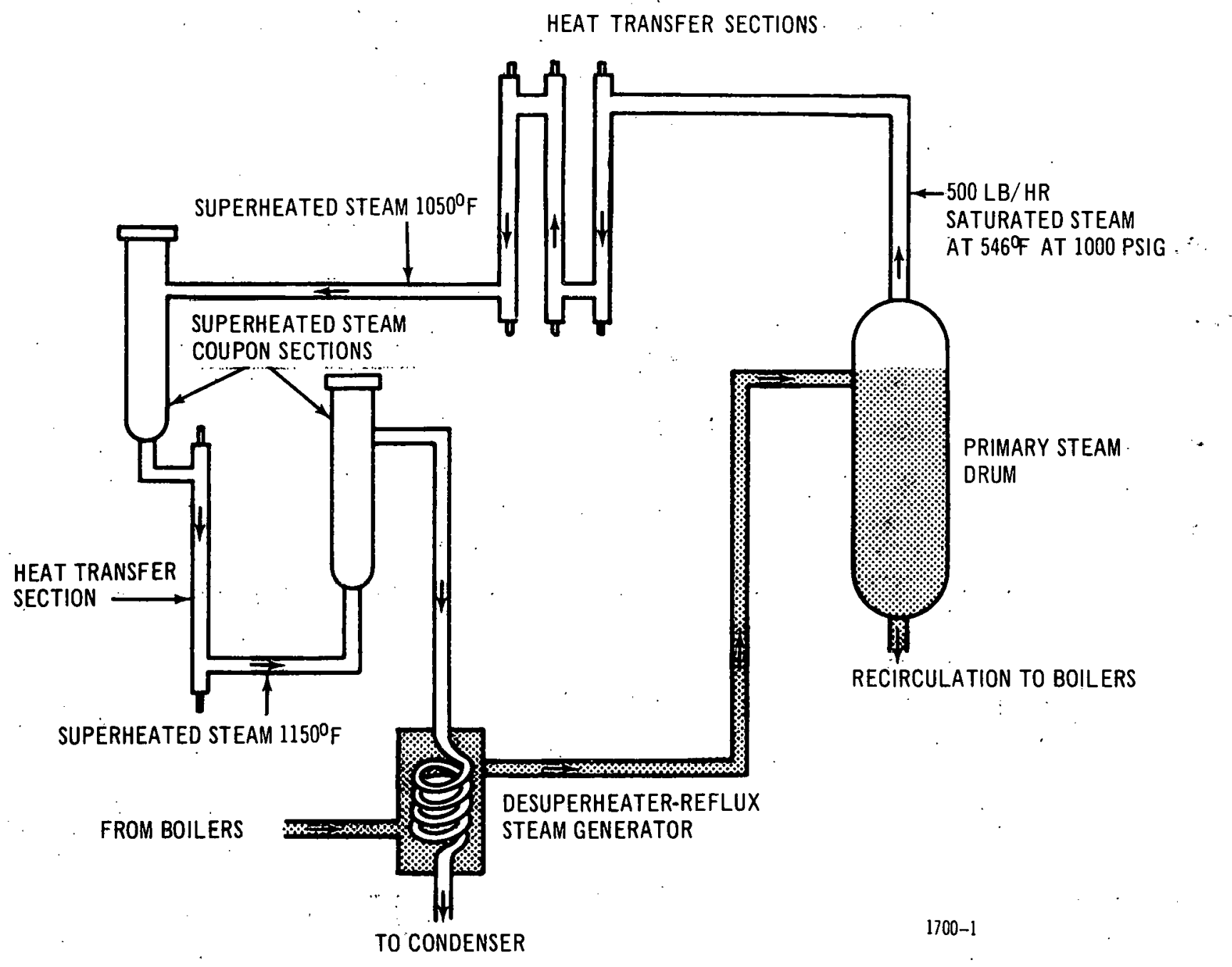

Figure 1. Superheat Corrosion Facility 


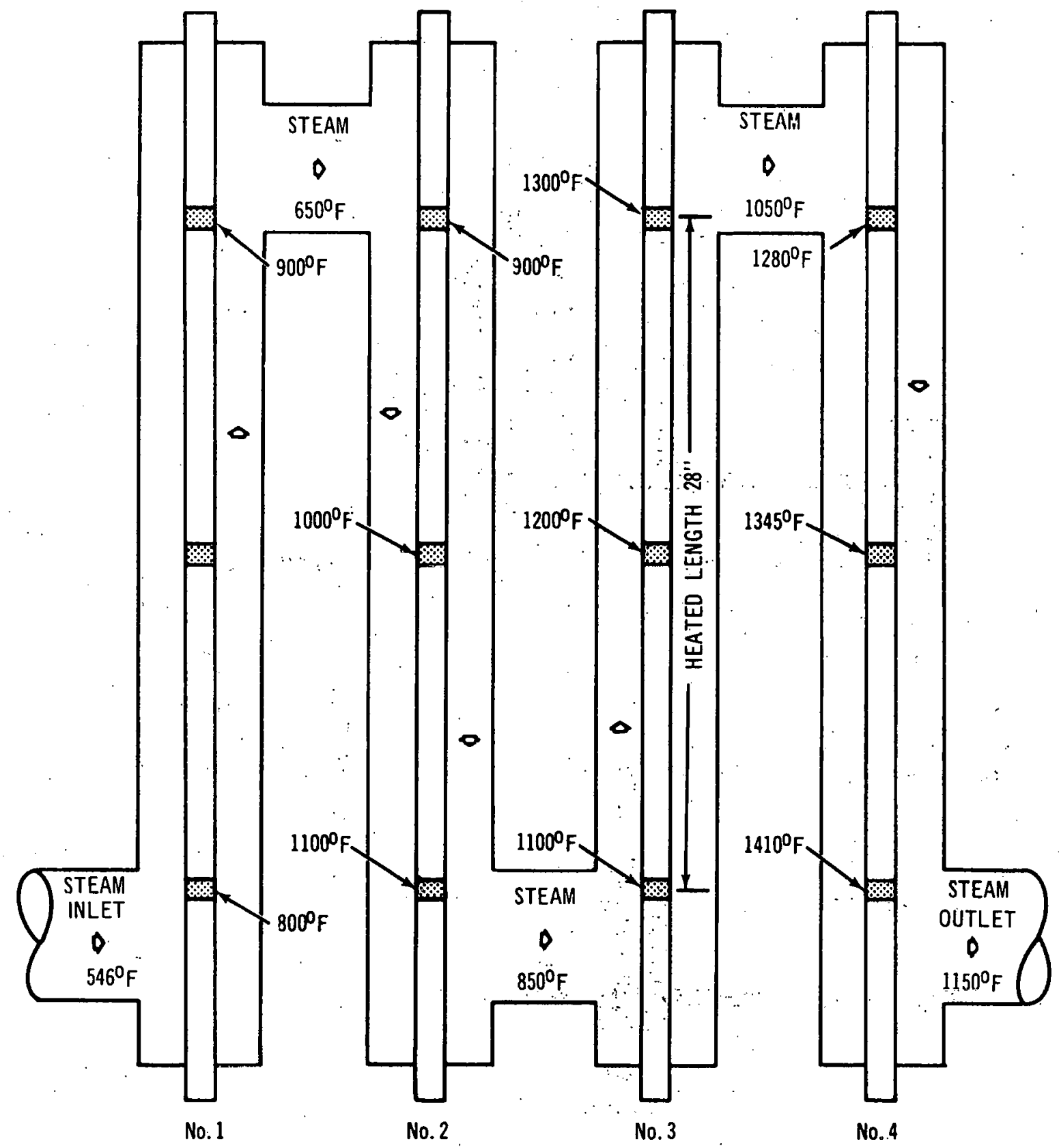

$1700-2$

Figure 2. Superheat Test Sheaths Temperature Gradients 
TABLE II

\section{OPERATING CONDITIONS DURING TEST}

\begin{tabular}{|c|c|c|c|c|c|c|}
\hline Run & 56 & 61 & 62 & 63 & 64 & $65 \mathrm{~B}-66$ \\
\hline Length of Test (hr) & 965 & 1011 & 1053 & : 1037 & 977 & 995 \\
\hline Steam Flow $(\mathrm{lh} / \mathrm{hr})$ & 439 & 110 & 403 & 433 & 421 & 450 \\
\hline Moisture in Inlet Steam (w/ & /o) 1 & 1 & $<1$ & 1 & 1 & 1 \\
\hline \multicolumn{7}{|l|}{ Steam Temperatures $\left({ }^{\circ} \mathrm{F}\right)$} \\
\hline Inlet & 546 & 546 & 546 & 546 & 546 & 546 \\
\hline Exit at 1st heater & 660 & 653 & 654 & 657 & 660 & 655 \\
\hline Exit at 2nd heater & 845 & 834 & 830 & 831 & 831 & 838 \\
\hline Exit at $3 \mathrm{rd}$ heater & 1048 & 1048 & 1049 & 1050 & 1053 & 1048 \\
\hline Exit at 4 th heater & not used & not used & 1160 & 1162 & 1163 & 1162 \\
\hline \multicolumn{7}{|l|}{ Inlet Steam Gas Content } \\
\hline Oxygen, (ppm) (range) 1 & $13.0-42.9$ & $12.5-28.5$ & $16.8-28.4$ & $13.8-28.0$ & $13.0-22.7$ & $15.0-29.3$ \\
\hline (mean) & 18.9 & 20.5 & 20.8 & 18.0 & 20.5 & 20.9 \\
\hline Hydrogen, (ppm) (range) & $1.5-8.0$ & $1.8-3.7$ & $1.7-3.1$ & $1.6-5.0$ & $1.5-2.8$ & $1.9-3.3$ \\
\hline (mean) & 2.4 & 2.4 & 2.6 & 2.3 & 2.4 & 2.5 \\
\hline \multicolumn{7}{|c|}{ Average Heat Flux (Btu/hr- $\left.\mathrm{ft}^{2}\right)$} \\
\hline 1st heater & 167,000 & 154,000 & 153,000 & 165,000 & 160,000 & 162,000 \\
\hline 2nd heater & 168,000 & 152,000 & 150,000 & 161,000 & 156,000 & 169,000 \\
\hline 3rd heater & 171,000 & 164,000 & 163,000 & 175,000 & 171,000 & 174,000 \\
\hline 4th heater & not used & not used & 121,000 & 129,000 & 126,000 & 131,000 \\
\hline \multicolumn{7}{|l|}{ Stress (psi) } \\
\hline 1st heater & 23,000 & 23,000 & 23,200 & 23,000 & 23,000 & 23,000 \\
\hline 2nd heater & 9,000 & 9,000 & 9,000 & 9,000 & 9,000 & 9,000 \\
\hline $3 r d$ heater & 4,500 & 4,500 & 4,500 & 4,500 & 4,500 & 4,500 \\
\hline 4th heater & not used & not used & 2,500 & 2,500 & 500 & 2,500 \\
\hline
\end{tabular}




\section{CORROSION RESULTS}

The corrosion results are reported on a descaled basis in milligrams per square decimeter $\left(\mathrm{mg} / \mathrm{dm}^{2}\right)$. For purposes of comparison, $2000 \mathrm{mg} / \mathrm{dm}^{2}$ is equivalent to approximately 0.001 inch of metal loss. Special emphasis has been given to the metal-to-system data in this work because of the potential problem caused by radioactive corrosion products that are transported by the steam and deposited downstream on the system equipment, e.g., the turbine blades. The metalto-system loss values were calculated from the following equation:

$$
\begin{gathered}
\text { Metal-to-system }=\text { descaled weight loss }- \text { metal calculated to be in } \\
\text { the adherent oxide. }
\end{gathered}
$$

For purposes of the above calculation, the oxide was assumed to consist of $\mathrm{Cr}_{2} \mathrm{O}_{3}, \mathrm{Fe}_{2} \mathrm{O}_{3}$, $\mathrm{Fe}_{3} \mathrm{O}_{4}$ and $\mathrm{NiO}$ in the ratio of the alloy's elemental composition with the iron divided equally between the two oxide forms. On this basis the oxide would be 72.8 percent metal. The validity of this choice will be discussed later.

No correction was made for any deposition that became an integral part of the oxide and was not removed in the cleaning step prior to descaling.

\section{Heat Transfer}

The uniform corrosion experienced by the Incoloy- 800 when exposed under heat transfer conditions to superheat the steam is summarized in Table III. It is obvious from the data that weight gain measurements alone cannot be used as any indication of the amount of corrosion on any one specimen. Weight gain data are useful with the descaled data, however, in establishing how much material is actually lost in transport to the environment.

\section{a. Weight Loss Calculations}

Each discrete datum point listed was obtained from one tubular specimen exposed with a linear.temperature gradient from one end to the other. As a result, the corrosion or corrosion rates with time for a specific temperature cannot be accurately established. The following treatment of the data (detailed in Appendix A) offers a method to develop rates that can be used for fuel design purposes. It's validity will remain to be verified.

The expected corrosion rate at a given temperature can be estimated provided that:

(1) the temperature distribution from colder to hotter end varies in a known way,

(2) the time dependence of the superheated steam oxidation process is known, and (3) the temperature dependence of the superheated steam oxidation process obeys a known function. 
TABLE III

CORROSION WITH HEAT TRANSFER IN SUPERHEATED STEAM

\begin{tabular}{|c|c|c|c|c|c|c|c|}
\hline $\begin{array}{c}\text { Run } \\
\text { Number }\end{array}$ & $\begin{array}{c}\text { Calculated } \\
\text { Metal } \\
\text { Temperature } \\
\left({ }^{\circ} \mathrm{F}\right) \\
\end{array}$ & $\begin{array}{l}\text { Steam } \\
\text { Velocity } \\
\text { (ft/sec) }\end{array}$ & $\begin{array}{l}\text { Incoloy } \\
\text { Tested* }\end{array}$ & $\begin{array}{c}\text { Exposure } \\
\text { Time } \\
\text { (hr) }\end{array}$ & $\begin{array}{l}\text { Weight } \\
\text { Gain } \\
\left(\mathrm{mg} / \mathrm{dm}^{2}\right)\end{array}$ & $\begin{array}{c}\text { Measured } \\
\text { Descaled } \\
\text { Weight } \\
\text { Loss } \\
\left(\mathrm{mg}_{/} / \mathrm{dm}^{2}\right) \\
\end{array}$ & $\begin{array}{l}\text { Calculated Loss } \\
\text { Metal-to-System } \\
\left.\text { (iug/dus } / \mathrm{du}^{2}\right)\end{array}$ \\
\hline 56 & $800-900$ & $100-120$ & A & 965 & -3 & 30 & 10 \\
\hline $61-64$ & & & A & 4078 & 32 & 45 & $+11^{* *}$ \\
\hline 56 & $900-1100$ & $120-160$ & A & 965 & 19 & 79 & 8 \\
\hline $61-64$ & 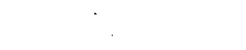 & & A & 4078 & 17 & 126 & 21 \\
\hline 56 & $1100-1300$ & $160-200$ & A & 965 & 21 & 165 & 30 \\
\hline $61-64$ & & & A & 4078 & -166 & 403 & 221 \\
\hline 62 & $1280-1410$ & $110 \div 130$ & $\mathbf{A}$ & 1053 & 59 & 316 & 72 \\
\hline 63 & & & A & 1037 & 53 & 416 & 51 \\
\hline $65 B-66$ & & & B & 995 & 47 & 431 & 82 \\
\hline
\end{tabular}

* See Table I

** Weight Gain

If it is assumed that the temperature dependence of the specific corrosion rate constant follows the Arrhenius equation and since the temperature distribution from inlet to outlet at each superheated steam test sheath is essentially linear, the descaled - metal loss (equal to the metal mass converted to oxide) of a sheath was derived in Appendix $A$, when $A / T_{0}$ is greater than 5 , as:

$$
\Delta W=\frac{A k_{0} f(t)}{\Delta T}\left[x^{-1} \exp (-x)-E i(x)\right]_{A / T_{i}}^{A / T_{0}}
$$

where

$\Delta W=$ metal loss in $\mathrm{mg} / \mathrm{dm}^{2}$

$A$ arid $k_{0}$ are the Arrhenius constants of the specific rate constant $k$, in:

$$
k=k_{0} \exp (-A / T)
$$


and have units :

$$
\begin{aligned}
\mathrm{k}_{0}= & \mathrm{mg} / \mathrm{dm}^{2} \mathrm{hr} \\
\mathrm{A}= & \text { a constant related to the activation energy and expressed } \\
& \text { in temperature units }\left({ }^{\circ} \mathrm{K}\right)
\end{aligned}
$$

where $\mathrm{T}$, in ${ }^{\circ} \mathrm{K}$, is the instantaneous temperature at any point along the sheath.

Also, in (1) where the bracketed term is to be evaluated between units $A / T_{0}$ and $\mathrm{A} / \mathrm{T}_{\mathrm{i}}$

$f(t)=$ the weight change-time dependence, hours raised to an appropriate power, $n$

$\mathrm{T}_{0}=$ the sheath surface temperature, ${ }^{\circ} \mathrm{K}$, at the test section outlet,

$\mathrm{T}_{\mathfrak{i}}=$ the sheath surface temperature, ${ }^{\circ} \mathrm{K}$, at the test section inlet

$\Delta \mathrm{T}=\left(\mathrm{T}_{0}-\mathrm{T}_{\mathbf{i}}\right)$, the temperature differential, ${ }^{\circ} \mathrm{K}$, over the length of the sheath

$x=a$ dimensionless integration variable

$E_{i}(x)=$ the exponential integral, given as $E_{i}(x)=\int_{x}^{\infty} x^{-1} e^{-x} d x$ and expandable, to a first approximation; when $x$ is large, say $>5$, as shown in formula 807 from Reference. 13.

\section{(1.) Consideration of rate constant versus. $1 / \mathrm{T}$}

If the weight loss data in Table $\Pi \mathrm{T}$ are consider ed a linear function of time $\left(t^{+1}\right)$, a parabolic function of time $\left(t^{+1 / 2}\right)$, and a cubic function of time $\left(t^{+}+1 / 3\right)$, the respective plots of weight loss versus time are shown in Figures $3,4,4$ and

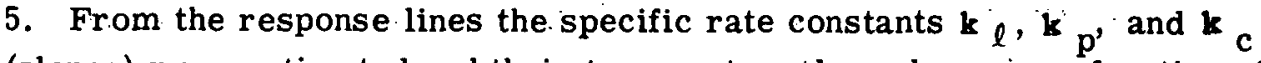
(slopes) were estimated and their temperature dependence as a function of the mean reciprocal absolute temperature is indicated in Figure 6. If the breaks shown in the three rate constant lines were real, a change in the mode of oxidation induced by the increased temperature would be indicated.

Because of the significance of such a change to the high-temperature performance of Incoloy, a test was made of the data to determine the degree of support for a break in the specific rate constant versus $1 / T . \therefore$ As detailed in Appendix A, the limited data available to date do not.support such breaks in the curves. Consequently, all the data have been pooled to obtain the best estimation of the desired rate constants. 


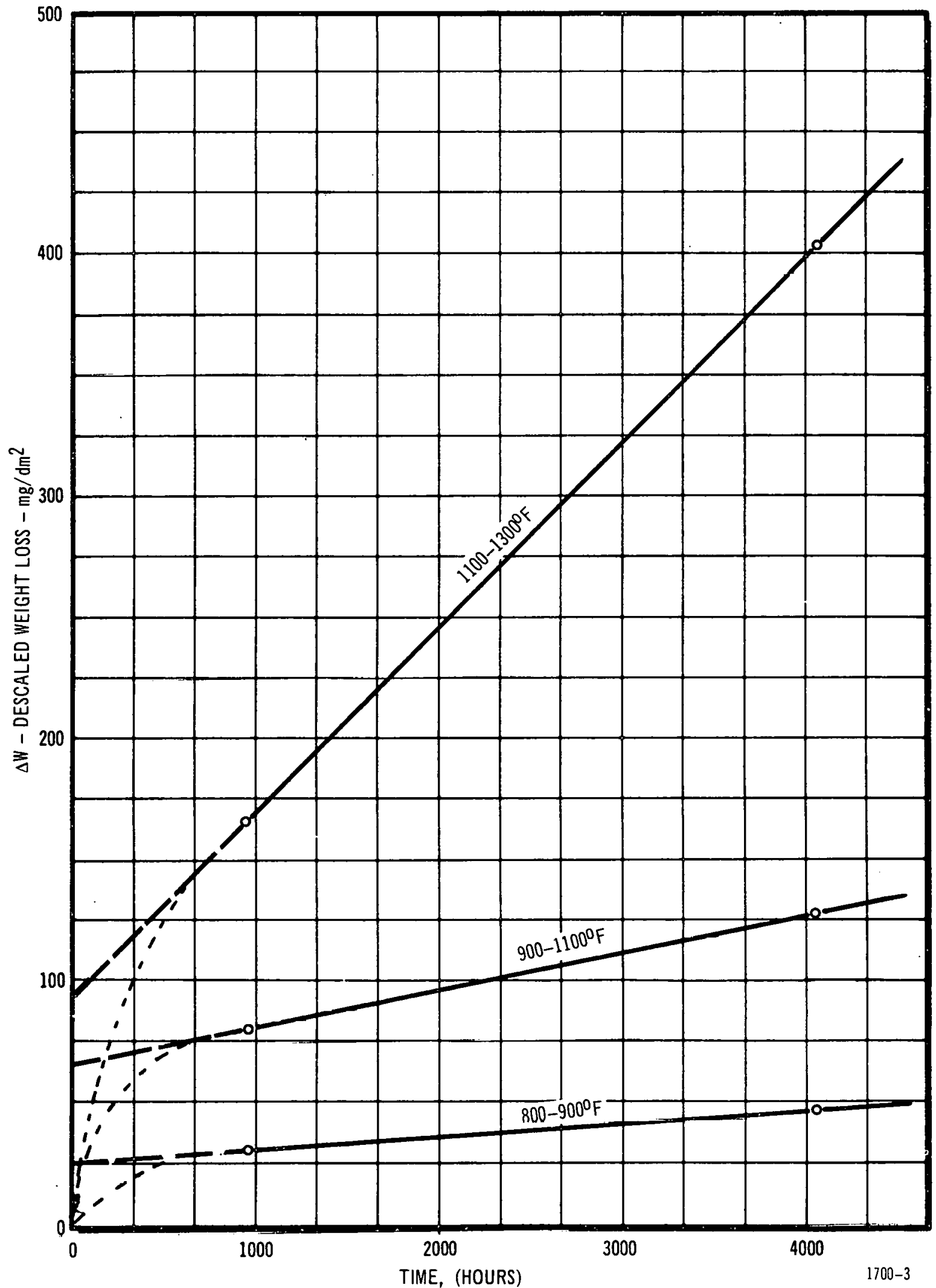

Figure 3. Weight Loss with Heat Transfer Versus Time 


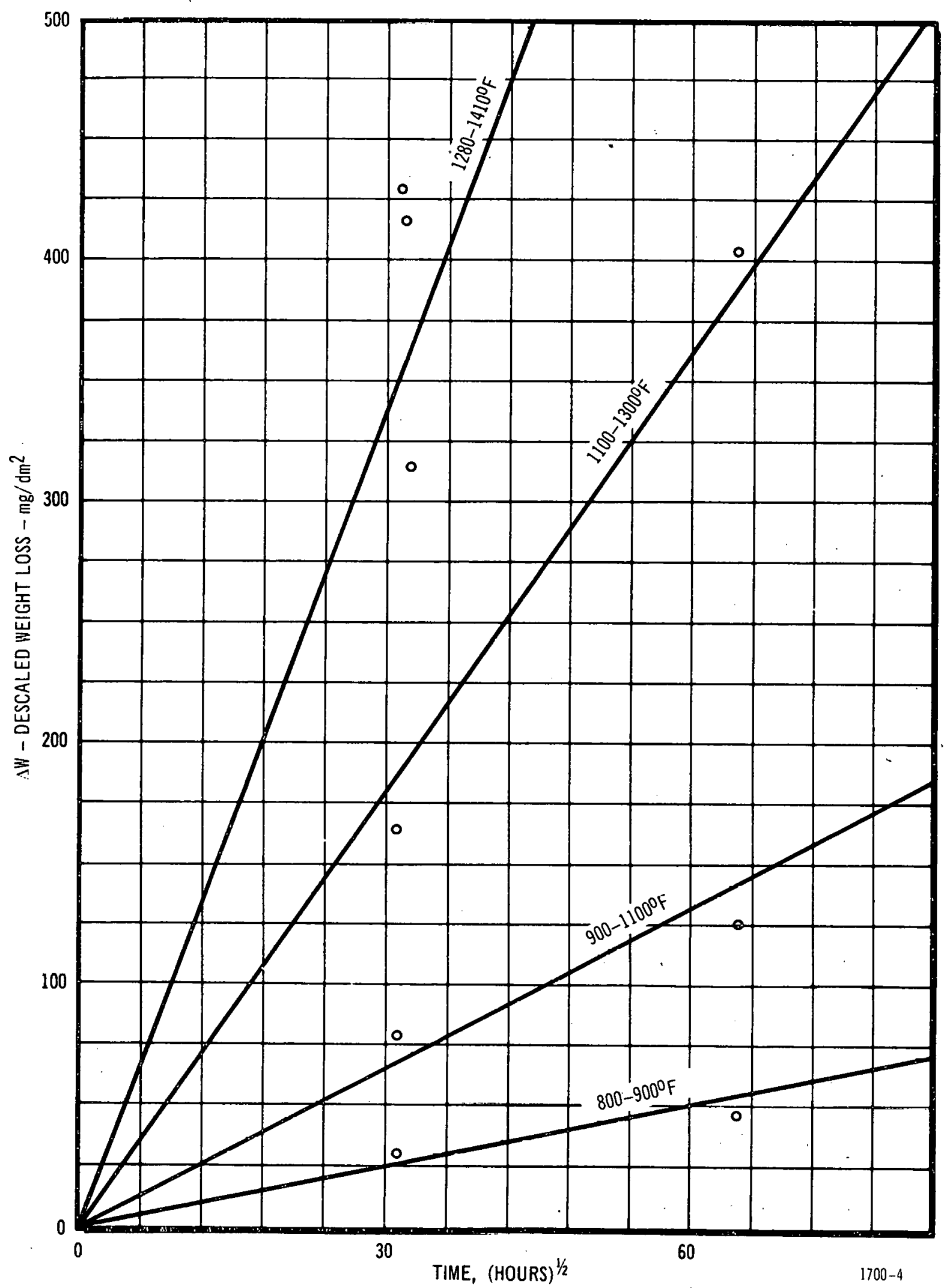

Figure 4. Weight Loss with Heat Transfer Versus Time ${ }^{(1 / 2)}$ in Superheated Steam 


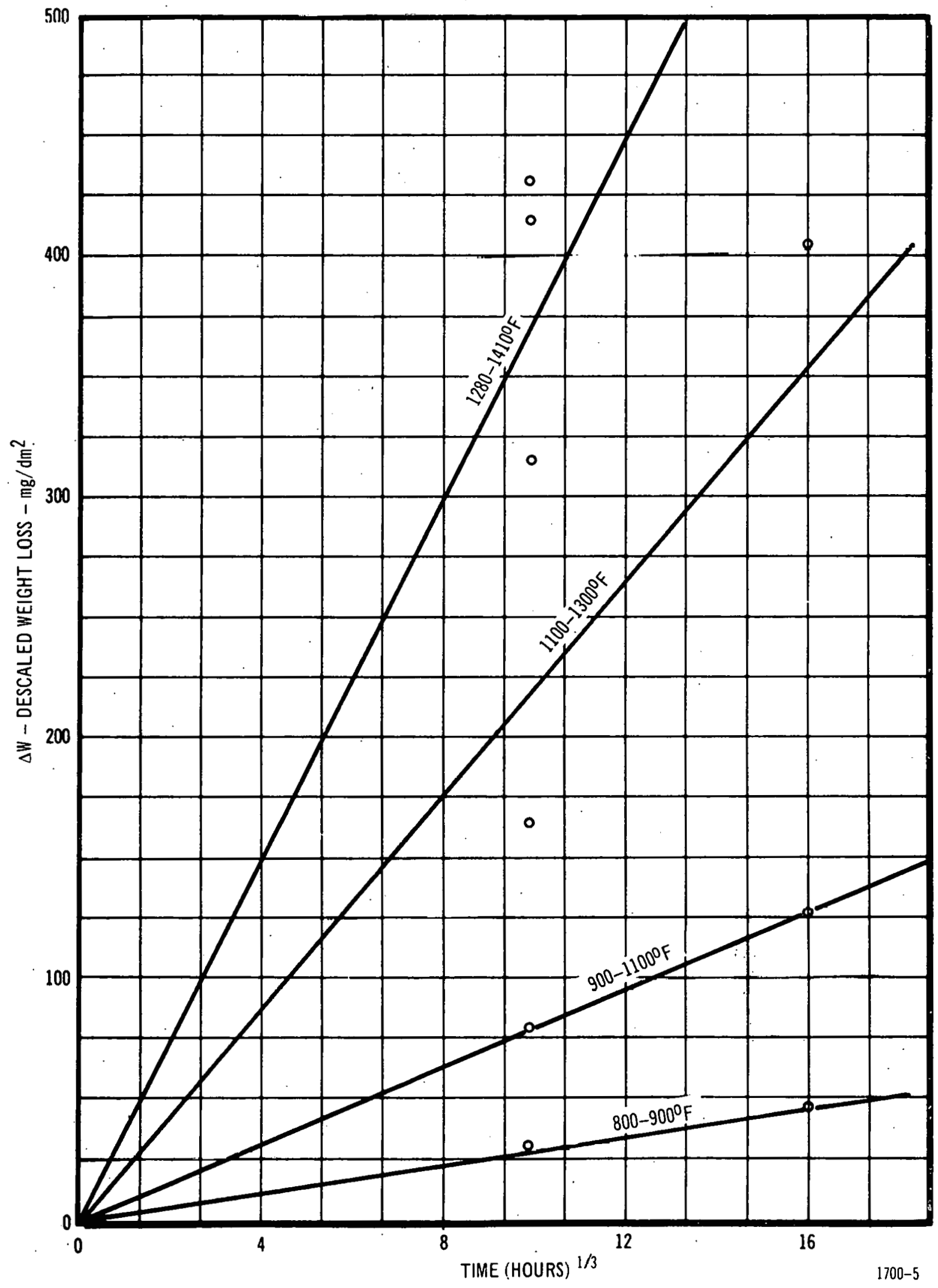

Figure 5. Weight Loss with Heat Transfer Versus Time ${ }^{(1 / 3)}$ in Superheated Steam 


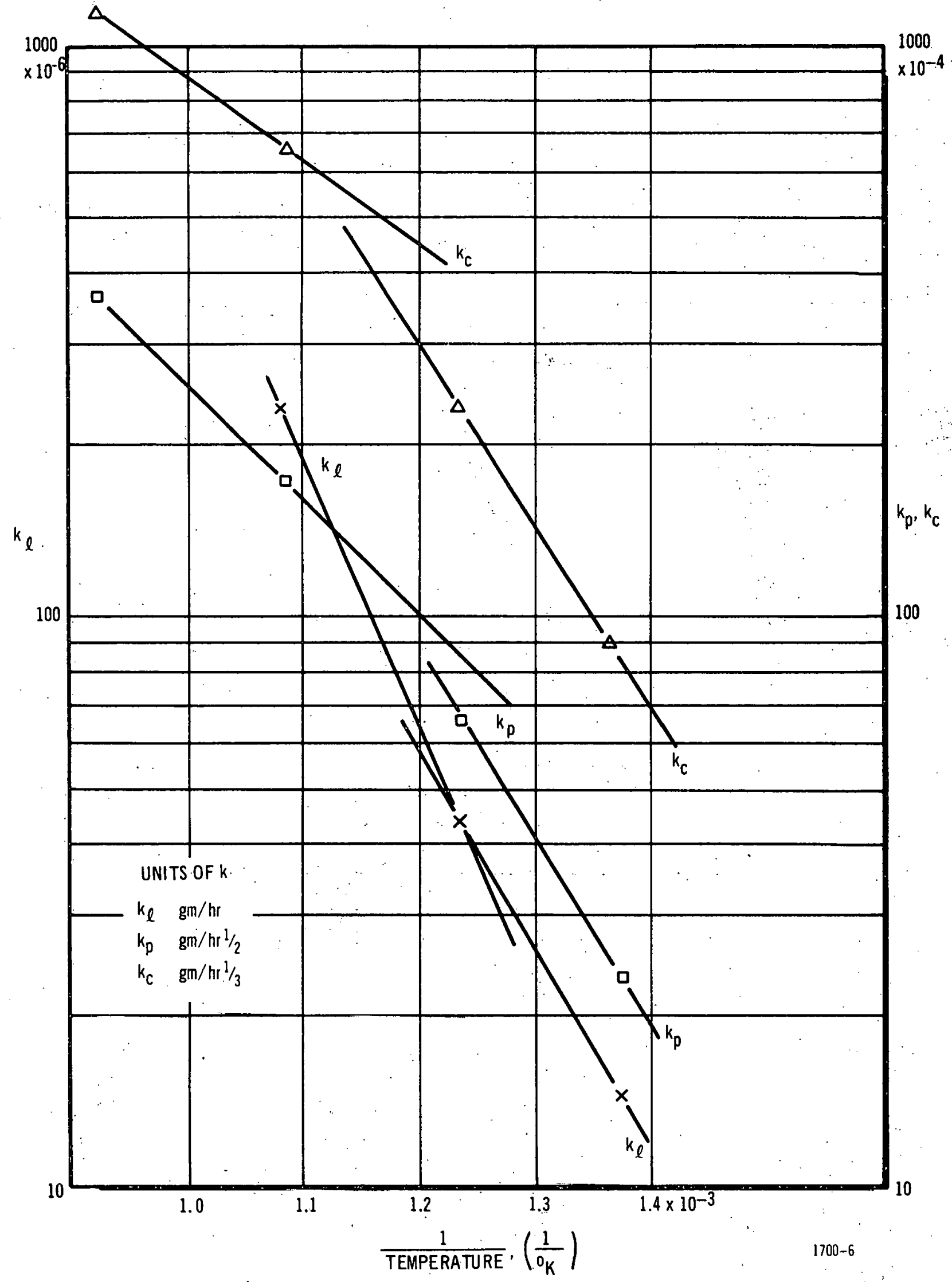

Figure 6. Corrosion Rate as a Function of Temperature 
(2.) Rate constant determination for weight loss versus time response

By the expansion of Equation (1) and the use of approximations detailed in Appendix A, the expressions for the corrosion rate constants become

$$
\Delta W=\frac{k_{0, n}}{A_{n}} t^{n}\left(T_{0}+T_{i}\right) \exp \left[-2 A_{n} /\left(T_{0}+T_{i}\right)\right]
$$

for the nonlinear behavior (time exponent $n$ ), and

$$
\Delta \mathrm{W}-\Delta \mathrm{W}_{0}=\frac{\mathrm{k}_{0, \ell}}{\mathrm{A}_{\ell}} \mathrm{t}\left(\mathrm{T}_{0}+\mathrm{T}_{\mathrm{i}}\right) \exp \left[-2 \mathrm{~A}_{\ell} /\left(\mathrm{T}_{0}+\mathrm{T}_{\mathrm{i}}\right)\right]
$$

for the linear case where $\Delta W_{0}$ is the intercept on the ordinate, Figure 3. Special considerations and assumptions are required, as described in Appendix $A$, for establishing a dependable intercept value, $\Delta \mathrm{W}_{0}$; for use in determining the weight loss versus time response at the higher temperature of exposure.

\section{(3.) Total corrosion}

The resolution of Equation (2) and (3), as detailed in Appendix A, resulted in the mean expressions, for a given temperature, $T$, in terms of $\mathrm{mg} / \mathrm{dm}^{2}$

(1) Nonlinear

$$
\Delta \mathrm{W}=\operatorname{antilog}\left[+0.361+0.385 \log \mathrm{t}+\log 2 \mathrm{~T}-\left(2.568 \times 10^{+3} / \mathrm{T}\right)\right]
$$

(2) Linear

$$
\begin{aligned}
\Delta \mathrm{W}= & \operatorname{antilog}\left[-0.305+\log \mathrm{t}+\log 2 \mathrm{~T}-\left(3.823 \times 10^{+3} / \mathrm{T}\right)\right] \\
& +\underset{ }{\operatorname{antillog}}\left[+0.887+\log 2 \mathrm{~T}-\left(1.908 \times 10^{+3} / \mathrm{T}\right)\right]
\end{aligned}
$$

It is important to note that the nonlinear time exponent was not forced, but calculated from the data to be 0.385 . As such, the data appear to favor a cubic oxide formation rate as compared to the parabolic. 
Ninety-five percent confidence levels can be placed upon the $\Delta \mathrm{W}$ in these expressions for any selected value of $t$ (hours) and $\mathrm{T}\left({ }^{\circ} \mathrm{K}\right)$ according to principles discussed in the Appendix. When this is done at $977^{\circ} \mathrm{K}\left(1300^{\circ} \mathrm{F}\right)$, Figure 7 is the result of the linear response and Figure 8 the nonlinear response. Figure 7 is drawn without the addition of the $\Delta \mathrm{W}_{0}$ factor [ the second term in Equation (5)] because of the large spread in the 95 percent confidence level required at $1300^{\circ} \mathrm{F}$. The large possible error in $\Delta \mathrm{W}_{0}$ results from the lack of more than one datum point for the $1280^{\circ}-1410^{\circ} \mathrm{F}$ exposure.

Based on the desire to design fuel cladding for a life of three years, the calculated and 95 percent confidence levels for the general corrosion weight loss of Incoloy-800 occurring at three temperatures of interest are summarized in Table IV. in which $\Delta W_{0}$ is included for the linear response according to principles discussed in the Appendix.

The predicted corrosion for three years exposure at $1300^{\circ} \mathrm{F}$ is calculated at 0.0016 inch based on a linear response and $<0.0005$ inch based on a nonlinear oxidation response. Using the upper 95 percent confidence level as a conservative value for design purposes increases these values to 0.0033 inch linear and 0.001 inch nonlinear. Additional work is needed to more accurately establish the true response and to decrease the span of the .95 percent ronfidence levels.

The values of the upper 95 percent confidence levels for the nonlinear and linear responses as a function of time are plotted in Figure 9 for the temperatures of 1050,1150 , and $1300^{\circ} \mathrm{F}$.

\section{b. Metal-to-System Loss}

The metal-to-system loss data in Table III do not lend themselves to analytical treatment as carried out for the descaled weight loss data. The $1100-1300^{\circ} \mathrm{F}$ results are significant for predicting long-term losses of metal to the system. Whereas, greater than 80 percent of the oxide corrosion product adhered during the first $1000-$ hour exposure, less than 50 percent of the total oxidation product remalned after 4000 hours. If it is assumed that an equilibrium oxidation condition has been reached within 4000 hours, it can be predicted that greater than half of the corrosion products from the Incoloy-800 metal operating at a temperature between 1200 and $1300^{\circ} \mathrm{F}$ will be carried downstream from the core. The actual weight of material involved for a core operating normally at a maximum temperature of $1300^{\circ} \mathrm{F}$ can be estimated, within the limitations of the data, from the predicted corrosion weight loss data in Table IV and knowledge of the total cladding surface area in a specific design expected to operate between 1200 and $1300^{\circ} \mathrm{F}$. 


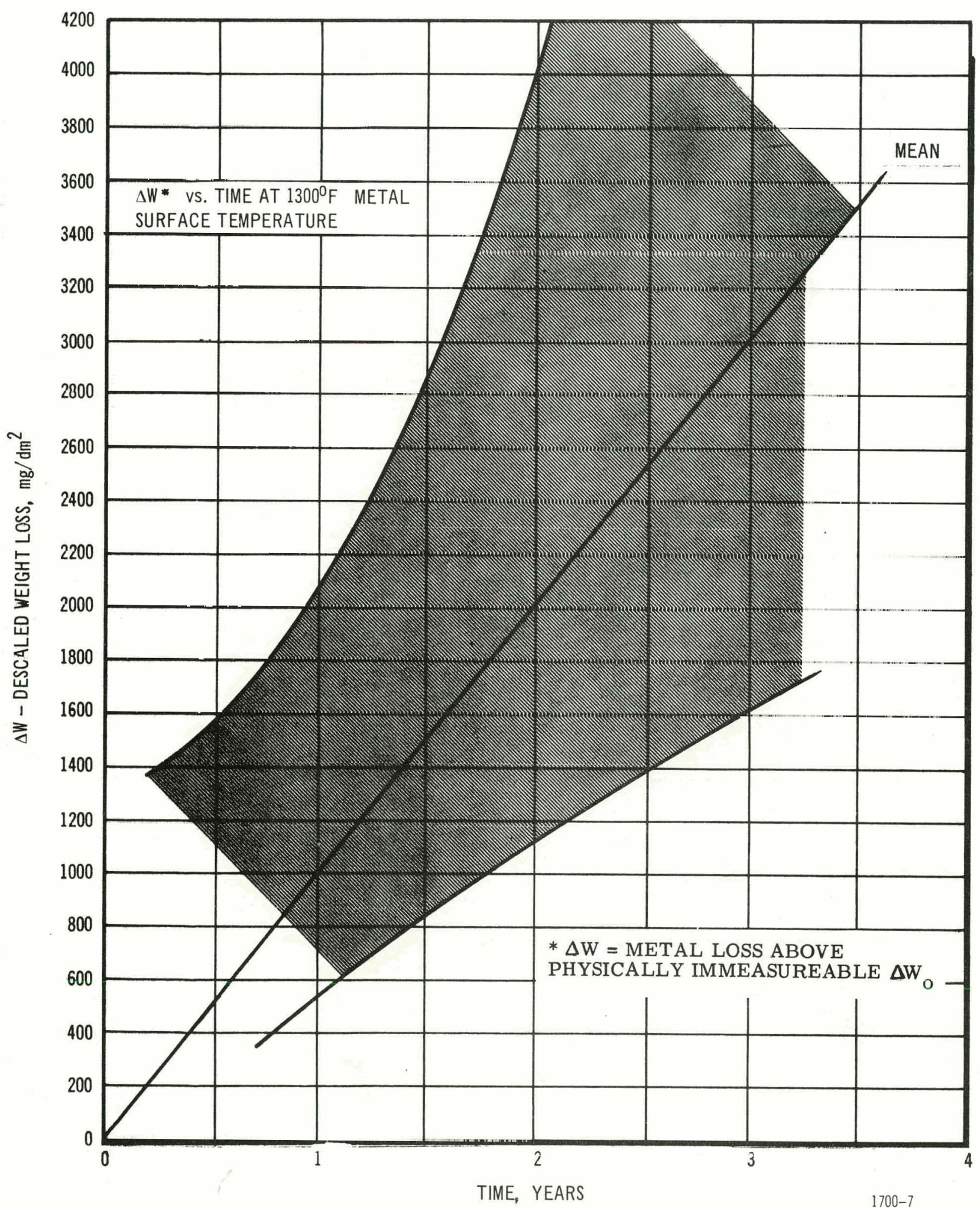

Figure 7. Weight Loss Linear Response (95 Percent Confidence Levels) 


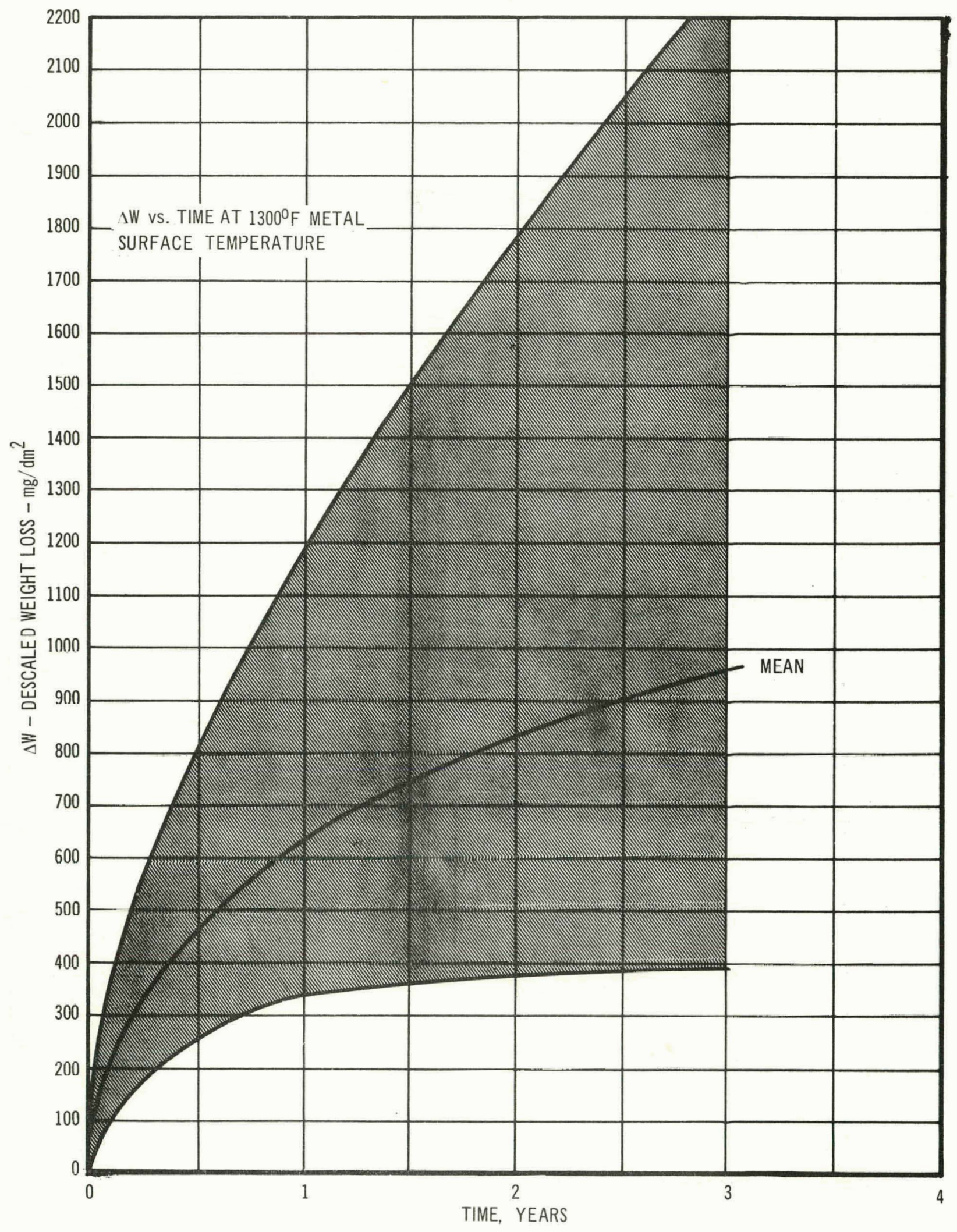

$1700-8$

Figure 8. Weight Loss Nonlinear Response (95 Percent Confidence Levels) 


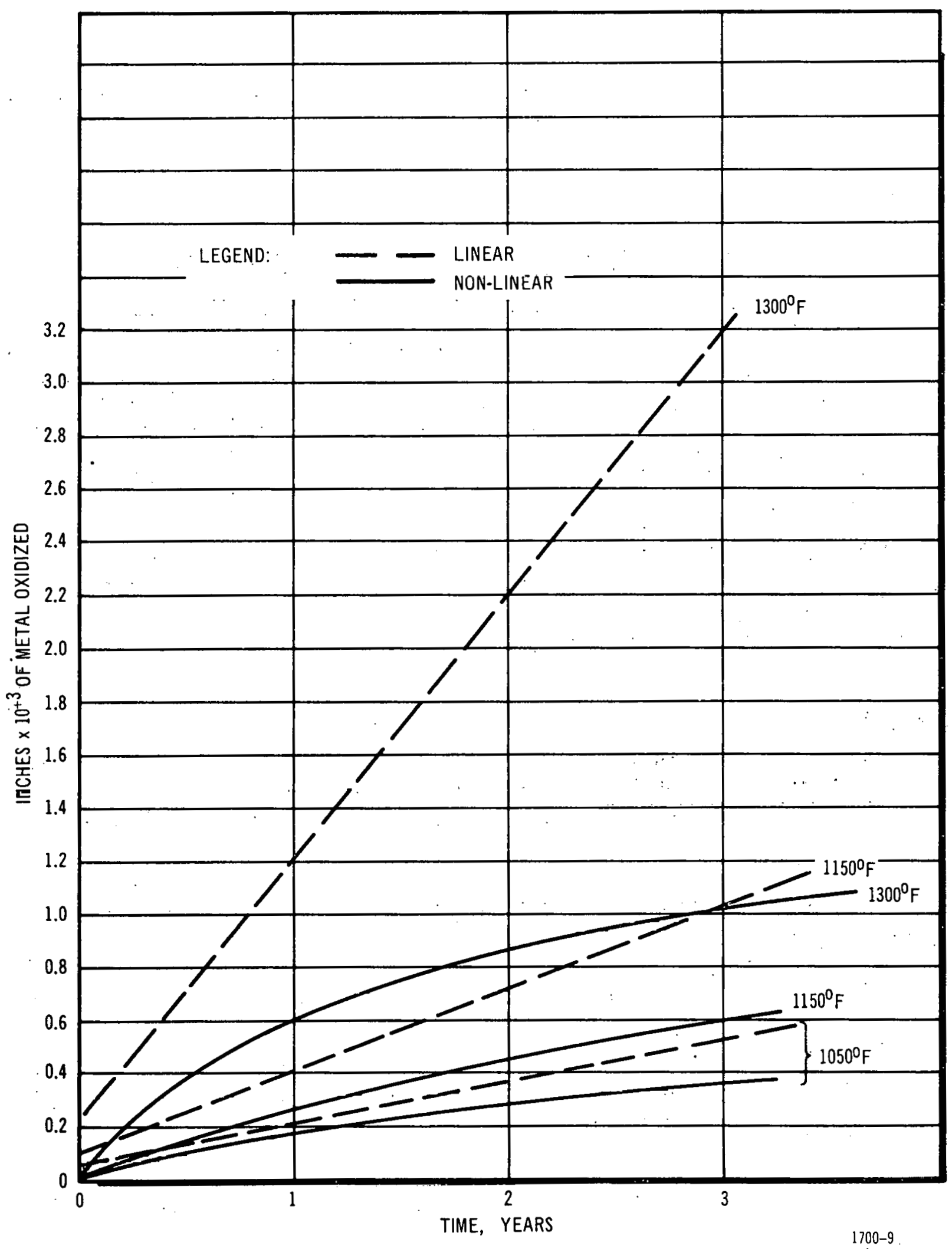

Figure 9. Incoloy-800 Oxidized in Superheated Steam (All curves are Upper 95 Percent Confidence Level) 
Further interpretation of the data is considered later in conjunction with electron microprobe studies of the alloy and oxide.

TABLE IV

PREDICTED THREE YEAR CORROSION WEIGHT LOSS

Incoloy -800

\begin{tabular}{|c|c|c|c|c|c|c|}
\hline \multirow{4}{*}{$\begin{array}{c}\text { Metal } \\
\text { Temperature } \\
\text { (o } \mathrm{F}) \\
\end{array}$} & \multicolumn{6}{|c|}{ Weight Loss $-\mathrm{mg} / \mathrm{dm}^{2}$} \\
\hline & \multicolumn{3}{|c|}{ Linear* } & \multicolumn{3}{|c|}{ Nonlinear } \\
\hline & \multirow[b]{2}{*}{ Equation } & \multicolumn{2}{|c|}{$95 \%$ Confidence Limits } & \multirow{2}{*}{ Equation } & \multicolumn{2}{|c|}{$95 \%$ Confidence Limits } \\
\hline & & Maximum & Minimum & & Maximum & Minimum \\
\hline 1300 & 3300 & 6520 & 1680 & 960 & 2380 & 390 \\
\hline 1150 & 1340 & 2150 & 830 & 510 & 1230 & 210 \\
\hline $1050^{\circ}$ & 690 & 1060 & 450 & 330 & 720 & 150 \\
\hline
\end{tabular}

* Includes value of intercept, $\Delta \mathrm{W}_{0}$

2. Isothermal

The corrosion experienced by specimens from two heats of Incoloy-800, when exposed isothermally to 1050 and $1150^{\circ} \mathrm{F}$ superheated steam with the oxygen and hydrogen controlled, is summarized in Table V. Each point represents the average of at least two specimens.

The results at both temperatures indicated an initially high corrosion rate that decreased to a lower constant rate within the first 1000 hours as shown in a plot of the data in Figure 10. Assuming a linear rate law of the form

$$
\Delta \mathrm{W}=\Delta \mathrm{W}_{0}+\mathrm{Rt}
$$

where $\Delta \mathrm{W}$ is the descaled weight loss in $\mathrm{mg} / \mathrm{dm}^{2}, \mathrm{t}$ is exposure time in months, $\Delta \mathrm{W}_{0}$ is the intercept representing the degree of early rapid corrosion, and $R$ is the linear rate constant, the 95 percent confidence levels can be established as follows:

\begin{tabular}{|c|c|c|}
\hline $\begin{array}{c}\text { Temperature } \\
\left({ }^{\circ} \mathrm{F}\right)\end{array}$ & $\begin{array}{c}\Delta \mathrm{W}_{0} \\
\mathrm{mg} / \mathrm{dm}^{2} \\
\end{array}$ & $\begin{array}{c}\mathrm{R} \\
\mathrm{mg} / \mathrm{dm}^{2}-\mathrm{mo} \\
\end{array}$ \\
\hline 1050 & $98 \pm 8$ & $3.6 \pm 1.2$ \\
\hline 1150 & $370 \pm 88$ & $10 \pm 18$ \\
\hline
\end{tabular}


TABLE V

CORROSION IN SUPERHEATED STEAM - ISOTHERMAL EXPOSURES

\begin{tabular}{|c|c|c|c|c|c|c|}
\hline $\begin{array}{c}\text { Temperature } \\
\left({ }^{\circ} \mathrm{F}\right)\end{array}$ & $\begin{array}{c}\text { Incoloy } \\
\text { Tested }\end{array}$ & $\begin{array}{c}\text { Run } \\
\text { Number }\end{array}$ & $\begin{array}{c}\text { Exposure } \\
\text { Time } \\
\text { (hours })\end{array}$ & $\begin{array}{c}\text { Weight } \\
\text { Gain } \\
\left(\mathrm{mg} / \mathrm{dm}^{2}\right)\end{array}$ & $\begin{array}{c}\text { Descaled } \\
\text { Weight Loss } \\
\left(\mathrm{mg} / \mathrm{dm}^{2}\right)\end{array}$ & $\begin{array}{c}\text { Calculated } \\
\text { Metal-to-System } \\
\text { Loss } \\
\left(\mathrm{mg} / \mathrm{dm}^{2}\right)\end{array}$ \\
\hline \multirow{3}{*}{1050} & Thin & 52 & 1000 & 8 & 108 & 24 \\
& & $58-59$ & 1271 & 24 & 95 & 8 \\
& $52-56$ & 1965 & 23 & 115 & 15 \\
& & $52,56-60$ & 5116 & 29 & 133 & 15 \\
& $58-63$ & 5266 & 29 & 133 & 15 \\
& $52,56-65$ & 10143 & 29 & 144 & 18 \\
& & & & & & \\
& \multirow{5}{*}{ Thick } & 62 & 1053 & 139 & 356 & $+44^{*}$ \\
& & $62-63$ & 2090 & 164 & 443 & 1 \\
& & $62-64$ & 3067 & 160 & 446 & 5 \\
& & $62-65$ & 4016 & 164 & 400 & $+10^{*}$ \\
& & $62-66,68$ & 5036 & 171 & 430 & $+7 *$ \\
\hline
\end{tabular}

* Calculated weight gain

The initial corrosion rate at $1150^{\circ} \mathrm{F}$ is about 3 to 4 times greater than for a corresponding time period at $1050^{\circ} \mathrm{F}$. Although the slopes of the constant rate portion of the curves are difficult to fix within the limited data available, it is encouraging that at both temperatures the slope (or corrosion rate) is low beyond the initially high rate. Utilizing the constants derived above, maximum corrosion of $<0.0002$ inch could be anticipated in 3 years of isothermal exposure to $1050^{\circ} \mathrm{F}$ superheated steam and 0.0008 inch when exposed to $1150^{\circ} \mathrm{F}$ steam.

Reference to the metal-to-system loss in Table $\mathrm{V}$ indicates an insignificant loss up to 5000 hours at $1150^{\circ} \mathrm{F}$ and a very low loss up to 10,000 hours at $1050^{\circ} \mathrm{F}$. The data indicate that the assumption of oxide composition used in calculating the metal-to-system loss may require some adjustment. For example, if the iron oxide in the $1150^{\circ} \mathrm{F}$ scale was essentially all $\mathrm{Fe}_{2} \mathrm{O}_{3}$ and other compositions remained relatively the same, the loss would increase slightly to the extent of eliminating the theoretical weight gains as indicated in the calculations summarized in Table V, with a net effect of no loss to system. At $1050^{\circ} \mathrm{F}$ the low metal-to-system loss does not change significantly with time, again indicating the possibility of no real loss-to-system but a possible error in the use of the oxide composition constant. 
i

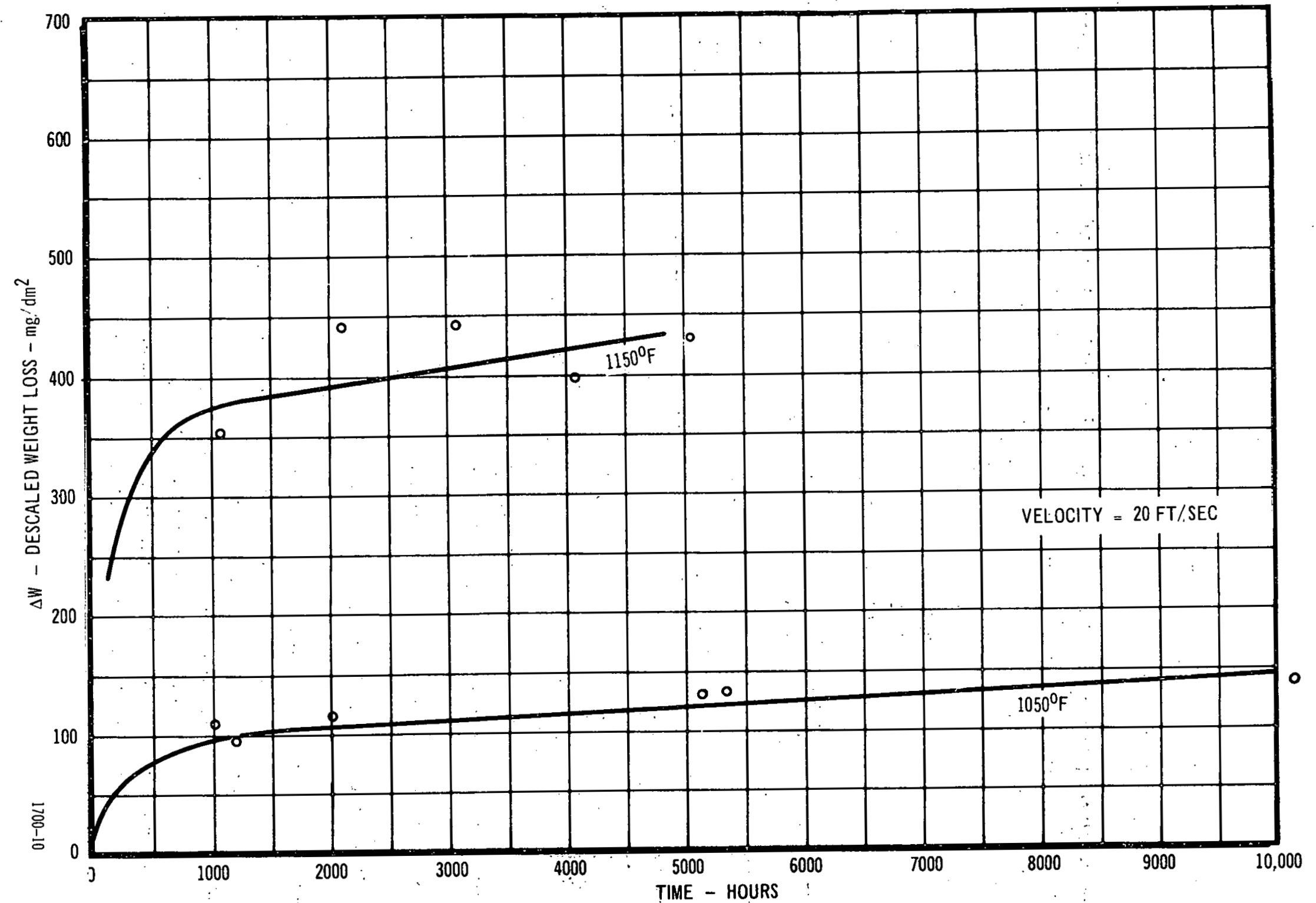

Figure 10. Corrosion of Incoloy-800 - Isothermal Exposures 
The fact that the metal-to-system loss for the $1150^{\circ} \mathrm{F}$ specimens averaged plus values and the $1050^{\circ} \mathrm{F}$ specimens averaged low loss values would require the oxide composition correction to be different in each case. The possibility of different oxide properties is considered real. Difficulty was experienced in descaling the $1150^{\circ} \mathrm{F}$ specimens by the procedure outlined earlier as compared to the relative ease in descaling the $1050^{\circ} \mathrm{F}$ specimens. The actual oxide composition will be discussed in more detail later.

At both temperaluies nu signifluanl luss of metai to the system can be assumed at the velocities of test. On this basis, weight gain measurements assume added import in establishing corrosion rates for Incoloy when exposed isothermally to typical SHR system environments.

Since weight gain measurements can be made on specimens without the destructive procedure required for the descaled weight loss data, many more time points and sample points at each time are available and one less handling step is required. Weight gain measurements were reexamined on a per coupon basis as shown in Table VI. The results show no significant weight gain for any one coupon after about 1000 -hour exposure at $1150^{\circ} \mathrm{F}$ and after about 2000 -hour exposure at $1050^{\circ} \mathrm{F}$. A very slight metal-to-system loss may be indicated with exposures over 5000 hours.

In summary, the isothermal exposure of Incoloy-800 to superheated steam up to $1150^{\circ} \mathrm{F}$ with the oxygen and hydrogen controlled, resulted in the formation of an adherent oxide film within the first 1000 hours followed by a low oxidation rate. An insignificant amount of the oxide was lost to the system. 
TABLE VI

\section{WEIGHT GAIN MEASUREMENTS OF ISOTHERMAL EXPOSURES (mg/dm $\left.{ }^{2}\right)$}

\begin{tabular}{|c|c|c|c|c|c|c|c|c|c|c|c|c|c|c|}
\hline \multicolumn{8}{|c|}{$1050^{\circ} \mathrm{F}$} & \multicolumn{7}{|c|}{$1150^{\circ} \mathrm{F}$} \\
\hline \multirow{2}{*}{$\begin{array}{l}\text { Exposure } \\
\text { (hours) }\end{array}$} & \multicolumn{4}{|c|}{ Specimen } & \multirow{2}{*}{$\begin{array}{c}\text { Exposure } \\
\text { (hours) }\end{array}$} & \multicolumn{2}{|c|}{ Specimen } & \multirow{2}{*}{$\begin{array}{c}\text { Exposure } \\
\text { (hours) } \\
\end{array}$} & \multicolumn{5}{|c|}{ Specimen } & \multirow{2}{*}{12} \\
\hline & 1 & $\underline{2}$ & $\underline{3}$ & 4 & & 5 & 6 & & 7 & 8 & 9 & 10 & 11 & \\
\hline 2953 & 32 & 29 & 29 & 35 & 1271 & 25 . & 25 & 1053 & 158 & 164 & 168 & 160 & 157 & 152 \\
\hline 4234 & 33 & 31 & 28 & 37 & 2165 & 27 & 26 & 2090 & 159 & 168 & 17.0 & 162 & $160^{\circ}$ & 155 \\
\hline 5116 & 30 & 28 & 23 & 33 & 3176 & 28 & $31:$ & 3067 & 160 & 168 & 172 & 163 & 161 & 155 \\
\hline 6127 & - & - & 29 & 35 & 4229 & 28. & 30 & 4016 & 159 & 168 & 173 & 163 & 162 & 155 \\
\hline 7180 & - & - & 27 & 35 & 5266 & 27 & 29 & 5036 & - & - & 178 & 164 & - & - \\
\hline 8217 & - & - & 27 & 37 & $:$ & & . & & & & & & & \\
\hline 9194 & - & - & 25 & 35 & & & & . & $\because$ & & 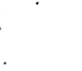 & & & . \\
\hline 10,143 & - & - & 23 & 35 & & & & & & & & & & \\
\hline
\end{tabular}




\section{METALLURGICAL EVALUATION}

\section{Heat Transfer}

Metallographic examination showed no evidence of deleterious localized attack. As noted previously with Incoloy and other iron-chromium-nickel alloys, $(2,6)$ a compositional change in the alloy took place at the metal-oxide interface. Sections of the heat transfer specimens exposed for 4078 hours at metal temperatures of 800 to $1300^{\circ} \mathrm{F}$ are shown in Figure 11 and comparable sections from about 1000 -hour exposure at metal temperatures of 1100 to $1410^{\circ} \mathrm{F}$ are shown in Figure 12.

The optical measurement of the depth of compositionally disturbed layer as a function of time and temperature is summarized in Table VII.

The layer growth, as measured optically, appears to be proportional to the square root of the exposure time. If no equilibrium alloy phase compositional disturbance were reached on this basis, the layer would grow to approximately 0.0017 inch after 3 years exposure at $1300^{\circ} \mathrm{F}$. The long-term effect on mechanical properties is not known.

The effect of temperature on the depth of the compositionally disturbed layer indicates a factor of 2 to 3 increase with each $100^{\circ} \mathrm{F}$ rise in temperature. More data will be required to firm this relationship.

The effect of temperature and time on the growth of the compositionally disturbed layer is considered further in conjunction with the electron-beam microprobe studies discussed in 3. below.

The resulting oxide after 4078-hour exposure is indicated in Figure 13a at a calculated metal temperature of $1100^{\circ} \mathrm{F}$ and in Figure $13 \mathrm{~b}$ at a temperature of $1300^{\circ} \mathrm{F}$. The $1100^{\circ} \mathrm{F}$ specimen is seen to have a duplex scale with the inner more adherent scale essentially intact. The $1300^{\circ} \mathrm{F}$ specimen, however, shows an irregular scaling with sporadic subsurface scale penetrations. The penetrations cannot be verified as intergranular because of the loss of grain identity coincident with the formation of the compositionally disturbed layer (see Figure 11f). The $1300^{\circ} \mathrm{F}$ specimen again emphasizes the inaccuracies of determining corrosion by weight gain or scale thickness measurements. 


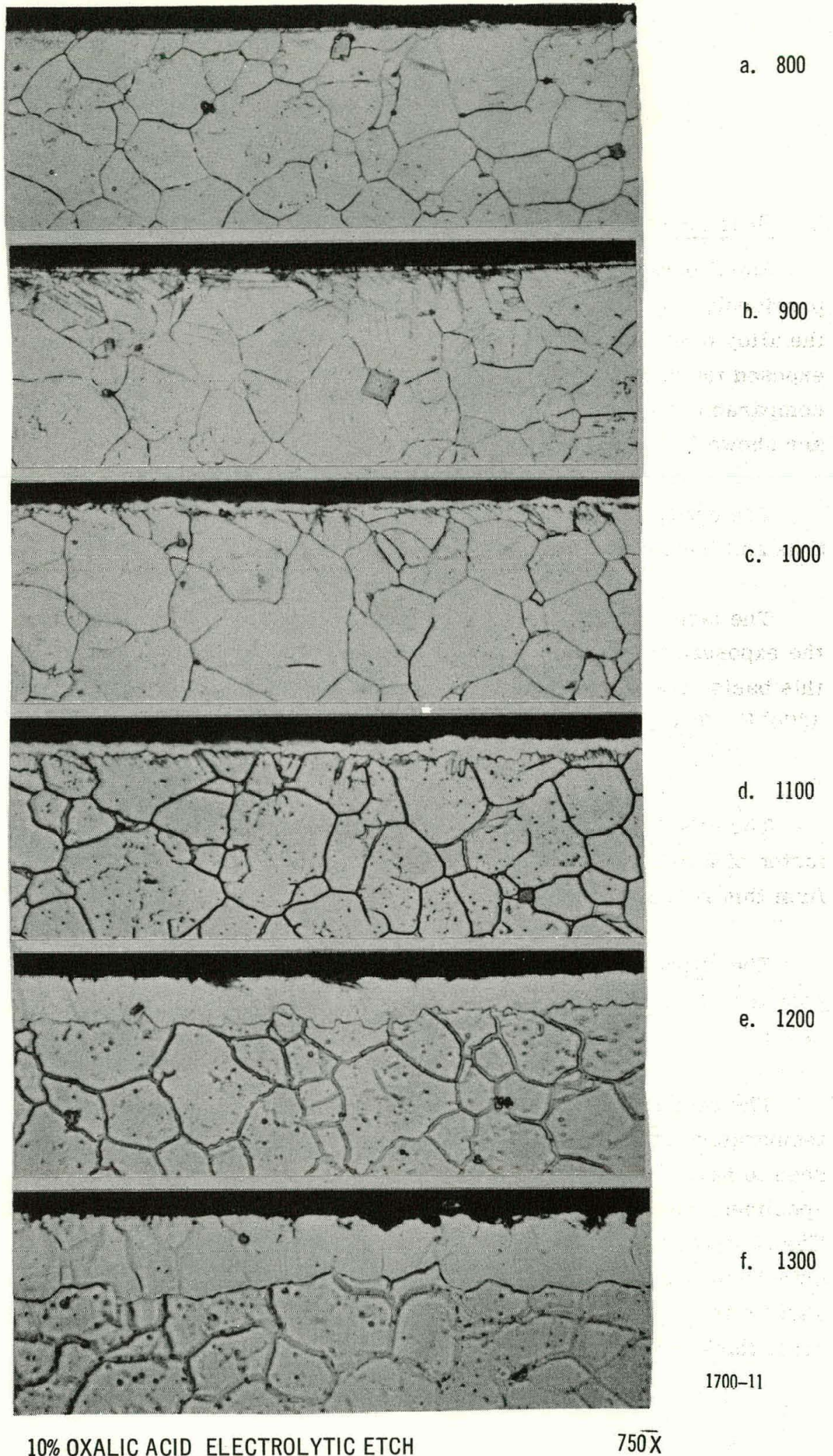

Figure 11. Incoloy-800 Heat Transfer Specimens, 4078 Hours Descaled 


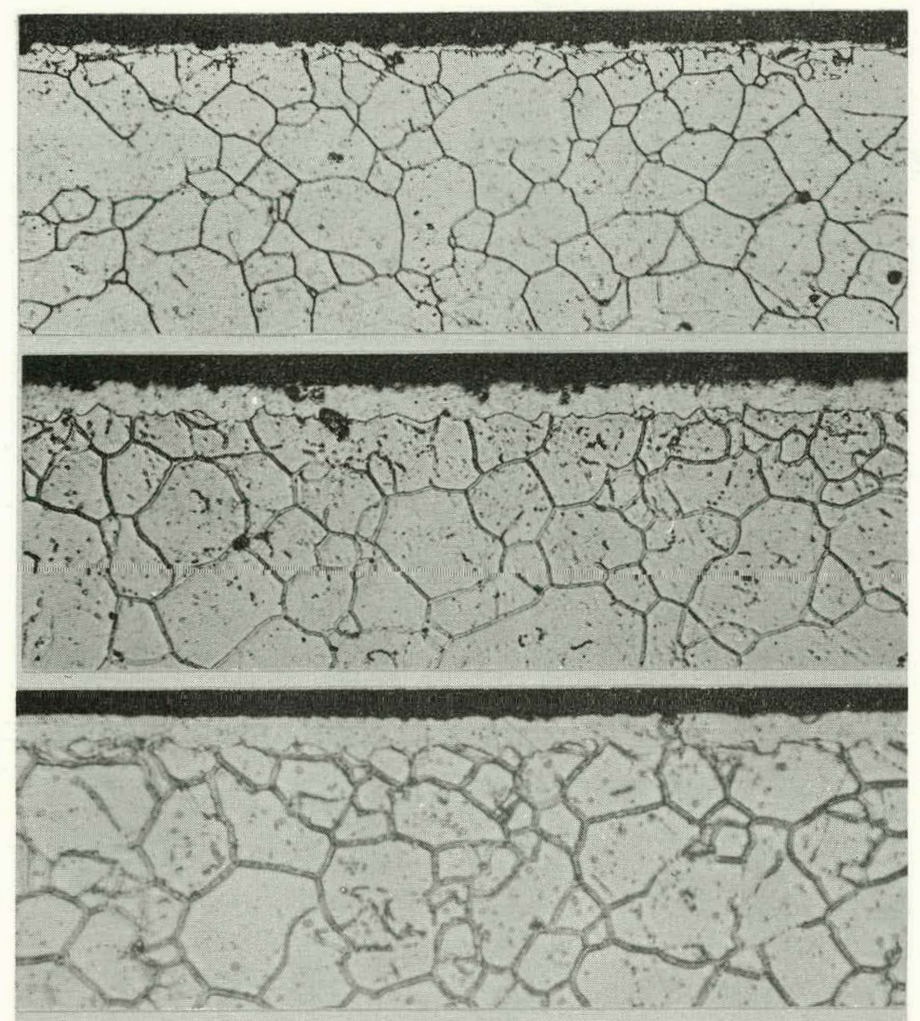

CALCULATED METAL TEMPERATURE ${ }^{\circ} \mathrm{F}$

a. $1100-1$

b. $1200-1$

c. $1280-2$

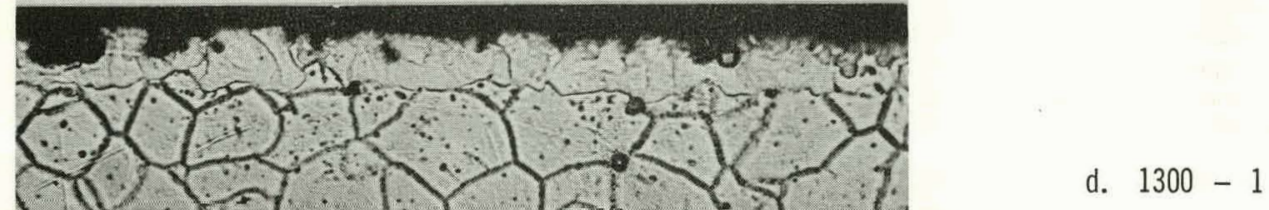

e. $1350-2$

f. $1410-2$

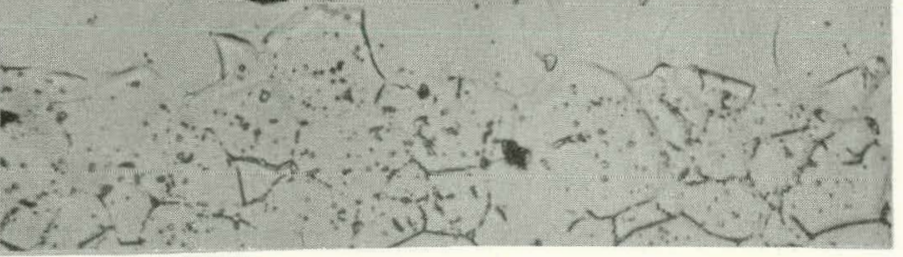

$750 x$

$1700-12$

KEY: 1. 10\% OXALIC ACID - ELECTROLYTIC ETCH 965 HOURS

2. $10 \%$ CHROMIC ACID - ELECTROLYTIC ETCH 1053 HOURS

Figure 12. Incoloy-800 Heat Transfer Specimens, Descaled 
CALCULATED METAL TEMPERATURE

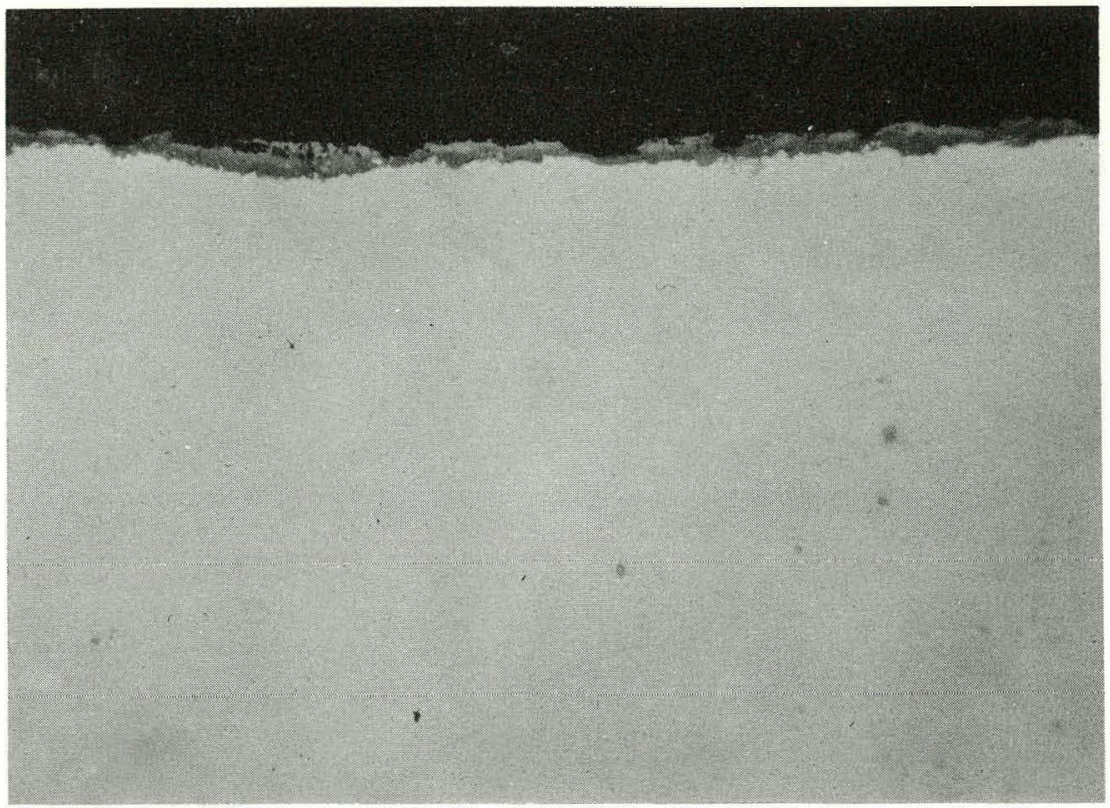

a. $1100^{\circ} \mathrm{F}$

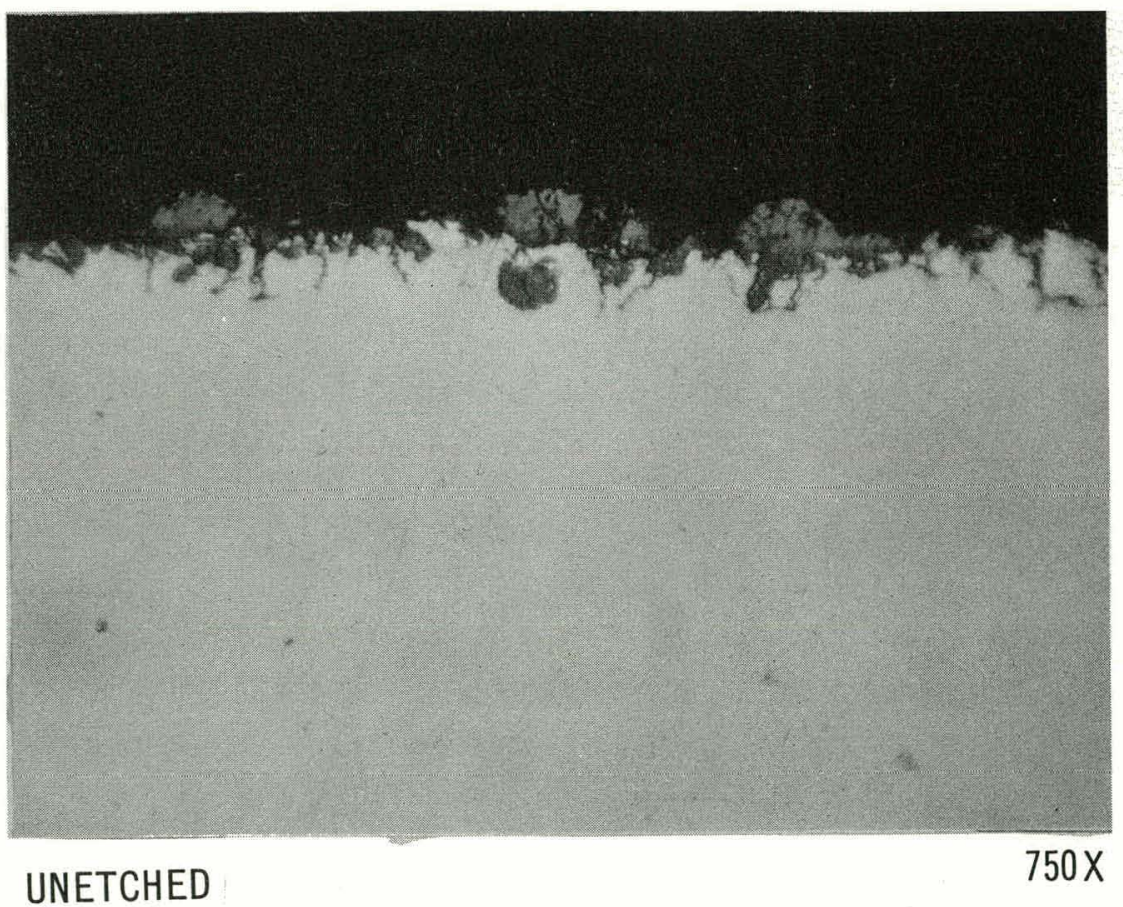

b. $1300^{\circ} \mathrm{F}$

$1700-13$

Figure 13. Incoloy-800 Scale after 4078 Hours Exposure with Heat $-30-$ Transfer 
TABLE VII

\section{DEPTH OF COMPOSITIONAL DISTURBANCE -}

HEAT TRANSFER SPECIMENS

\begin{tabular}{|c|r|c|}
\hline $\begin{array}{c}\text { Calculated } \\
\text { Metal } \\
\text { Temperature } \\
\left({ }^{\circ} \mathrm{F}\right)\end{array}$ & $\begin{array}{c}\text { Exposure } \\
\text { Time } \\
\text { (hours) }\end{array}$ & $\begin{array}{c}\text { Average } \\
\text { Thickness } \\
(\text { inch } \times 10+3)\end{array}$ \\
\hline 1100 & 965 & 0.06 \\
1200 & 4078 & 0.13 \\
1300 & 965 & 0.17 \\
& 9078 & 0.33 \\
1350 & 4078 & 0.33 \\
1410 & 1053 & 0.67 \\
& 1053 & 0.58 \\
\hline
\end{tabular}

\section{Isothermal}

The standard evaluation procedure for the coupons exposed isothermally to the 1050 and $1150^{\circ} \mathrm{F}$ superheated steam was to mount one scaled and one descaled specimen for each time point with photomicrographs taken as needed.

The average oxide thicknesses formed on the Incoloy-800 at various exposure times were measured from the photomicrographs and tabulated with the descaled weight losses in Table VIII. The scale continued to form for the first 2000 hours at $1050^{\circ} \mathrm{F}$ as previously noted with weight gain measurements (Table VI). A typical $1050^{\circ} \mathrm{F}$ scale is shown in Figure 14. The thin oxide is seen to have two phases.

The irregularity of the scale formed at $1150^{\circ} \mathrm{F}$, as shown in Figure 15, makes the measurement of average oxide depth difficult and somewhat meaningless. A comparison of the average oxide thickness and descaled weight loss columns in Table VIII emphasizes the inaccuracy of using scale thickness data as a measure of corrosion rates. Three distinct oxide layers are seen to be present. 


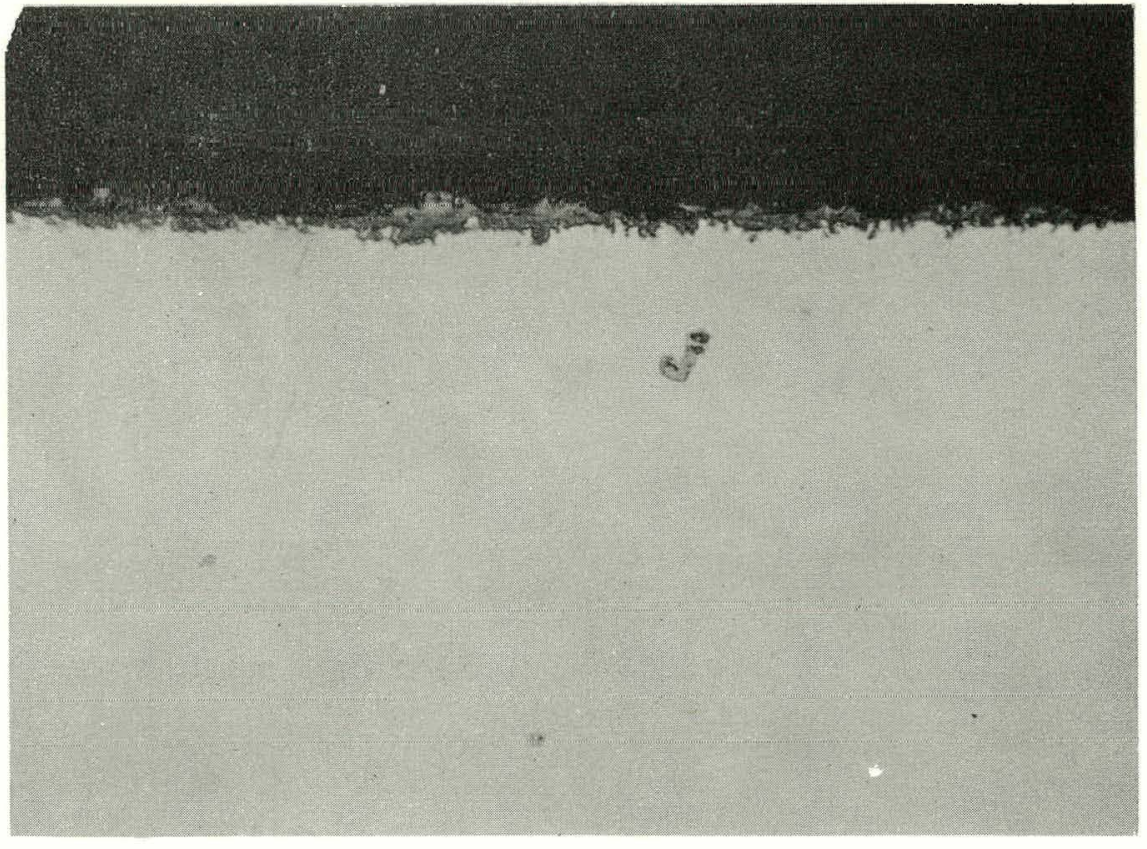

UNETCHED

$750 x$

Figure 14. Incoloy - 800 Scale after 5266 Hours Isothermal

$1700-14$ Exposure in $1050^{\circ} \mathrm{F}$ Superheated Steam

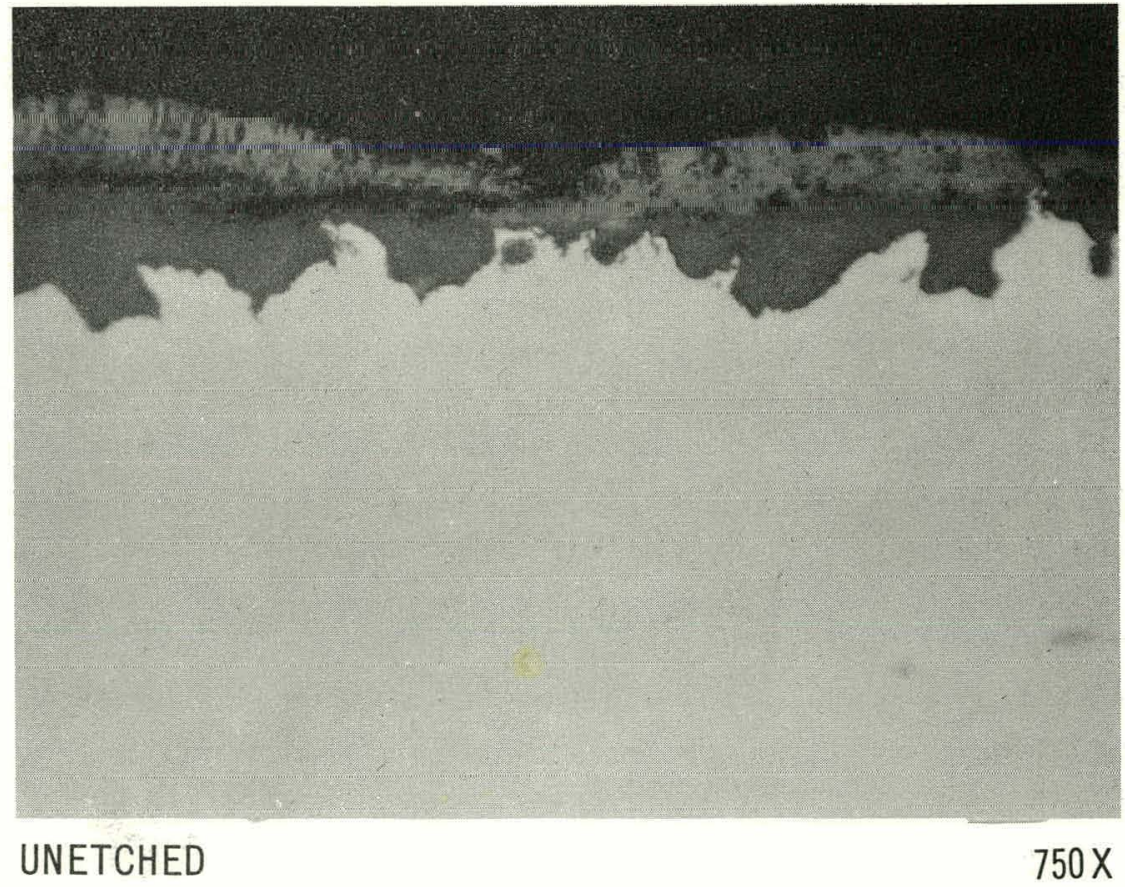

Figure 15. Incoloy-800 Scale after 3067 Hours Isothermal Exposure in $1150^{\circ} \mathrm{F}$ Superheated Steam 
TABLE VIII

DEPTH OF COMPOSITIONAL DISTURBANCE ISOTHERMAL SPECIMENS

\begin{tabular}{|c|c|c|c|c|}
\hline $\begin{array}{c}\text { Temperature } \\
\left({ }^{\circ} \mathrm{F}\right)\end{array}$ & $\begin{array}{c}\text { Exposure } \\
\text { Time } \\
\text { (hours) }\end{array}$ & $\begin{array}{c}\text { Measured } \\
\text { Average } \\
\text { Oxide } \\
\text { Thickness } \\
\left(\text { inch } \times 10^{+3}\right)\end{array}$ & $\begin{array}{c}\text { Desralen } * \\
\text { Weight Loss } \\
\left(\text { inch } \times 10^{+3}\right)\end{array}$ & $\begin{array}{c}\text { Cnmpositinnal } \\
\text { Disturbance } \\
\left(\text { inch } \times 10^{+3}\right)\end{array}$ \\
\hline 1050 & 1000 & 0.13 & 0.05 & 0.13 \\
& 1965 & 0.15 & 0.06 & 0.17 \\
& 5116 & 0.17 & 0.07 & 0.21 \\
& 10,143 & 0.17 & 0.07 & 0.25 \\
& 1053 & 0.50 & 0.18 & 0.25 \\
& 2090 & 0.83 & 0.22 & 0.25 \\
& 3067 & 1.00 & 0.22 & 0.33 \\
& 4016 & 0.58 & 0.20 & 0.42 \\
& 5036 & 0.67 & 0.22 & 0.58 \\
\hline
\end{tabular}

* From Table V

The compositionally disturbed layer reported previously for specimens exposed for 2000 hours at $1050^{\circ} \mathrm{F},{ }^{(6)}$ was studied further as a function of increased time and temperature. Optical measurements are summarized in Table VIII. The layer continued to grow at both $1050^{\circ} \mathrm{F}$ and $1150^{\circ} \mathrm{F}$. The layer was of uniform depth at $1050^{\circ} \mathrm{F}$ (Figure 16) but very patchy at $1150^{\circ} \mathrm{F}$ (Figure 17).

The Incoloy exposed at $1050^{\circ} \mathrm{F}$ precipitated carbides $\left(\mathrm{Cr}_{23} \mathrm{C}_{6}\right)$ in the grain boundaries. A concentration of the precipitate below the optical boundary of the compositionally disturbed layer is seen in Figure 16.

The $1150^{\circ} \mathrm{F}$ exposure resulted in a much heavier concentration of carbides in the grain boundaries. The concentration of precipitate under the layer was present at 1000 hours, but not after longer exposures. Carbide precipitation on an apparent prior grain structure is seen in Figure 17. Indications of this dual precipitation pattern were found in the as-received material. 


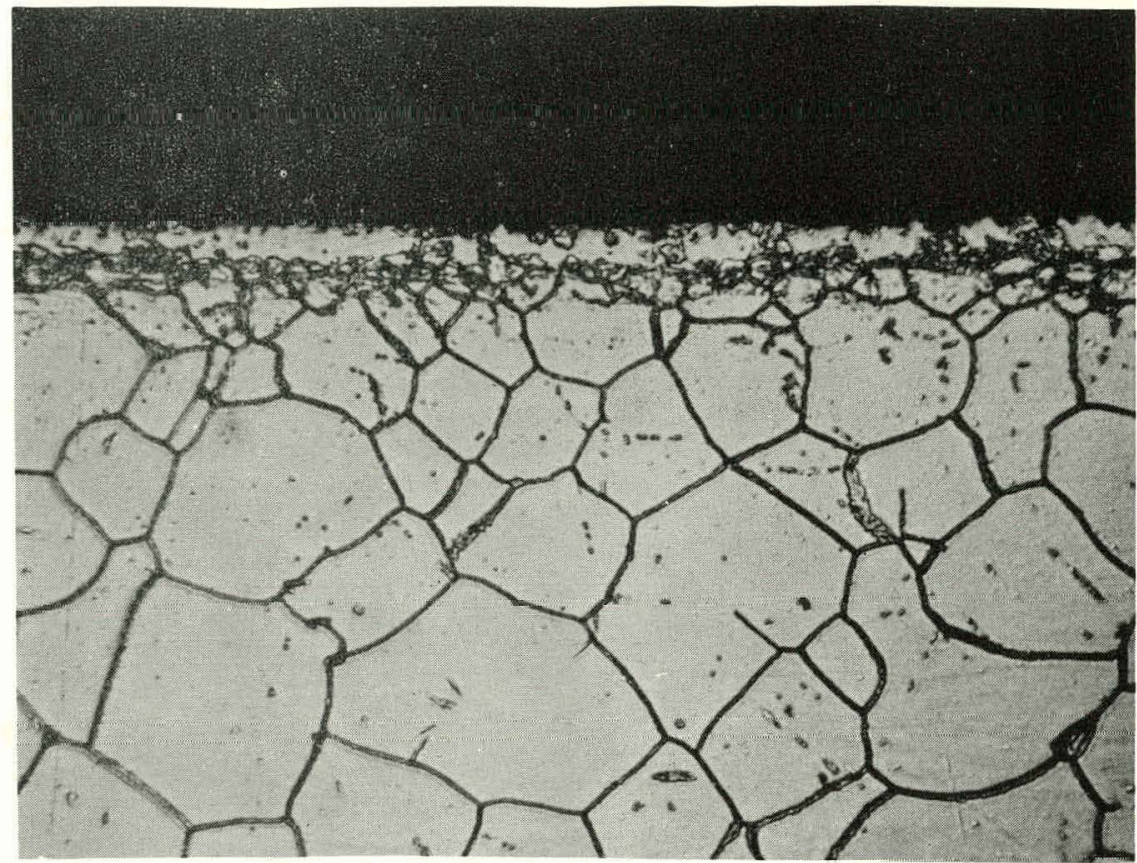

ETCHANT - 10\% OXALIC

Figure 16. Microstructure of Incoloy - 800 after 5116 Hours Isothermal Exposure in $1050^{\circ} \mathrm{F}$ Superheated Steam

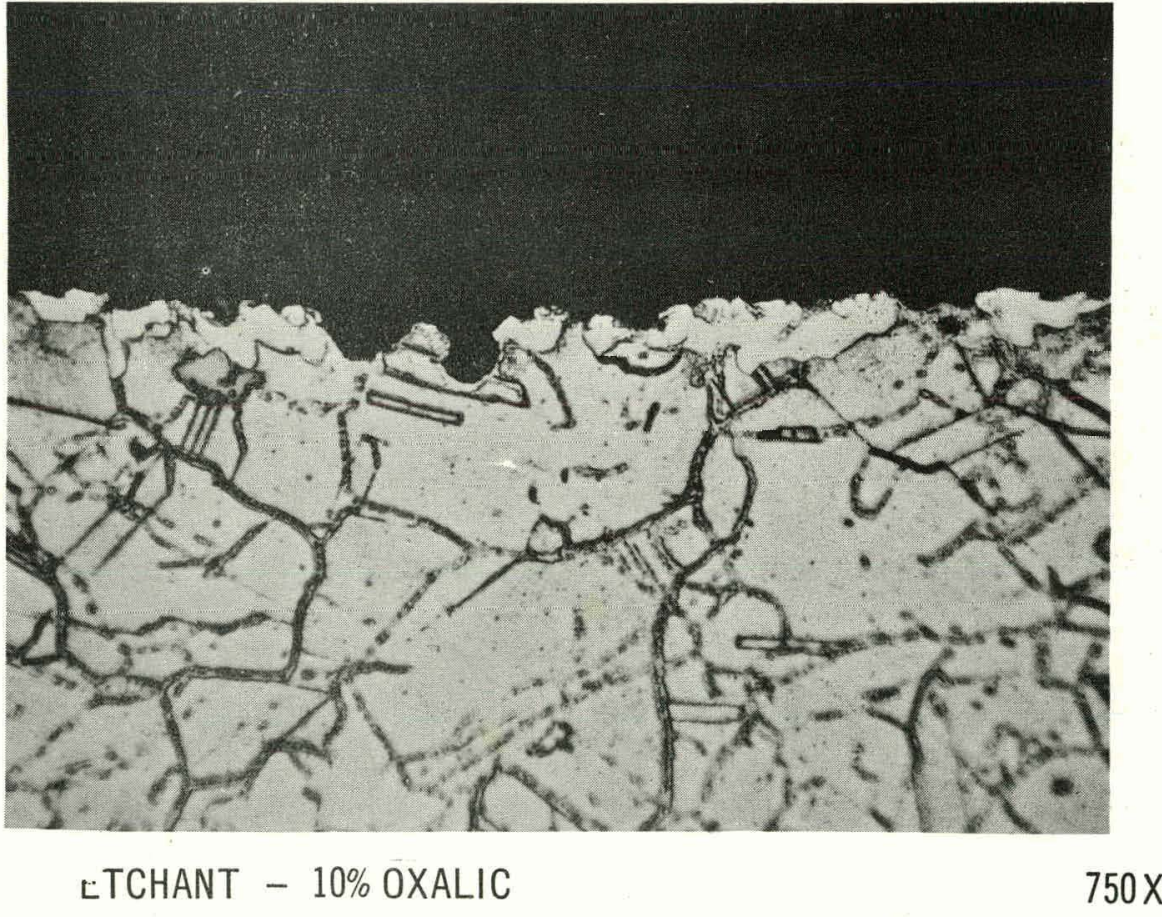

Figure 17. Microstructure of Incoloy-800 after 3067 Hours Isothermal Exposure in $1150^{\circ} \mathrm{F}$ Superheated Steam 


\section{Electron Microprobe Studies}

The oxidation of Incoloy in superheated steam is partially selective. That is, the major alloying elements, iron, chromium, and nickel do not enter the oxide phase in proportions to their bulk alloy content. If the thermodynamically noble element, nickel, did not enter the oxide phase at all, the process would be fully selective. Partial selectivity arises from the entrance of some nickel into the oxide phase.

Any degree of selectivity results in a compositionally disturbed region in the alloy phase near the oxide-alloy interface. The disturbance is sufficiently great to be optically detectable, as noted previously, and constitutes a layer or "case" whose mechanical properties may be detrimentally different than those of the bulk alloy phase. For this reason the layer growth habits, morphology and kinetics, must be assessed. Partial selectivity is also of importance in considering the makeup of the metal oxides lost to the system from fuel cladding. The resultant radioactivity from activated nickel transported downstream, for example, can be of more concern than the chromium and iron because of its $n-p$ reaction to form Co-58.

The electron microprobe has offered a method to strengthen the quantitative evaluation of the long term effects of partial selectivity. This instrument can establish composition and concentration gradients over narrow space increments, permitting the morphology and kinetics of layer growth and oxide release to be more clearly defined. The procedures through which such definition is achieved is discussed in the following paragraphs for two Incoloy specimens exposed, isothermally, to steam at $1050^{\circ} \mathrm{F}$ for 1000 and 5116 hours.

The interpretative techniques required to adapt electron microprobe traces to mixed selective - nonselective (that is partially selective) oxidation processes have been documented separately. ${ }^{(9)}$ That discussion examined the factors that would permit some excess of noble constituents to diffuse back into the alloy lattice as the oxide-alloy interface moved back in space from its original position. The key physical factors in the development of the kinetic model were: 1) the absence of subsurface voiding, and 2) the presence of a thermodynamically controlled displacement reaction in which a noble oxide is reduced by active elemental metal in proportion to oxide-alloy interfacial alloying element weight fractions. The first imposes the condition, Figure 18, that, at any time,

$$
\int_{0}^{\infty}\left[C_{N}(x, t)-C_{N}(\infty, t)\right] d x=\int_{0}^{\infty}\left[C_{A}(\infty, t)-C_{A}(x, t)\right] d x
$$

The second imposes that:

$$
\int_{0}^{\infty}\left[C_{N}(x, t)-C_{N}(\propto, t)\right] d x=\int_{0}^{\infty}\left[C_{A}(\propto, t)-C_{A}(x, t)\right] d x \rightarrow \text { finite limit }
$$




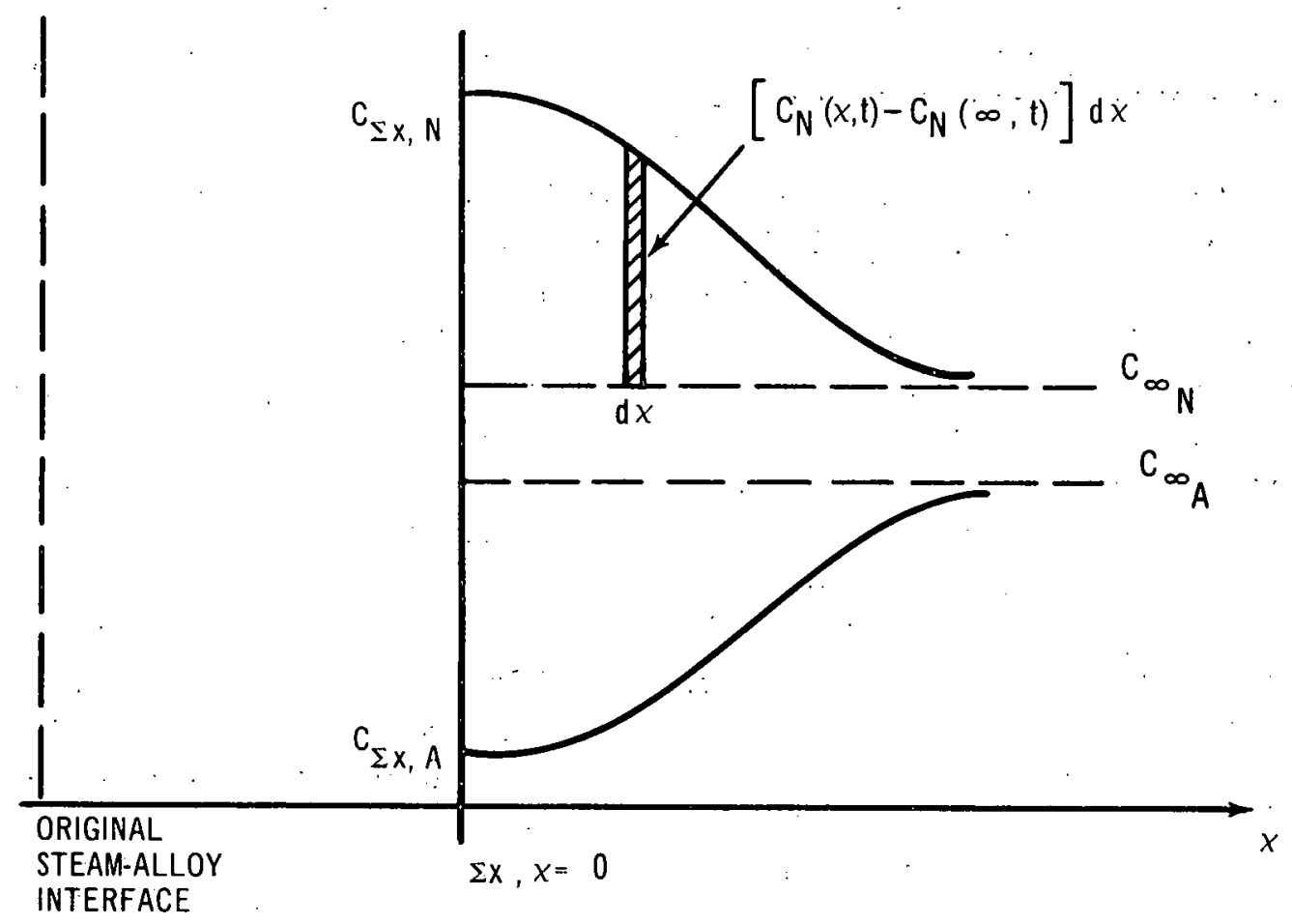

$1700-18$

Figure 18. Schematic Representation of Disturbed Alloy Layer Concentration Profiles 
as the equilibrium value of $\mathrm{C}_{\Sigma \mathrm{X}}$ is approached as a result of the displacement reaction. This implies that the extent of compositional disturbance tends to a constant value. In the two expressions:

$$
\begin{aligned}
& C_{N}=\text { Sum of concentrations of noble constituents, } \\
& C_{A}=\text { sum of concentrations of active constituents, } \\
& x=\text { distance into metal from observed interface, } \\
& \underline{t}=\text { time of exposure at temperature. }
\end{aligned}
$$

The discussion ${ }^{(9)}$ developed the following expressions to describe the kinetics of mixed selective-nonselective oxidation phenomena, as applied to an element (or sum of several elements) that behaves in a noble fashion:

$$
\begin{gathered}
\mathrm{d} \widehat{\mathrm{X}} / \mathrm{dt}=\mathrm{C}_{\infty}\left\{1-\left(\mathrm{C}_{\Sigma \mathrm{x}} / \mathrm{C}_{\mathrm{e}}\right)[1-\exp (-\alpha \mathrm{t})]\right\} \mathrm{d} \Sigma \overline{\mathrm{X}} / \mathrm{dt} \\
\mathrm{C}_{\Sigma \mathrm{x}}=\mathrm{C}_{\mathrm{e}}+\left(\mathrm{C}_{\infty}-\mathrm{C}_{\mathrm{e}}\right) \exp (-\alpha \mathrm{t}) \\
\mathrm{C}(x, \mathrm{t})-\mathrm{C}_{\infty}=\frac{\widehat{\mathrm{X}}}{16 \times 10^{+6 \sqrt[6]{\pi D t}}} \exp \left(-x^{2} / 4 \mathrm{Dt}\right)
\end{gathered}
$$

where

$$
\begin{array}{ll}
\widehat{X} & =\int_{0}^{\infty}\left(C-C_{\infty}\right) \mathrm{d} x=\text { Accumulated excess alloy phase storage, } \mathrm{mg} / \mathrm{dm}^{2}, \\
C_{\infty} & =\text { bulk alloy weight fraction, } \\
C_{\Sigma x} & =\text { oxide-alloy interface alloy phase weight fraction, } \\
C_{e} & =\text { oxide-alloy interface alloy phase equilibrium weight fraction, } \\
\alpha & =\text { specific rate constant for change in } \mathrm{C}_{\Sigma \mathrm{x}}, \mathrm{mo}^{-1}, \\
\mathrm{~d} \Sigma \overline{\mathrm{X}} / \mathrm{dt} & =\mathrm{d} \Delta \mathrm{W} / \mathrm{dt}=\text { descaled corrosion rate, } \mathrm{mg} / \mathrm{dm}^{2}-\mathrm{mo} \text { not necessarily constant, } \\
\mathrm{C}(x, t) & =\text { the alloy phase concentration at any time, weight fraction, } \\
\mathrm{D} & =\text { alloy phase diffusitivity, } \mathrm{dm}^{2} / \mathrm{mo},
\end{array}
$$

and where $\Sigma x$, the observable oxide-alloy interface at any time corresponds to $x=0$. Microprobe traces give $C(x, t)$ from which using (11) $\widehat{X}$ may be determined, as well as $D$. $\widehat{X}$ may also be determined by planimeter area measurements of $\int_{0}^{\infty}\left(C-C_{\infty}\right) d x$ and in traces examined to date the two values of $\widehat{\mathrm{X}}$ thus obtained are in fair agreement. $C \Sigma x$ may be determined 
from (11) by setting $\chi=0, \quad C_{e}$ and $\alpha$ may then be determined from (10). The rate constants in $\mathrm{d} \Sigma \overline{\mathrm{X}} / \mathrm{dt}$ may then be determined from (9). In this determination it should be pointed out that the standard method of reporting $\Delta \mathrm{W}$ as used previously $\Delta \mathrm{W}=\Delta \mathrm{W}_{0}+\mathrm{Rt}$ is of dubious value in microprobe trace interpretation since the greatest microprobe trace perturbation is probably occurring in the time that $\Delta \mathrm{W}$ is climbing asymptotically to its steady-state linear rate " $R$ ". However, as explained in previous paragraphs, that the $\Delta \mathrm{W}$-time response approaches a constant should be implicitly built into $\mathrm{d} \Sigma \overline{\mathrm{X}} / \mathrm{dt}$. To do this, the expression

$$
\Sigma \bar{X}=\Delta W=k_{0} t \exp \left[k_{1} /(t+1)\right]
$$

appears satisfactory. From it

$$
\mathrm{d} \Sigma \overline{\mathrm{X}} / \mathrm{dt}=\mathrm{k}_{0} \exp \left[\mathrm{k}_{1} /(\mathrm{t}+1)\right]\left[\frac{\mathrm{k}_{1}}{(\mathrm{t}+1)^{2}}-\frac{\mathrm{k}_{1}}{\mathrm{t}+1}+1\right]
$$

Combination of (13), (10), and (9) followed by a series of integrations by parts leads to

$$
\widehat{\mathrm{X}}=\frac{\mathrm{C}_{\infty} \mathrm{k}_{0}}{\alpha \mathrm{C}_{\mathrm{e}}} \exp \left[\mathrm{k}_{1} /(\mathrm{t}+1)\right]\left\{\left(2 \mathrm{C}_{\mathrm{e}}-\mathrm{C}_{\infty}\right)[1-\exp (-\alpha \mathrm{t})]-\left(\mathrm{C}_{\mathrm{e}}-\mathrm{C}_{\infty}\right)[1-\exp (-2 \alpha \mathrm{t})]\right\}
$$

These principles have been employed in the 1000 hour and 5116 hour Incoloy specimens exposed isothermally to $1050^{\circ} \mathrm{F}$ steam whose microprobe traces are shown in Figures 19 and 20 . Alloy phase trace analysis yields the information of Table IX for iron and nickel, both of which behave nobly in this instance.

TABLE IX

ELECTRON MICROPROBE EVALUATION

\begin{tabular}{|c|c|c|c|c|}
\hline \multirow{2}{*}{$\mathrm{X}$} & \multicolumn{2}{|c|}{1000 Hour Exposure } & \multicolumn{2}{c|}{5116 Hour Exposure } \\
\cline { 2 - 5 } & $\mathrm{Ni}$ & $\mathrm{Fe}$ & $\mathrm{Ni}$ & \multicolumn{1}{c|}{$\mathrm{Fe}$} \\
$\mathrm{n}$ & 19.95 & 9.77 & 37.87 & 19.86 \\
$\mathrm{D}$ & $34.06 \times 10^{-11}$ & $175.8 \times 10^{-11}$ & $1.87 \times 10^{-11}$ & $13.45 \times 10^{-11}$ \\
$\mathrm{C}_{\Sigma \times}$ & 0.359 & 0.458 & 0.443 & $0.474^{\prime}$ \\
\hline
\end{tabular}




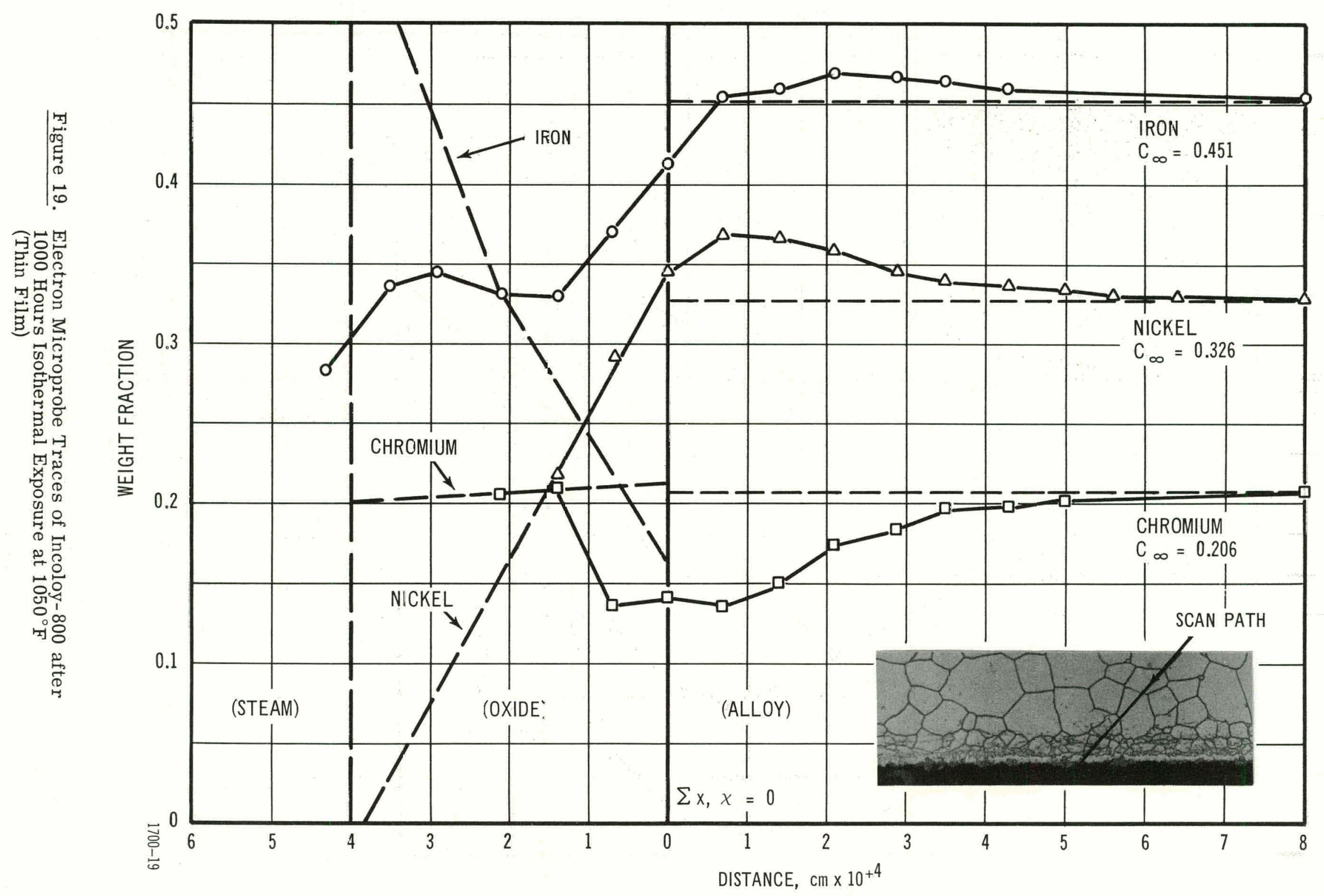




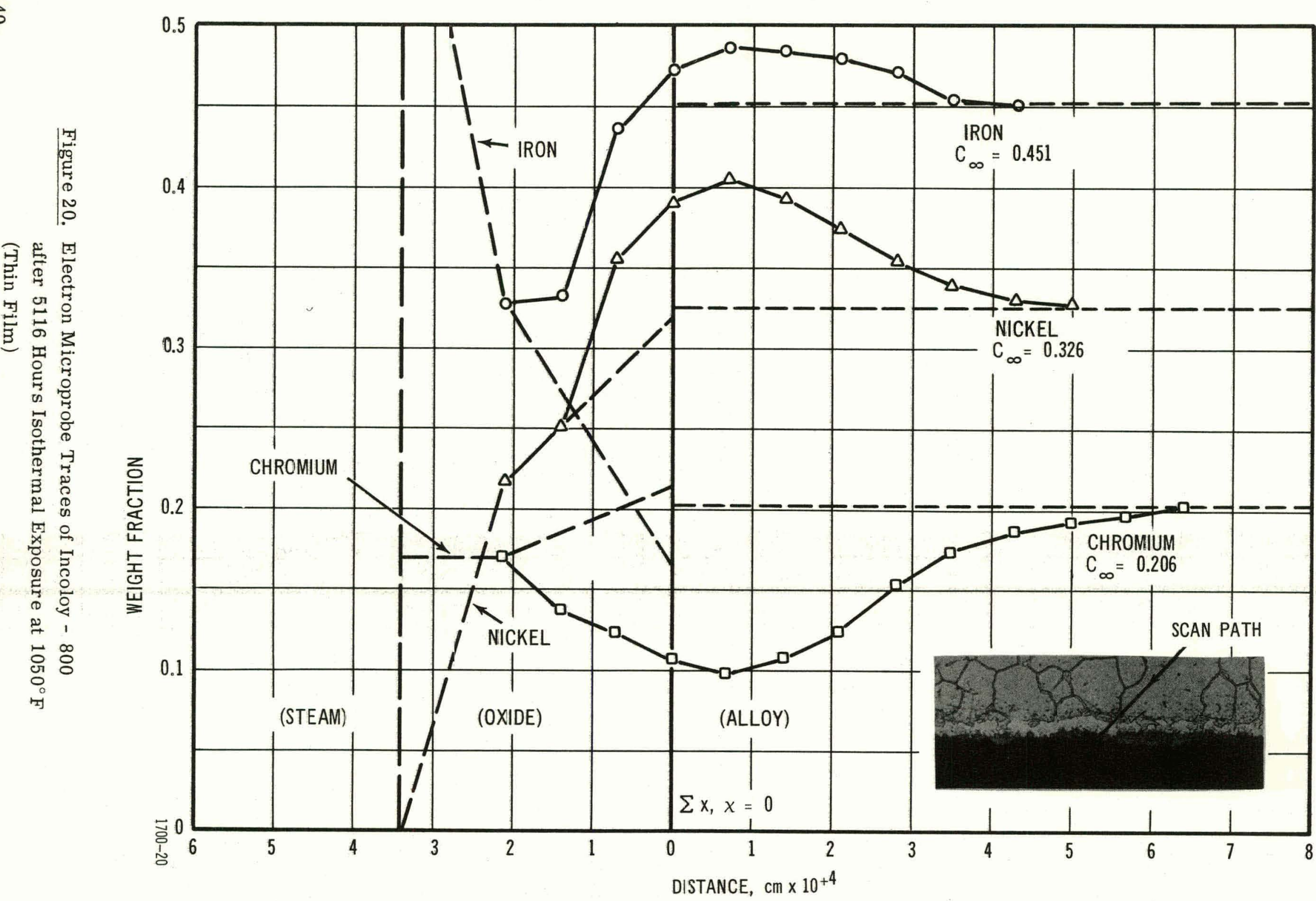


From these values, with $\mathrm{C}_{\infty \mathrm{Ni}}=0.326$ and $\mathrm{C}_{\infty \mathrm{Fe}}=0.451$, the following values are obtained

\begin{tabular}{|c|c|c|c|}
\hline & $\mathrm{Ni}$ & $\mathrm{Fe}$ & Alloy \\
\hline$\alpha$ & 0.14 & 0.163 & \\
\hline $\mathrm{C}_{\mathrm{e}}$ & 0.514 & 0.486 & \\
\hline $\mathrm{k}_{0}$ & & & 21.2 \\
\hline$k_{1}$ & & & 2. 83 \\
\hline
\end{tabular}

therefore, $\Delta \mathrm{W}$ or $\Sigma \overline{\mathbf{x}}$ is given by

$$
\Delta W=21.2 t \exp [2.83 /(t+1)]
$$

The values of $D$ decrease with increasing concentration as expected. The dependence of $D$ can be obtained from the data, if desired, to fit a form $D=D e^{-\delta C \Sigma x}$.

The original discussion ${ }^{(9)}$ also described the amounts of noble elements entering the oxide phase as being given by

$$
\mathrm{dX}(\mathrm{NS}) / \mathrm{dt}=\mathrm{C}_{\Sigma \mathrm{x}} \mathrm{d} \Sigma \overline{\mathrm{X}} / \mathrm{dt}-\mathrm{d} \widehat{\mathrm{X}} / \mathrm{dt}
$$

where the notation (NS) signifies the nonselective fraction. Note that if fully selective, no noble oxide is formed and $\widehat{X}=\int C_{\Sigma x} d \Sigma \bar{X} / d t$. This particular situation requires a different series of expressions for its description.

Expression (16) integrates to give

$$
x_{(N S)}=C_{e} \Delta W-\frac{\left(C_{e}-C_{\infty}\right)}{\alpha} k_{0} \exp \left[k_{1} /(t+1)\right][1-\exp (-\alpha t)]-\widehat{X}
$$

when (17) is used with (15) Table $\mathrm{X}$ is obtained.

The concept of a limiting $\widehat{\mathrm{X}}$ demands that when steady-state is established at $\mathrm{C}_{\Sigma \mathrm{x}}=\mathrm{C}_{\mathrm{e}}$ all elements will enter the oxide phase in proportion to their bulk concentrations. Note, in the column titled "Fraction of Bulk", that this condition is being approached, i. e., the fraction of the bulk alloy is tending to unity. 
TABLE $X$

\section{QUANTITIES CONVERTED TO OXIDE}

\begin{tabular}{|l|c|c|c|c|}
\hline \multirow{2}{*}{$\mathrm{Fe}$} & \multicolumn{2}{|c|}{1000 Hour Exposure } & \multicolumn{2}{c|}{5116 Hour Exposure } \\
\cline { 2 - 5 } & $\begin{array}{c}\text { Amount } \\
\left(\mathrm{mg} / \mathrm{dm}^{2}\right)\end{array}$ & $\begin{array}{c}\text { Fraction } \\
\text { of Bulk }\end{array}$ & $\begin{array}{c}\text { Amount } \\
\left(\mathrm{mg} / \mathrm{dm}^{2}\right)\end{array}$ & $\begin{array}{c}\text { Fraction } \\
\text { of Bulk }\end{array}$ \\
\cline { 2 - 5 } $\mathrm{Cr}$ & 34.05 & 0.77 & 78.37 & 0.81 \\
$\mathrm{Ni}$ & 49.21 & 2.43 & 87.23 & 1.97 \\
Alloy & 13.10 & 0.41 & 45.10 & 0.65 \\
$\begin{array}{l}\text { By descaled } \\
\text { weight } \\
\text { measurement }\end{array}$ & 96.36 & & 210.7 & \\
\hline
\end{tabular}

As $\mathrm{t}$ becomes $>>1, \widehat{\mathrm{X}}$ in (14) approaches its equilibrium value, given by

$$
\widehat{\mathrm{x}}_{\mathrm{e}}=\mathrm{k}_{0} \mathrm{C}_{\infty} / \alpha
$$

The use of this value in (11), at $\mathrm{x}=0$, with an appropriate value of $\mathrm{D}$, and the equilibrium value, $\mathrm{Ce}$, of $\mathrm{C}_{\sum \mathrm{x}}$ will give the time for the limiting compositional disturbance to be achieved. In the case of nickel, for instance, $\mathrm{D}$ as a function of $\mathrm{C}_{\Sigma \mathrm{x}}$ can be determined as:

$$
\mathrm{D}_{\mathrm{Ni}}=8.52 \times 10^{-5} \exp \left(-34.56 \mathrm{C}_{\Sigma \mathrm{x}}\right)
$$

at

$$
C_{\sum x}=C_{e}=0.514 \quad D_{N i}=1.66 \times 10^{-12} \mathrm{dm}^{2} / \mathrm{mo}
$$

and $t$ equilibrium, $\widehat{x}_{e}$ will be from (18)

$$
\widehat{\mathrm{X}}_{\mathrm{e}}=21.2 \times 0.326 / 0.14=49.36 \mathrm{mg} / \mathrm{dm}^{2} \text {. }
$$

From (11) at $\chi=0$, therefore,

$$
\sqrt{t_{e}}=\frac{49.36}{\left(0.514-0.326 \times 16 \times 10^{+6} \sqrt{\pi \times 1.66 \times 10^{-12}}\right.}
$$

giving $\mathrm{t}$ equilibrium as 51.26 months. The depth of the equilibrium compositionally disturbed: layer can be determined from (11) say for a change of 0.001 percent above $C_{\infty}$. Then, if $x_{0(e)}$ is the effective depth of the equilibrium layer 


$$
10^{-5}=\frac{49.36}{16 \times 10^{+6} \sqrt{\pi \times 51.26 \times 1.66 \times 10^{-12}}} \exp \left[-x_{0(e)}^{2} /(4 \times 51.26 \times 1.66)^{\times 10^{-12}}\right]
$$

giving $x_{0(e)}$ as 5.75 microns. Or, using a linear approximation, as shown in Figure 21:

$$
\frac{(0.514-0.326) \times 8 \times 10^{+6}}{2} \times_{0(\mathrm{e})}=49.36
$$

where the bracketed term is the rise in weight fraction, $8 \times 10^{+6}$ is the alloy density, $\mathrm{mg} / \mathrm{dm}{ }^{3}$ and $x_{0}$ is in decimeters. This gives $x_{0(e)}$ as 6.56 microns.

It should be pointed out that the calculations for the rate constants $k_{0}, k$, and for $x_{0}$ are all based on nickel. This leads to first approximations only. Rigorously the noble elements iron and nickel in this instance should be balanced against the active element chromium, such that everywhere in the alloy phase:

$$
\mathrm{C}_{\mathrm{Fe}}+\mathrm{C}_{\mathrm{Ni}}+\mathrm{C}_{\mathrm{Cr}}=0.983
$$

Then $\mathrm{C}_{\mathrm{e}}$ and $\alpha$ should be determined for the sum $\mathrm{C}_{\mathrm{Fe}}+\mathrm{C}_{\mathrm{Ni}}$ and $\mathrm{k}_{0}$ and $\mathrm{k}$, evaluated for $\alpha_{\mathrm{Ni}}+\mathrm{Fe}$ and $\mathrm{C}_{\mathrm{Ni}}+\mathrm{Fe}$

It should also be pointed out that the rise of $x_{0}$, the effective layer depth, that which is essentially optically detectable, as a function of time may well follow some simple time dependence until it is within just a few fractions of a micron of $x_{0(e)}$. As previously discussed for the $1300^{\circ} \mathrm{F}$ heat transfer sheath specimens, a square root of time dependence of $x_{0}$ is quite satisfactory up to 4000 hours at that temperature.

The dashed lines in the oxide phase in Figures 19 and 20 represent the best probable oxide distribution lines $\left(\mathrm{Fe}_{2} \mathrm{O}_{3}, \mathrm{Cr}_{2} \mathrm{O}_{3}\right.$ and $\left.\mathrm{NiO}\right)$ that can be estimated with these and other Incoloy microprobe data, taking $\mathrm{X}$-ray source area and dissociation pressure considerations into effect. Precision planimeter measurements establish that no oxide is apparently lost in 1000 hours. At 5116 hours, however, the oxide phase density can be calculated to be $5.39 \mathrm{~g} / \mathrm{cm}^{3}$. Its iron, chromium, and nickel contents are respectively, $\mathrm{mg} / \mathrm{dm}^{2} 51.17,19.24$, and 42.07 . Therefore, the metallic mass in the oxide lost to the steam environment is composed of, in $\mathrm{mg} / \mathrm{dm}^{2}$, iron 27.20, chromium 67.99, and nickel 3.03 .

The total amount lost is a much larger fraction than that determined by descaled weight measurements as shown in Table $V$. One reason for such a discrepancy is that the electron microprobe traces used as a basis for the calculations were performed across thin oxide films 
where possibly the maximum oxide loss-to-system had occurred (see Figure 20). These results need to be "averaged" with similar calculations across the areas of thick oxide films. As far as the distribution in the oxide phase is concerned, it is quite obvious that when films are only 2 to 4 microns thick very little implicit information is a vailable.

The low proportion of nickel lost to the system is encouraging since the $n, p$ reaction product, Co-58, is a major source of activity downstream. The possibility of the composition of the oxide lost to the system approaching the relative bulk alloy concentrations could not be developed from the data available, but will be included in future studies.

The results to date have been limited to developing and testing a model for use in the predicting of the long-term effects of partial selectivity. The work has been performed with specimens exposed isothermally to $1050^{\circ} \mathrm{F}$ superheated steam for various time periods. Additional electron microprobe traces taken ${ }^{(6)}$ have not been sufficiently complete to permit the above type of quantitative treatment for exposures at other temperatures and with heat transfer. Such traces are being obtained under a combination of well-controlled microprobe conditions and trace area choices for both Incoloy heat transfer sheath and isothermal coupon specimens.

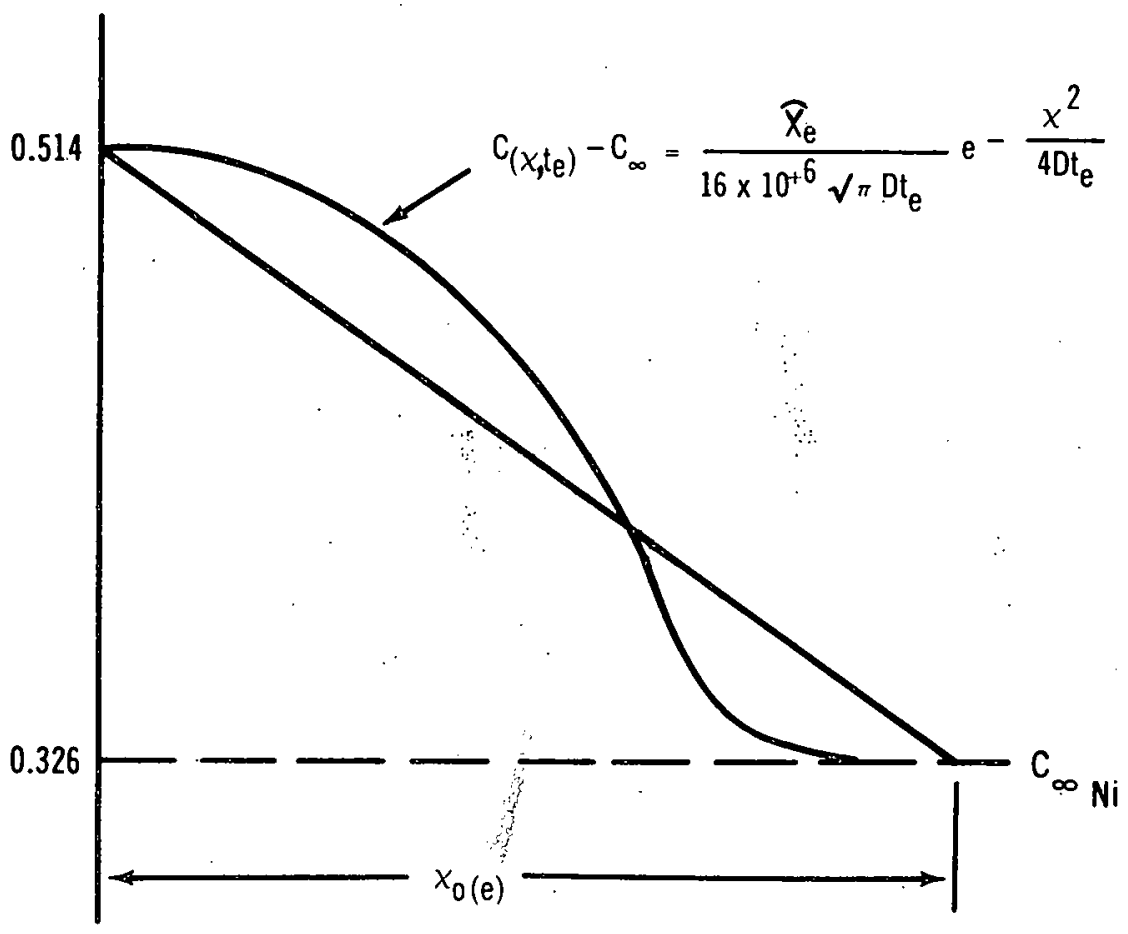

$1700-21$

Figure 21. Linear Approximation for the Equilibrium Layer Thickness, $x_{0(e)}$ 


\section{DISCUSSION OF RESULTS}

The very limited data available in the literature on the corrosion of Incoloy-800 in superheated steam are reported in terms of scale thickness or weight gain measurements. The limitations of interpreting such data have been discussed previously.

Eberle and Anderson ${ }^{(10)}$ studied the scaling behavior of Incolōy-8ư in conjunction with similar studies of ferritic and austenitic alioys in $1100-1500^{\circ} \mathrm{F}$ steam taken from the boiler of a conventional $1050^{\circ} \mathrm{F}, 2000$ psig pressure superheated steam utility plant. The testing conditions resulted in little to no temperature gradient across the tube walls so the results are comparable to the isothermal results in the present work. Utilizing velocities between 1 to $2 \mathrm{ft} / \mathrm{sec}$, they found average scale thicknesses of 0.0006 and 0.0007 inch in exposures of 12 and 18 months respectively at $1200^{\circ} \mathrm{F}$ and 0.0007 inch for both time periods at $1350^{\circ} \mathrm{F}$.

They state that their Incoloy had a slight and sporadic subsurface scale penetration with shallow surface cracks which may have originated in the tube fabrication and that a rather general intergranular subscale attack was experienced which may have been promoted by overstressing. In general, they found that the Incoloy possessed a high resistance to scaling with a thin scale formed; a low subsurface scale formation, and little evidence of flaking and exfoliation of scale.

Their average oxide thickness was the same as the $0.0006-0.0007$ inch experienced in approximately 7 months in the present work with Incoloy exposed to $1150^{\circ} \mathrm{F}$ superheated steam containing $20 \mathrm{ppm}$ oxygen and $2.5 \mathrm{ppm}$ hydrogen. It is not clear at this time whether any difference does exist because of a different oxidation phenomena in the presence of the oxygen. In both cases, the velocities were low as compared to the heat transfer specimens.

Eberle and Anderson performed careful analyses of the scale with the results as reported in Table XI. It is interesting that the chromium and nickel contents in the scale of the Incoloy at $1350^{\circ} \mathrm{F}$ were lower than that observed at $1200^{\circ} \mathrm{F}$.

Pessl ${ }^{(11)}$ carried out some limited exposures of Incoloy to $1022^{\circ} \mathrm{F}$ super heated steam containing $<0.05 \mathrm{ppm} \mathrm{O}_{2}$ and $3-4 \mathrm{ppm} \mathrm{O}_{2}$. He obtained a weight gain of $8 \mathrm{mg} / \mathrm{dm}^{2}$ in 1000 hours in the deoxygenated steam and $10 \mathrm{mg} / \mathrm{dm}^{2}$ in 600 hours in the steam containing oxygen.

The results compare favorably with the $8 \mathrm{mg} / \mathrm{dm}^{2}$ weight gain experienced in the present work with a 1000 -hour exposure at $1050^{\circ} \mathrm{F}$. 
TABLE XI

\section{ANALYSIS OF SCALE AFTER 18 MONTHS EXPOSURE}

\begin{tabular}{|c|c|c|c|}
\hline & \multirow{2}{*}{$\begin{array}{c}|c| \\
\text { Shemical } \\
\text { Composition }\end{array}$} & $\begin{array}{c}\text { Original } \\
\text { Alloy }\end{array}$ & \multicolumn{2}{|c|}{ Temperature, ${ }^{\circ} \mathrm{F}$} \\
\cline { 3 - 4 } & 44.3 & 1200 & 1350 \\
\hline $\mathrm{Fe}$ & 20.69 & 24.5 & 30.0 \\
$\mathrm{Cr}$ & 34.66 & 22.7 & 19.8 \\
$\mathrm{Ni}$ & 0.55 & 0.50 & 0.42 \\
$\mathrm{Si}$ & 0.79 & 2.7 & 3.6 \\
$\mathrm{Mn}$ & &
\end{tabular}

Additional work by Pessl ${ }^{(12)}$ indicated that a 2400 -hour exposure to the $1022^{\circ} \mathrm{F}$ steam with $3-4 \mathrm{ppm} \mathrm{O}_{2}$ resulted in an average descaled weight loss of approximately $40 \mathrm{mg} / \mathrm{dm}^{2}$. This value is roughly $1 / 3$ of the weight loss obtained in the present work at $1050^{\circ} \mathrm{F}$ with $20 \mathrm{ppm} \mathrm{\textrm {O } _ { 2 }}$ and $2.5 \mathrm{ppm} \mathrm{H}_{2}$ in the steam.

The corrosion data presented have been interpreted generally as representing a process with an initially high time dependent rate that decreased to a lower constant rate after some time period. The assumption of a linear response for long-term extrapolation is an important, yet conservative interpretation of the data available and is worthy of some consideration as to applicability of corrosion mechanisms and theory.: A transition from nonlinear to linear kinetics is consistent with the concept of mechanical defecting at $p-n$ junctions in the oxide. Defect generation, regardless of whether it is followed by oxide spalling, tends to destroy the barrier properties of the oxide film. Expressed quantitatively, the barrier film, $W_{1}$, grows at a rate which is inversely proportional to its thickness and transforms to a nonbarrier film at some constant rate, $\mathrm{k}_{2}$. That is

$$
\mathrm{dW}_{1} / \mathrm{dt}=\left(\mathrm{k}_{1} / \mathrm{w}_{1}\right)-\mathrm{k}_{2}
$$

The nunbarrier film grows at a rate proportional to the defect rate, i. e., ,

$$
\mathrm{dW}_{2} / \mathrm{dt}=\mathrm{k}_{2} \text {. }
$$

The two rate expressions integrate to give

$$
\begin{gathered}
w_{1}+\left(k_{1} / k_{2}\right) \ln \left[1-\left(k_{2} / k_{1}\right) w_{1}\right]=-k_{2} t \\
w_{2}=k_{2} t
\end{gathered}
$$


It is apparent that as $k_{2} t$ becomes large, the term $1-\left(k_{2} / k_{1}\right) w_{1}$ must tend to zero. That is, $W_{1}$ reaches a limiting thickness $\mathrm{k}_{1} / \mathrm{k}_{2}$ while $\mathrm{W}_{2}$ continues to grow. The total oxide weight (which is proportional to the metal loss) is :

$$
\Delta \mathrm{W}=\mathrm{w}_{1}+\mathrm{W}_{2}
$$

Whể plottcd, Figurc 32, it will be seen that $w_{1}+W_{2}$ asymptotically approaches a linear time response, the asymptote having intercept $k_{1} / k_{2}$ and slope $k_{2}$.

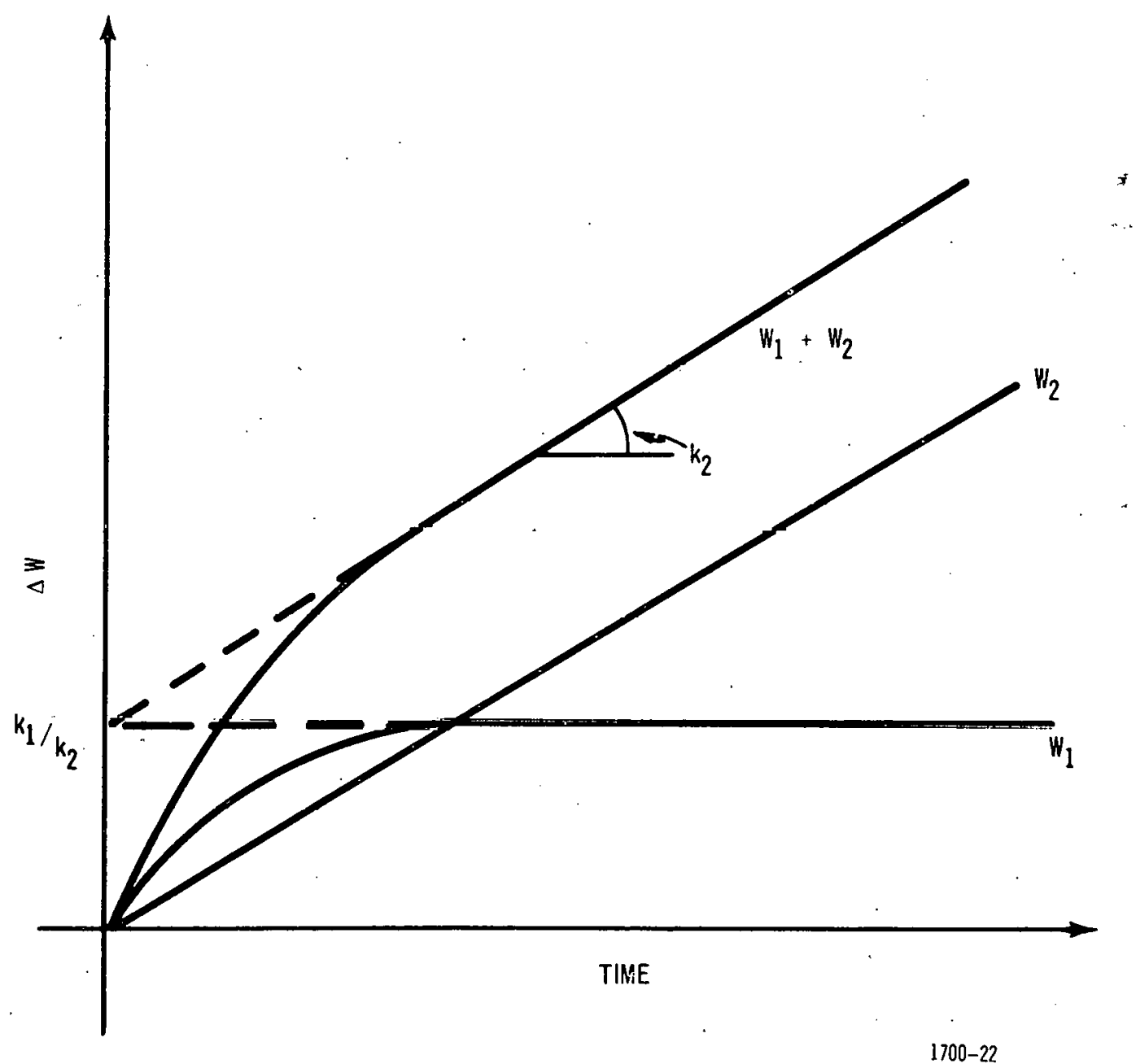

Figure 22. Schematic Representation of Transition to Linear Oxidation Response 
A careful study of the data available gives some insight into the ability to use rates obtained from the isothermal testing for predicting the corrosion performance of the fuel cladding materials when transferring heat to the steam. Extrapolation of the mean isothermal corrosion data for three years exposure in $1050^{\circ} \mathrm{F}$ steam [Equation (6)] is less than one-third the comparable corrosion when tested under heat transfer (Appendix A) at a metal temperature of $1050^{\circ} \mathrm{F}$. A similar comparison at $1150^{\circ} \mathrm{F}$ indicated the isothermal corrosion about one-half that experienced under comparable metal temperatures with heat transfer.

Reference to the compositionally disturbed layer formed on Incoloy-800 indicates a greater denth of disturbance with exposure isothermally (Table VIII) than when exposed with heat transfer (Table VII). The layer appears more uniform in the latter case (Figures 17 and 11, respectively).

Based on this preliminary comparison, it appears that a real difference exists in the oxidation of Incoloy-800 exposed isothermally as compared to exposure with heat transfer, both at the same metal temperature. The factor of 8 difference in steam velocity would not be expected to account for the extent of the differences indicated.

Preliminary examination of additional microprobe traces indicate that the displacement reaction control, on which the model herein discussed is based, may be too restrictive. Of particular concern are changes in diffusivity, like those between 1000 and 5116 hours of the 1050 . Incoloy specimens (Figures 19 and 20). Expression (11) does not allow for the onset of the equilibrium value, $\widehat{\mathrm{X}}_{e}$, of the excess stored mass of noble elements. Note that after $\widehat{\mathrm{X}}_{\mathrm{e}}$ has been reached both $\widehat{\mathrm{X}}_{e}$ and $\mathrm{C}_{e}$, the equilibrium alloy phase surface concentration [available from setting $x=0$ in expression (11)], are constant. Therefore if equilibrium is reached, the evaluation of expression (11) after equilibrium as a function of times in excess of $t_{e}$ must keep the fraction $1 / \sqrt{\mathrm{Dt}}$ constant. That is at longer times $\mathrm{D}$ will appear smaller. For the Incoloy specimens in question it is quite possible that $\widehat{\mathrm{X}}_{e}$ was reached before 5116 hours [noting that 2 time points will never strongly support parameter estimation in expressions (10) and (11)]. This is a more powerful argument for apparent diffusivity decrease than that offered based on concentration changes. Two additional analytical models are being developed and their applicability will be explored in future reports of the selective oxidation process. 


\section{REFERENCES}

1. Pursel, C. A., "USAEC NUCleAR SUPERHEAT PROGRAMME, SMALL AND MEDIUM POWER REACTORS," International Atomic Energy Agency, Vienna, 1961, pp 83-110.

2. Gaul, G. G. and Pearl, W. L., "FUEL CLADDING CORROSION TESTING IN SIMULA TED SUPERHEAT REACTOR ENVIRONMENT PHASE I. GENERAL CORROSION TYPE-304 STAINLESS STEEL, " Nuclear Science and Engineering; $1 ' l, 30-41$ (19̈63).

3. Spalaris, C. N., Boyle, R. F., Evans, T. F., and Esch, E. L., "DESIGN, FABRICATION AND. IRRADIATION OF SUPERHEAT FUEL ELEMENT SH-4B IN VBWR," GEAP-3796, September 1, 1961.

4. Spalaris, C. N., "FUEL ELEMENT EXPERIMENTS IN SADE-VBWR NUCLEAR SUPERHEAT LOOP," GEAP-4240, May 1963.

5. Pearl, W. L., Gaul, G. G., and Wozadlo, G. P., "LOCALIZED CORROSION OF STAINLESS STEELS AND HIGH NICKEL ALLOYS IN SIMULATED SUPERHEAT REACTOR ENVIRONMENT," GEAP-4450, February 1964.

6. Pearl, W. L., and Gaul, G. G., "GENERAL AND STRESS CORROSION OF HIGH NICKEL ALLOYS IN SIMULATED SUPERHEAT REACTOR ENVIRONMENT," GEAP-4165A, March 1963.

7. Fitzsimmons, M. D., Pearl, W. L., and Siegler, M., "SIMULATED BOILING WATER REACTOR AND SUPERHEAT REACTOR CORROSION FACILITY," Nuclear Science and Engineering: 17, 18-29 (1963).

8. Siegler, M. and Snyder, D. T., "AN IN-LINE INSTRUMENT FOR THE RAPID AUTOMATIC DETERMINATION OF GAS CONCENTRATIONS IN OUT-OF-PILE SIMULATED BOILING WATER REACTOR AND SUPERHEATED STEAM LOOPS," 6th Conference on Analytical Chemistry in Nuclear Technology, Gatlinburg, Tennessee, TD-7655, October 9-11, 1962.

9. Brush, E. G., "ELECTRON BEAM MICROPROBE STUDIES OF THE OXIDATION BEHAVIOR WITH IRON-CHROMIUM-NICKEL SYSTEM IN HIGH TEMPERATURE STEAM 1. TRACE INTERPRETATION TECHNIQUES," GEAP-4490, March, 1964. 
10. Eberle, F. and Anderson, C. H., "SCALING BEHAVIOR OF SUPERHEATER TUBE ALLOYS IN ALLOYS IN ASME HIGH TEMPERATURE STEAM RESEARCH TESTS AT $1100-1500^{\circ} \mathrm{F}$," Trans. ASME, Ser. A., J. Eng. Power, 84, 223-257, July 1962.

11. Pessl; H., PRocendings of the nuClear superheat MeEting - No. 7, Sioux Falls, South Dakota, COO-266, September 12-14, 1962, pp 15-17.

12. Pessl, H., PROCEEdINGS OF THE NUCLEAR SUPERHEAT MEETING - No. 8, Idaho Falls, Idaho, COO-267, March 20-22, 1963, p. 16.

13. Peirce, B.O. and Foster, R.M., "A Short Table of Integrals," Ginn and Company, N.Y.C., 1957. 


\section{ACKNOWLEDGMENT}

The authors gratefully acknowledge the assistance of the Corrosion Engineering Group (under the direction of $M$. Siegler) for the operation of the CL-1 and CL-4 superheat facilities; M. D. Fițsimmons who designed the new and modified facilities required for the program; A. E: Pickett and D. F. MacMillan who performed most of the metallography; R. F. Kirby who procured the special test materials; and the many other members of the Vallecitos Atomic Laboratory who contributed their efforts and counseling in making the work possible. The electron beam microprobe analyses were performed by the Advanced Metals Research Corporation of Sommerville, Massachusetts. 


\section{APPENDIX A}

\section{LONG-TERM CORROSION RATE DATA EXTRAPOLATION}

\section{DERIVATION OF CORROSION RATES FROM WEIGHT CHANGE} MEASUREMENTS OF HEAT TRANSFER TEST SPECIMENS

When given a cylindrical test sheath of outside radius, $r(\mathrm{~cm})$, whose outside area is immersed in steam such that the metal temperature varies uniformly from $l=0$ to $l=L(\mathrm{~cm})$ (Figure A-1); the descaled metal loss, $\Delta W^{\prime}$, will be given by the following equation, at any time, $t$ :

$$
\Delta W^{\prime}=\int_{0}^{t} \int_{0}^{L}\left(2 \pi r d \Delta W^{\prime \prime} / d t\right) d t d \ell,
$$

where $d \Delta W \% d t$ is the corrosion rate $\left(g / \mathrm{cm}^{2}-h r^{n}\right)$, assumed to be of the form:

$$
\mathrm{d} \Delta \mathrm{W}^{\prime \prime} / \mathrm{dt}=\mathrm{k} n \mathrm{t}^{\mathrm{n}-1}
$$

For clarity the weight change symbols used in this document have units as follows:

$$
\begin{aligned}
\Delta \mathrm{W} & =\mathrm{mg} / \mathrm{dm}^{2} \text { (used in document text) } \\
\Delta \mathrm{W}^{\prime} & =\mathrm{g} \\
\Delta \mathrm{W}^{\prime \prime} & =\mathrm{g} / \mathrm{cm}^{2}
\end{aligned}
$$

In the rate expression $\mathrm{k}$ is the specific rate constant $\left(\mathrm{g} / \mathrm{cm}{ }^{2}-\mathrm{hr}{ }^{\mathrm{n}}\right)$, and $\mathrm{n}$ riay have any value such that $0<\mathbf{n} \leq 1$. A special case develops, as explored in future paragraphs, should $\mathbf{n}=1$ and $\Delta W^{\prime}$ not pass through the origin.

The substitution of expression (A-2) into (A-1) and integration with respect to $t$ gives (assuming that $\Delta W^{\prime}$ passes through the origin):

$$
\Delta W^{\prime}=2 \pi r t^{n} \int_{0}^{L} d \ell
$$

If the rate constant $\mathrm{k}$ is assumed to vary in temperature according to the Arrhenius equation, then:

$$
k=k_{0} \exp (-A / T) \text {, }
$$

in which $A$, a quantity related to the activation energy, is expressed in temperature $\left({ }^{\circ} \mathrm{K}\right)$ units. In the case of the superheat test sheaths under discussion, $T$ is known to vary linearly with $\ell$. That is, the temperature, $T$, at any point along the sheath will be given by:

$$
T=T_{i}+b l,
$$




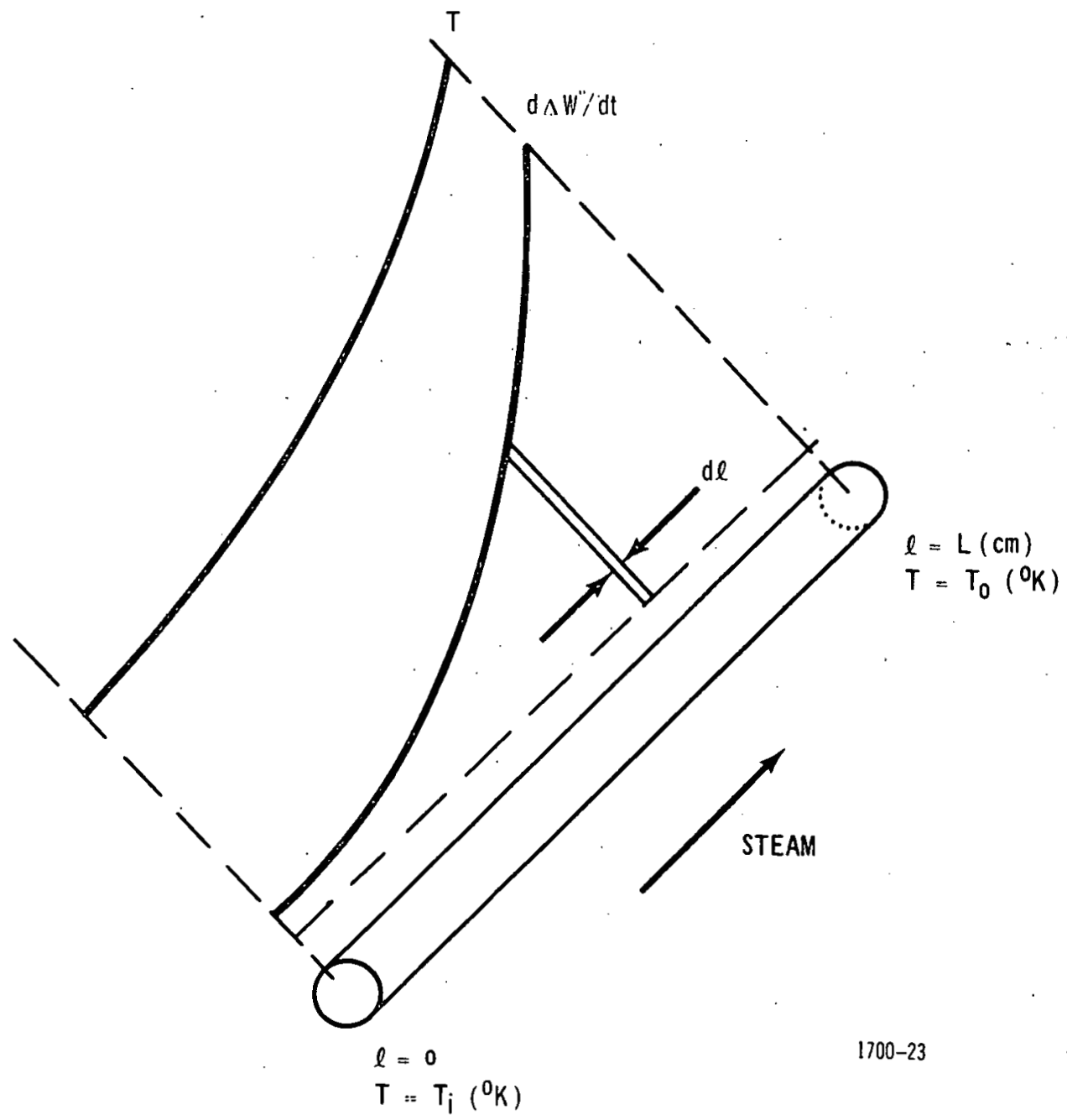

Figure A-1. Schematic Representation of Temperature and Rate Changes Along Any Given Superheat Test Sheath

where the constant $b$, if $T_{i}$ is the metal temperature at the inlet end $(\ell=0)$ and $T_{0}$ the metal temperature at the outlet end $(l=L)$, is given by:

$$
\mathbf{b}=\left(\mathrm{T}_{0}-\mathrm{T}_{\mathrm{i}}\right) / \mathrm{L}
$$

substitution of expressions (A-4) and (A-5) into (A-3) results in:

$$
\Delta W^{\prime}=2 \pi r k_{0} t^{n} \int_{0}^{L} \exp \left[-A /\left(T_{i}+b \ell\right)\right] d \ell
$$

If now a variable $x$ is defined such that:

$$
x=\frac{A}{T_{i}+b l}
$$


then,

$$
\mathrm{b} d \ell=-\mathrm{A} x^{-2} \mathrm{~d} x
$$

or, using expression (A-6),

$$
\mathrm{d} \ell=-\mathrm{LA}\left(\mathrm{T}_{0}+\mathrm{T}_{\mathrm{i}}\right)^{-1} x^{-2} \mathrm{~d} x
$$

Furthermore, at $\ell=0 \quad x=A / T_{i}$ and at $\ell=L$, again using expression $(A-6), x=A / T_{0}$. Therefore, expression (A-7) becomes

$$
\Delta W^{\prime}=-(2 \pi r L) A k_{0}\left(T_{0}-T_{i}\right)^{-1} t^{n} x_{A / T_{i}}^{A / T_{0}} \exp (-x) d x
$$

Using successive integration by parts, in which $\exp (-x) d x$ is always set equal to dv, and $\frac{\mathrm{d} \mathfrak{j}}{\mathrm{d} x^{j}}\left(x^{-2}\right)$ is always set equal to $\mathrm{u}$, expression $(A-8)$ becomes

$$
\begin{aligned}
(\mathrm{A}-8) & =\int \mathrm{udv}=\mathrm{uv}-\int \mathrm{vdu}^{\prime}=-(2 \pi \mathrm{rL}) \mathrm{Ak}_{0}\left(\mathrm{~T}_{0}-\mathrm{T}_{\mathrm{i}}\right)^{-1} \mathrm{t}^{\mathrm{n}}\left\{\operatorname { e x p } ( - x ) \left[-x^{-2}+2 x^{-3}-2.3 x^{-4}\right.\right. \\
& \left.\left.+2.3 .4 x^{-5}-2.3 .4 .5 x^{-6}+\cdots\right]\right\}_{\mathrm{A} / \mathrm{T}_{\mathrm{i}}}^{\mathrm{A} / \mathrm{T}_{0}}
\end{aligned}
$$

The large bracketed term, \{\} , in $x$ can be reduced to, as a first approximation when $A / T_{0}$ is greater than 5,

$$
\{\}=\operatorname{Ei}(x)-x^{-1} \exp (-x)
$$

where $\operatorname{Ei}(x)$ is the exponential integral. Thus,

$$
\left.\Delta W^{\prime}=(2 \pi r L) A k_{0} \cdot T_{0}-T_{i}\right)^{-1} t^{n}\left[x^{-1} \exp (-x)-E i(x)\right]_{A / T_{i}}^{A / T_{0}}
$$

* Equation (1), page 11 corrected for change of units. 


\section{COMPARISON OF TEMPERATURE DEPENDENCE IN THE}

LOW AND HIGH TEMPERATURE RANGES

The oxidation temperature dependence as indicated in Figure 6, page 16, may vary from the low $\left(800-1100^{\circ} \mathrm{F}\right)$ to the high temperature range $\left(1100-1410^{\circ} \mathrm{F}\right)$. The variation, if real, would indicate a change in the relative activation energy constant $A$. That such a change could be expected is logical, arising either as a result of different oxidation products (particularly in regards to steric defect nature) or as a result of changing the oxidant potential, which could be due to a varying extent of oxygen and hydrogen recombination as a function of temperature.

A test of whether the data support a change in the constant, A, can be made with the use of expression (A-9). A rigorous test would let the time exponent, $n$, vary and would evaluate the regression values of the constants $\left(n, k_{0}\right.$, and $A$ ) by setting

$$
\Delta=\Delta W^{\prime}-[\text { expression }(A-9)]
$$

and solving the simultaneous equations,

$$
\begin{aligned}
& \partial / \partial \mathrm{n} \Sigma \Delta^{2}=0, \\
& \partial / \partial \mathrm{k}_{0} \Sigma \Delta^{2}=0, \\
& \partial / \partial \mathrm{A} \Sigma \Delta^{2}=0 .
\end{aligned}
$$

Differential treatment of expression (A-9) as it stands will lead to the appearance of $A$ under the summation sign and its evaluation becomes exceptionally tedious by hand calculation. In addition, the nonlinear appearance of $A$ (appearing as an exponent under the summation sign) makes the assignment of an error variance to $A$ difficult, if not impossible. Such a variance is necessary for the desired comparison of the temperature dependence of A. Therefore, a firstapproximation, expression (A-9) will be linearized as explained in the following paragraph. Furthermore, since (at least visually from Figure 4, page 14) a parabolic time dependence (i. e., $n=1 / 2$ ) gives about the same deviation of all points from the eye imposed $\Delta W=k_{p} \sqrt{t}$ line, comparisons of constants will be sought by assigning a second approximation, the value of $1 / 2$ to $n$ in expression (A-9).

In view of this latter assumption, expression (9) can be written,

$$
k_{(p)}=\Delta W^{\prime}(2 \pi r L)^{-1} t^{-1 / 2}=k_{0(p)} A_{(p)}\left(T_{0}-T_{i}\right)^{-1}\left[x^{-1} \exp (-\chi)-E_{i}(x)\right]_{A / T_{i}}^{A / T_{0}}
$$


Figure 6, page 16 , provides $7000^{\circ} \mathrm{K}$ as a rough estimate of $\mathrm{A}_{(\mathrm{p})}$. Therefore, considering the values of $\mathrm{T}\left[\right.$ maximum value of $\mathrm{T}$ is $\left.1039^{\circ} \mathrm{K}\left(1410^{\circ} \mathrm{F}\right)\right]$, the exponential integral expansion, may be dropped for terms higher than $x^{-2}$. Thus, expression $(A-10)$ becomes

$$
k_{(p)}=\Delta W^{\prime}(2 \pi r L)^{-1} t^{-1 / 2}=k_{0(p)}\left[\left(T_{0}-T_{i}\right) A_{(p)}\right]^{-1}\left[T_{0}^{2} \exp \left(-A_{(p)} / T_{0}\right)-T_{i}^{2} \exp \left(-A_{(p)} / T_{i}\right)\right]
$$

Linearization of this last expression can be achieved by adopting values of $T_{0}$ and $T_{i}$ such that the exponential term can be factored. If $\mathrm{T}_{0}$ is chosen in both exponential terms the resulting values of the rate constants will be biased downward, and if $\mathrm{T}_{\mathrm{i}}$ is chosen, they will be too high. Therefore, the previously mentioned first approximation necessary for linearization will be to choose the exponent temperature term as the arithmetic mean of inlet and outlet temperatures, $\left(T_{0}+T_{i}\right) / 2$. When this is done, expression (A-11) becomes, upon factoring the difference of the squares, $\mathrm{T}_{0}^{2}-\mathrm{T}_{\mathrm{i}}^{2}=\left(\mathrm{T}_{0}+\mathrm{T}_{\mathrm{i}}\right)\left(\mathrm{T}_{0}-\mathrm{T}_{\mathrm{i}}\right)$,

$k_{(p)}=\Delta W^{\prime}(2 \pi r L)^{-1} t^{-1 / 2}=k_{0(p)} A_{(p)}^{-1}\left(T_{0}+T_{i}\right) \exp \left\{-A_{(p)}\left[\left(T_{0}+T_{i}\right) / 2\right]^{-1}\right\}$ or,

$\mathrm{k}_{(p)}=\Delta \mathrm{W}^{\prime}\left[(2 \pi r \mathrm{~L})\left(\mathrm{T}_{0}+\mathrm{T}_{\mathrm{i}}\right)\right]^{-1} \mathrm{t}^{-1 / 2}=\mathrm{k}_{0(\mathrm{p})} \mathrm{A}_{(\mathrm{p})}^{-1} \exp \left\{-\mathrm{A}_{(\mathrm{p})}\left[\left(\mathrm{T}_{0}+\mathrm{T}_{\mathrm{i}}\right) / 2\right]^{-1}\right\}$

Expression $(A-12)$ can be linearized for regression analysis by logarithmic transformation. Thus,

$\underset{\ldots}{\log k_{(p)}}=\log \Delta W^{\prime}\left[(2 \pi r L)\left(T_{0}+T_{i}\right)\right]^{-1} t^{-1 / 2}=\log k_{0(p)} A_{(p)}^{-1}-0.434 A_{(p)}\left[\left(T_{0}+T_{i}\right) / 2\right]^{-1}$

For the purposes of standard linear regression analyses, expression (A-13) can be written

$$
y=a_{0}-a_{1} x_{1}
$$

where

$$
y=\log \Delta W\left[(2 \pi r L)\left(T_{0}+T_{i}\right)\right]^{-1} t^{-1 / 2}
$$




$$
\begin{aligned}
& a_{0}=\log k_{0(p)} A_{(p)}^{-1}, \\
& a_{1}=0.434 A_{(p)}, \\
& x_{1}=\left[\left(T_{0}+T_{i}\right) / 2\right]^{-1} .
\end{aligned}
$$

In estimating the coefficients $a_{0}$ and $a$, in the two temperature ranges of interest, the test data will be expressed in gram mass units (descaled metal loss), square centimeter area units, degree Kelvin temperature units, and hour time units. These units will be used throughout the Appendix, unless otherwise specified. The data are, with $2 \pi \mathrm{rL}=298.7 \mathrm{~cm}^{2}$.

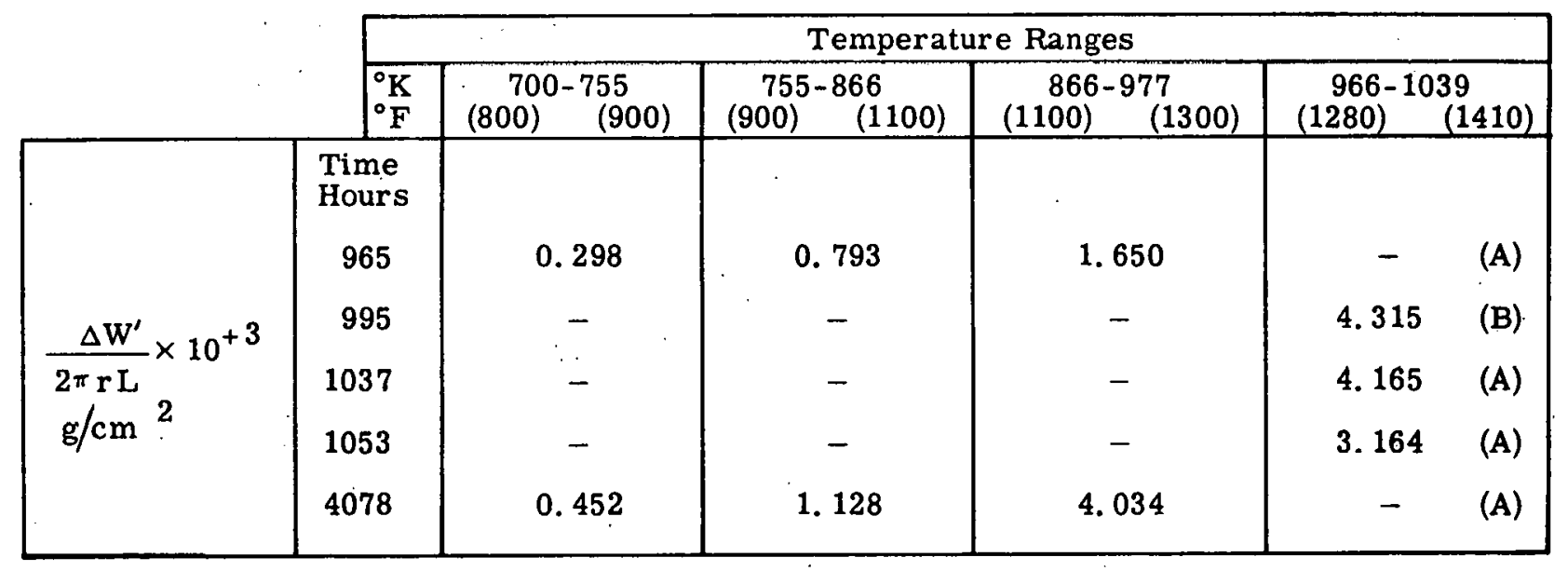

The standard regression equations for expression (A-14) are .

$$
\begin{aligned}
& \mathrm{Na}_{0}-\mathrm{a}_{1} \Sigma x_{1}=\Sigma \mathrm{y}, \\
& \mathrm{a}_{0} \Sigma x_{1}-\mathrm{a}_{1} \Sigma x_{1}^{2}=\Sigma x_{1} \mathrm{y} .
\end{aligned}
$$

where $\mathrm{N}$ represents the number of pairs of experimental observations (weight change versus time). Their application to the data yields : 


\begin{tabular}{|l|c|c|}
\cline { 2 - 3 } \multicolumn{1}{c|}{} & $\begin{array}{c}700-866^{\circ} \mathrm{K} \\
\text { Range }\end{array}$ & $\begin{array}{c}866-1039^{\circ} \mathrm{K} \\
\text { Range }\end{array}$ \\
\hline $\mathrm{N}$ & 4 & 5 \\
\hline$\Sigma \mathrm{y}^{2}$ & -32.208 & -36.683 \\
$\Sigma x_{1}$ & 259.502 & 269.239 \\
$\Sigma x_{1}{ }^{2}$ & $5.214 \times 10^{-3}$ & $5.160 \times 10^{-3}$ \\
$\Sigma x_{1} \mathrm{y}$ & $-42.038 \times 10^{-3}$ & $-37.888 \times 10^{-3}$ \\
$\mathrm{a}_{0}$ & -4.461 & $-3.337 \times 10^{-6}$ \\
$\mathrm{a}_{1}$ & $+2.755 \times 10^{+3}$ & $+2.622 \times 10^{+3}$ \\
$\mathrm{~s}^{2}\left(\mathrm{y}_{0} x_{1}\right)$ & 0.0072 & 0.0159 \\
$\mathrm{~s}^{2}\left(\mathrm{a}_{1}\right)$ & $36.83 \times 10^{+4}$ & $133.64 \times 10^{+4}$ \\
\hline
\end{tabular}

where $\mathrm{s}^{2}\left(\mathrm{y} \cdot \mathrm{x}_{1}\right)$ is the regression variance of $\mathrm{y}$ on $x_{1}$, and $\mathrm{s}^{2}\left(\mathrm{a}_{1}\right)$ is the regression variance of the rate constant $a_{1}$, being given by

$$
\begin{aligned}
& \mathrm{s}^{2} \cdot\left(\mathrm{y} \cdot x_{1}\right)=\left[\mathrm{s}\left(\mathrm{y}^{2}\right)-\mathrm{a}_{1}^{2} \mathrm{~s}\left(\mathrm{x}_{1}{ }^{2}\right)\right] /(\mathrm{N}-2) \\
& \mathrm{s}^{2}\left(\mathrm{a}_{1}\right)=\mathrm{s}^{2}\left(\mathrm{y} \cdot \mathrm{x}_{1}\right) / \mathrm{s}\left(\mathrm{x}_{1}{ }^{2}\right)
\end{aligned}
$$

where

$$
\begin{aligned}
& \mathrm{s}\left(\mathrm{y}^{2}\right)=\left[\mathrm{N} \Sigma \mathrm{y}^{2}-(\Sigma \mathrm{y})^{2}\right] / \mathrm{N} \\
& \mathrm{s}\left(\mathrm{x}_{1}{ }^{2}\right)=\left[\mathrm{N} \Sigma x_{1}{ }^{2}-\left(\Sigma x_{1}\right)^{2}\right] / \mathrm{N} .
\end{aligned}
$$

If the variances in the two temperature ranges are homogeneous, then a joint estimate of the variance of $\mathrm{s}^{2}\left(\mathrm{y} \cdot x_{1}\right)_{700-1039}$ for the entire range is

$$
\mathrm{s}^{2}\left(\mathrm{y} \cdot x_{1}\right)_{700-1039}=\left[\mathrm{s}^{2}\left(\mathrm{y} \cdot x_{1}\right)_{700-866}+\mathrm{s}^{2}\left({\left.\mathrm{y} \cdot x_{1}\right)}_{866-1039}\right] /\left(\mathrm{N}_{700-866}+\mathrm{N}_{866-1039}-4\right)\right. \text {. }
$$


or,

$$
\dot{s}^{2}\left(y \cdot x_{1}\right) 700-1039=0.0124
$$

The difference $a_{1(700-866)}-a_{1(866-1039)}$ may be examined by noting that the 95 percent confidence limits on this difference are given by

$$
a_{1 \text { low }}-a_{1 \text { high }} \pm s\left(y \cdot x \text { 1) } 700-1039 t_{05,5} \sqrt{\frac{1}{s\left(x_{1}^{2}\right)_{\text {low }}}+\frac{1}{s\left(x_{1}^{2}\right)_{\text {high }}}} .\right.
$$

The difference is

$$
(2.755-2.622) \times 10^{+3}=\cdot 133
$$

The Student $t$ value at the 0.05 level with 5 degrees of freedom is 2.57 so that the 95 percent confidence limits are

$$
\pm 2.57 \sqrt{0.124} \sqrt{\frac{10^{+8}}{1.955}+\frac{10^{+8}}{1.188}}
$$

or, \pm 331 . Since the limits on the difference include zero as a probable valie for the difference; the conclusion that $a_{1}$ and that consequently $A$ is the same for the two temperature ranges must follow.

The 95 percent confidence limits on the constants $a_{0}$ are given by

$$
-4.561-(-4.631)_{ \pm}(2.57)(0.111) \sqrt{\frac{1}{4}+\frac{1}{5}+\frac{\bar{\chi}_{1}^{2} \text { low }}{s\left(x_{1}^{2}\right)_{\text {low }}}+\frac{\bar{\chi}_{2}^{2}}{s^{2}\left(\chi_{1}^{2}\right)_{\text {high }}}},
$$

where $\bar{x}_{1}$ signifies the experimental mean of $x_{1}$. They are given by

$$
\begin{aligned}
& \bar{x}_{1700-866}=\Sigma x_{1700-866} / 4=1.28 \times 10^{-3}, \\
& \bar{x}_{1866-1039}=\Sigma x_{1866-1039} / 5=1.01 \times 10^{-3},
\end{aligned}
$$


so that the limits are

$$
0.170 \pm(2.57) \cdot(0.111) \sqrt{0.45+\frac{164}{1.955}+\frac{102}{1.188}}
$$

or $0.170 \pm 3.851$. Once again zero is a probable value of the difference so that

$$
a_{0} 700-866=a_{0} 866-1039:
$$

Therefore, the data do not support the break in the rate versus $1 / \mathrm{T}$ curve that is included in Figure 6, page 16. 


\section{RATE CONSTANT ESTIMATION FOR THE OXIDATION \\ OF INCOLOY IN SUPERHEATED STEAM}

Since there is no reason to suspect a break in the rate versus $1 / T$ curve, the data from 700 to $1039^{\circ} \mathrm{K}$ may be pooled to provide rate constant estimation for use in total corrosion prediction at any given temperature, within the range of temperatures so far examined experimentally. There are two approaches of interest, both involving the time dependence of the descaled metal loss. The first is to assume that it is curvilinear. The second, and more pessimistic (as discussed on page 10) is to assume that it is linear after some initial transient that occurred prior to 900 hours.

\section{Curvilinear Time Dependence}

Here the time exponent, $n$, in expression (A-9) should not be chosen a priori. With the same linearization principles used previously, expression (A-9) becomes

$$
\Delta W^{\prime}\left[(2 \pi r L)\left(T_{0}+T_{i}\right)\right]^{-1}=k_{0(n)} A_{(n)}^{-1} t^{n} \exp \left\{-A_{n}\left[\left(T_{0}+T_{i}\right) / 2\right]^{-1}\right\}
$$

Logarithmic transformation leads to

$$
y=a_{0}+a_{1} x_{1}-a_{2} x_{2}
$$

where

$$
\begin{aligned}
& y=\log \Delta W^{\prime}\left[(2 \pi r L)\left(T_{0}+T_{i}\right)\right]^{-1}, \\
& a_{0}=\log k_{0(n)} A_{(n)}^{-1}, \\
& a_{1}=n \\
& x_{1}=\log t \\
& a_{2}=0.434 A_{(n)}, \text { and } \\
& x_{2}=\left[\left(T_{0}+T_{i}\right) / 2\right]^{-1} .
\end{aligned}
$$

The regression equations are:

$$
\mathrm{Na} \mathrm{N}_{0}+\mathrm{a}_{1} \Sigma x_{1}-\mathrm{a}_{2} \Sigma x_{2}=\Sigma \mathrm{y},
$$

* Equation (2), page 17 corrected for change of units. 


$$
\begin{aligned}
& a_{0} \Sigma x_{1}+a_{1} \Sigma x_{1}^{2}-a_{2} \Sigma x_{1} x_{2}=\Sigma x_{1} y \\
& a_{0} \Sigma x_{2}+a_{1} \Sigma x_{1} x_{2}-a_{2} \Sigma x_{2}^{2}=\Sigma x_{2} y .
\end{aligned}
$$

In this instance they will only be applied to the 700 to $977^{\circ} \mathrm{K}\left(800\right.$ to $\left.1300^{\circ} \mathrm{F}\right)$ temperature span since the single time point, roughly replicated three times at 1000 hours over 966 to $1039^{\circ} \mathrm{K}$, will strongly bias the coefficient $\mathrm{n}$ towards unity. Use of the 700 to $977^{\circ} \mathrm{K}$ data yields for $\mathrm{N}$, the number of observations, equal to 6 , and noting that $(2 \pi \mathrm{rL})=298.7 \mathrm{~cm}^{2}: \Sigma \mathrm{y}=-37.37$, $\Sigma y^{2}=233.407, \Sigma x_{1}=19.785, \Sigma x_{1}^{2}=65.827, \Sigma x_{2}=7.384 \times 10^{-3}, \Sigma x_{2}^{2}=9.171 \times 10^{-6}$, $\Sigma x_{1} x_{2}=24.349 \times 10^{-3}, \Sigma x_{1} y=-123.002, \Sigma x_{2} y=-46.205 \times 10^{-3}$, from which,

$$
\begin{array}{ll}
\mathrm{a}_{0} & =-4.369, \\
\mathrm{a}_{1} & =+0.385, \\
\mathrm{a}_{2} & =+2.568 \times 10^{+3}, \\
\mathrm{~s}^{2}\left(y_{\cdot} x_{1} x_{2}\right) & =0.0054, \\
\mathrm{~s}^{2}\left(\mathrm{a}_{1}\right) & =0.0092, \\
\mathrm{~s}^{2}\left(\mathrm{a}_{2}\right) & =6.46 \times 10^{+4},
\end{array}
$$

where

$$
\begin{array}{ll}
s^{2}\left(y \cdot x_{1} x_{2}\right) & =\left[s\left(y^{2}\right)-a_{1} s\left(x_{1} y\right)-a_{2} s\left(x_{2} y\right)\right] /(N-3) \\
s^{2}\left(a_{1}\right) & =C_{11} s^{2}\left(y \cdot x_{1} x_{2}\right) \\
s^{2}\left(a_{2}\right) & =C_{22} s^{2}\left(y \cdot x_{1} x_{2}\right) \\
s\left(y^{2}\right) & =\left[N \Sigma y^{2}-(s \cdot y)^{2}\right] / N \\
s\left(x_{1}^{2}\right) & =\left[N \Sigma x_{1}^{2}-\left(\Sigma x_{1}\right)^{2}\right] / N \\
s\left(x_{2}^{2}\right) & =\left[N \Sigma x_{2}^{2}-\left(\Sigma x_{2}\right)\right] / N
\end{array}
$$




$$
\begin{aligned}
& \mathrm{s}\left(x_{1} x_{2}\right)=\left[\mathrm{N} \dot{x}_{1} x_{2}-\dot{x}_{1} \dot{u x}_{2}\right] / \mathrm{N} \text {, } \\
& S\left(x_{1} y\right)=\left[N x_{1} y-\because x_{1} \ddot{z y}\right] / N \text {, } \\
& s\left(x_{2} y\right)=\left[N \dot{x}_{2} y-\ddot{y} x_{2}: y\right] / N, \\
& C_{11}=s\left(x_{2}^{2}\right) / \text { (Det.). } \\
& \mathrm{C}_{22}=\mathrm{s}\left(x_{1}^{2}\right) / \text { (Det.). }
\end{aligned}
$$

$C_{12}=C_{21}=s\left(x_{1} x_{2}\right) /($ Det. $)=0$ in this particular instance since $s\left(x_{1} x_{2}\right)=0$.

$$
\text { (Det.) }=\left|\begin{array}{ll}
\mathrm{s}\left(\lambda_{1}^{2}\right) & \mathrm{s}\left(x_{1} x_{2}\right) \\
\mathrm{s}\left(x_{1} x_{2}\right) & \mathrm{s}\left(x_{2}^{2}\right)
\end{array}\right|
$$

Thus, expression (A-15) on a weight loss per unit area basis $\left(\mathrm{g} / \mathrm{cm}^{2}\right)$ at a given temperature, $T$, (as opposed to a temperature span, $T_{\mathfrak{i}}$ to $T_{0}$ ) for nonlinear response becomes

$$
\log \Delta \mathrm{W}_{(\mathrm{n})}^{u}=-4.389+0.385 \log \mathrm{i}+\log 2 \mathrm{~T}=2.508 \times 10^{+3} \mathrm{~T}^{-1}
$$

\section{Linear Response}

\section{a. Rate Considerations}

The weight luss-time response is assumed to be given by

$$
\Delta W^{\prime}=\Delta W_{0}^{\prime}+k_{(\ell)} t
$$

To adapt the previous temperature dependency principles at $\mathrm{t}=0$ and $\Delta \mathrm{W}^{\prime \prime}=0$, in which the linear expression must be written

$$
\Delta \mathrm{W}^{\prime}-\Delta \mathrm{W}_{0}^{\prime}=\mathrm{k}_{(\mathrm{l})} \mathrm{t} .
$$

Treated as before, this expression becomes 


$$
\left.\left.\left(\Delta W^{\prime}-\Delta W_{0}^{\prime}\right)\left[(2 \pi r L)\left(T_{0}+T_{i}\right) t\right]^{-1}=k_{0(()} A^{-1}(())^{\exp }\right\}-A_{(c)}\left[\left(T_{0}+T_{i}\right) / 2\right]^{-1}\right\}
$$

There are only three temperature spans where $\Delta W_{0}^{\prime}$ mảy be determined. 700-755, 755-866. and $866-977^{\circ} \mathrm{K}$.

Since there are but two time points, $\Delta W_{0}^{\prime}$ can be exactly determined as

$\begin{array}{llll}700-755^{\circ} \mathrm{K} & 0.0747 & \mathrm{~g} & \text { (total), } \\ 755-866^{\circ} \mathrm{K} & 0.2060 & \mathrm{~g} & \text { (total). } \\ 866-977^{\circ} \mathrm{K} & 0.2724 & \mathrm{~g} & \text { (total). }\end{array}$

The logarithmically transformed regression equations of expression (A-18) will be similar to those of expression $(A-14)$ with $\Delta W^{\prime}$ replaced by $\left(\Delta W^{\prime}-\Delta W_{0}^{\prime}\right)$ and $t^{1 / 2}$ replaced by $t . \quad N$ will have a value of 6 and $(2 \pi \mathrm{rL})$ a value of $298.7 \mathrm{~cm}^{2}$. The summation values are $\Sigma y=-60.052$, $\Sigma \mathrm{y}^{2}=602.306, \Sigma x_{1}=7.384 \times 10^{-3}, \quad \Sigma x_{1}^{2}=9.170 \times 10^{-6}, \quad \Sigma x_{1} \mathrm{y}=-74.219 \times 10^{-3}$ from which

$$
\begin{array}{ll}
\mathrm{a}_{0} & =-5.304, \\
\mathrm{a}_{1} \ldots & =+3.823 \times 10^{+3} \\
\mathrm{~s}^{2}\left(\mathrm{y} \cdot \mathrm{x}_{1}\right) & =0.0157, \\
\mathrm{~s}^{2}\left(\mathrm{a}_{1}\right) & =18.8 \times 10^{+4}
\end{array}
$$

Here, $s^{2}\left(y \cdot x_{1}\right)$ and $s^{2}\left(a_{1}\right)$ are determined as for expression (A-14). Thus, the metal loss above $\Delta \mathrm{W}_{0}^{\prime}$ for a linear response, in $\mathrm{g} / \mathrm{cm}^{2}$ at a given temperature, $\mathrm{T}$, will be

$$
\log \left(\Delta \mathrm{W}^{\prime \prime}-\Delta \mathrm{W}_{0}^{\prime \prime}\right)_{(\ell)}=-5.304+\log \mathrm{t}+\log 2 \mathrm{~T}-3.823 \times 10^{+3} \mathrm{~T}^{-1}
$$

* Equation (3), page 17 corrected for change of units. 
b. Intercept $\left(\Delta \mathrm{W}_{0}^{\prime}\right)$ Considerations

The discussion, page 46 , of linear response kinetics established $\Delta \mathrm{W}_{0}$ (Figure 22, page 47) as the ratio of two rate constants, i. e., $\Delta W_{0}=k_{1} / k_{2}$, where $k_{2}$ is equivalent to $\mathrm{k}_{(\ell)}$ in expression (A-18). The $\Delta \mathrm{W}_{0}$ data, (Figure 3 , page 13) suggest that as the temperature increases the ratio $\mathrm{k}_{1} / \mathrm{k}_{2}$ may not continue to increase as dictated by the Arrhenius temperature dependence. This can only be true if the rate constants $\mathrm{k}_{0}$ and $\mathrm{A}$ associated with $\mathrm{k}_{1}$ and $\mathrm{k}_{2}$ are changing with temperature. Additional time points in the $966-1039^{\circ} \mathrm{K}$ range should clarify this point. Here, without a measured $\Delta \mathrm{W}^{\prime}{ }_{0}$ for the highest temperature range, and to avoid the difficulties of using $k_{(2)}$ (in $\Delta W_{0}^{\prime}=k_{1} / k_{2}$ ) whirh has a varianr.e, $\wedge \mathrm{W}_{0}^{\prime}$ will he assumed to have the same form with respect to temperature as has the rate constant $\mathrm{k}_{(\ell)}$ in expression(A-18). However, with only three values, the 95 percent confidence limits, applied in the next paragraph in the calculation of total amounts of Incoloy oxidized in superheated steam are unrealistically high. To avoid this situation, an extra degree of freedom is obtained by calculating the mean slope from expression (A-20) and running its line through the mean of three values at about 1000 hours in the 966 to $1039^{\circ} \mathrm{K}$ range. When this is done the data to be treated are

\begin{tabular}{|c|c|c|c|}
\hline $\begin{array}{l}\text { Temperature } \\
\text { Range, }{ }^{\circ} \mathrm{K} \\
\end{array}$ & $\begin{array}{c}\Delta W_{0}^{\prime} /(2 \pi r L) \\
\times 10+3 \\
\end{array}$ & $\mathrm{y}$ & $x_{1} \times 10^{+3}$ \\
\hline $700-755$ & 0.25 & -6.763 & 1. 374 \\
\hline $755-866$ & 0.69 & -6.371 & 1. 233 \\
\hline $866-977$ & 0.91 & -6.307 & 1. 085 \\
\hline $966-1039$ & 2.16 & -5.958 & 0.997 \\
\hline
\end{tabular}

where

$$
\begin{aligned}
& \mathrm{y}=\log \Delta \mathrm{W}_{0}^{\prime}\left(\mathrm{T}_{0}+\mathrm{T}_{\mathrm{i}}\right)^{-1}, \\
& \mathrm{a}_{0}=\mathrm{k}_{\left(0, \Delta \mathrm{W}_{0}^{\prime}\right){ }^{\mathrm{A}}\left(\Delta \mathrm{W}_{0}^{\prime}\right)}, \\
& x_{1}=\left[\left(\mathrm{T}_{0}+\mathrm{T}_{\mathrm{i}}\right) / 2\right]^{-1} .
\end{aligned}
$$

Proceeding similarly to the steps taken in the evaluation of expression (A-14), the summation values are $\Sigma y=25.399, \Sigma y^{2}=161.604, \Sigma x_{1}=4.689 \times 10^{-3}$, $\Sigma x_{1}^{2}=5.579 \times 10^{-6}, \Sigma x_{1} y=29.931 \times 10^{-3}$. These lead to values of

$$
\begin{array}{ll}
a_{0} & =-4.113 \\
a_{1} & =+1.98 \times 10^{+3}
\end{array}
$$




$$
\begin{aligned}
& s^{2}\left(y \cdot x_{1}\right)=0.0135 \\
& s^{2}\left(a_{1}\right)=16.5 \times 10^{+4}
\end{aligned}
$$

Thus, the rise in $\Delta W_{0}^{\prime \prime}, \mathrm{g} / \mathrm{cm}^{2}$, as a function of temperature $T$, is

$$
\log \Delta \mathrm{W}_{0}^{\prime \prime}=-4.113+\log 2 \mathrm{~T}-1.908 \times 10^{+3} \cdot \mathrm{T}^{-1}
$$


IV. TOTAL CORROSION IN TERMS OF DESCALED METAL LOSS (PER UNIT AREA) OF INCOLOY IN SUPERHEATED STEAM

\section{Curvilinear Response}

The mean loss, as a function of time is given by expression $(\mathrm{A}-17)$ as

$$
\log \Delta \mathrm{W}_{(\mathrm{n})}^{i}=-4.369+0.385 \log \mathrm{t}+\log 2 \mathrm{~T}-2.568 \times 10^{+3} \mathrm{~T}^{-1},
$$

where $\Delta W_{(n)}^{\prime \prime}$ will be in $\mathrm{g} / \mathrm{cm}^{2}, t$ in hours and $\mathrm{T}$ in ${ }^{\circ} \mathrm{K}$. For given temperatures and times 95 percent confidence limits can be placed upon extrapolated values of $\Delta \widetilde{W}^{\prime \prime}(n)$ through the use of

$$
\log \Delta \tilde{W}_{(\mathrm{n})}^{\prime \prime}=[\operatorname{expression}(\mathrm{A}-17)] \pm\left(\mathrm{t}_{05, N-3,)} \sqrt{\operatorname{var}\left(\log \Delta \widetilde{\mathrm{W}}_{(\mathrm{n})}^{\prime \prime}\right)}\right.
$$

where an estimate of $\operatorname{var}\left(\log \Delta \tilde{\mathrm{W}}_{(\mathrm{n})}^{\prime \prime}\right)$ is given by

$$
\operatorname{var}\left(\log \Delta \widetilde{\mathrm{W}}_{(\mathrm{n})}^{\prime \prime}\right)=\left(\mathrm{s}_{\mathrm{y} \cdot x_{1}{ }_{2}}^{2}\right)\left[\frac{1}{\mathrm{~N}}+\mathrm{C}_{11}(\log \tilde{\mathrm{t}}-\overline{\log \mathrm{t}})^{2}+\mathrm{C}_{22}\left(\tilde{\mathrm{T}}^{-1}-\overline{\mathrm{T}}^{-1}\right)^{2}\right]
$$

in which the covariant term is omitted since in this particular case $C_{12}=C_{21}=0$, and in which

$$
\begin{aligned}
\frac{\tilde{t}}{\log t}= & \text { is the desired time, } \\
& \text { experimental times } \\
\widetilde{T}= & \text { the desired temperature, } \\
\bar{T}^{-1}= & \text { the mean of the reciprocal } \\
& \text { experimental temperatures. }
\end{aligned}
$$

$\mathrm{N}$ has the value 6 and, therefore, $\mathrm{t}_{05,3}=3.183$. Also, $\mathrm{s}^{2}{\mathrm{y} . \mathrm{x}_{1} x_{2}}=0.0054$, $C_{11}=1.708$ and $C_{22}=11.98 \times 10^{+6}$. Using these values and noting that $1 \mathrm{mg} / \mathrm{dm}^{2}=$

$1 \mathrm{~g} / \mathrm{cm}^{2} \times 10^{+5}$, the following values of the mean $\Delta \mathrm{W}$. and its 95 percent confidence limits are obtained for 1,2 , and 3 years at 1050,1150 , and $1300^{\circ} \mathrm{F}$ through use of expressions (A-17) and (A-22). 


\begin{tabular}{|c|c|c|c|c|c|}
\hline & \multicolumn{4}{|c|}{$\begin{array}{l}\text { Descaled metal loss for curvilinear response. } \mathrm{mg} / \mathrm{dm}{ }^{2} \text {. for a mean of } \\
\log \Delta \mathrm{W}_{(\mathrm{n})}=0.361+0.385 \log \mathrm{t} \text { (hours) }+\log 2 \mathrm{~T}\left({ }^{\circ} \mathrm{K}\right)-2.568 \times 10^{+3} \cdot \mathrm{T}^{-1}\left({ }^{\circ} \mathrm{K}\right) *\end{array}$} \\
\hline & & \multicolumn{4}{|c|}{ Temperature ${ }^{\circ} \mathrm{F}$} \\
\hline & & 1050 & 1150 & 1300 & \\
\hline \multirow{3}{*}{1 Year } & Lower & 129 & 193 & 339 & \\
\hline & Mean & 214 & 332 & 631 & \\
\hline & Upper & 357 & 575 & 1180 & \\
\hline \multirow{3}{*}{2 Years } & Lower & 137 & 207 & 374 & $\because$ \\
\hline & Mean & 278 & 430 & 817 & \\
\hline & Upper & 565 & 895 & 1790 & \\
\hline \multirow{3}{*}{3 Years } & Lower & 148 & 212 & 387 & \\
\hline & Mean & 327 & 505 & 960 & \\
\hline & Upper & 720 & 1235 & 2380 & \\
\hline
\end{tabular}

* Equation (4), page 17

\section{Linear Response}

In this instance the expected value of $\Delta \tilde{W}_{(\ell)}^{\prime}$ can be determined from expressions $(A-20)$ and (A-21) with 95 percent confidence limits given by (on a unit area basis)

$$
\log \left(\Delta \tilde{W}^{\prime \prime}-\Delta W_{0}^{\prime \prime}\right)=[\operatorname{expression}(A-20)] \pm\left(t_{05}, N-2\right) \sqrt{\operatorname{var} \log \left(\Delta \tilde{W}^{\prime \prime}-\Delta W_{0}^{\prime \prime}\right)}
$$

where

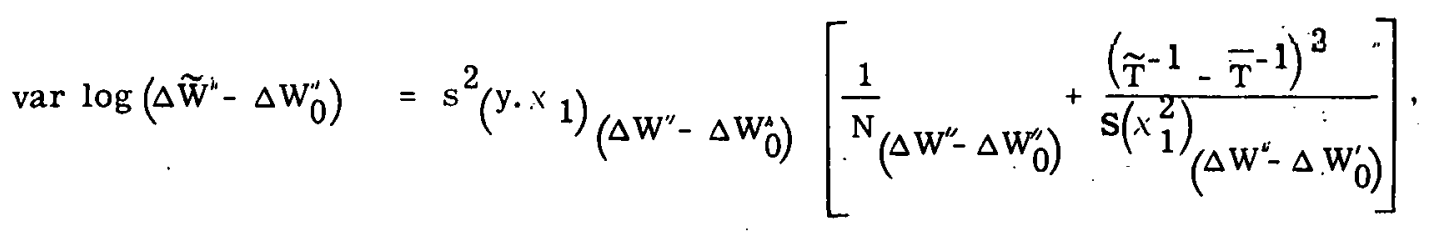

and,

$$
\log \Delta \tilde{W}_{0}^{\prime \prime}=[\operatorname{expression}(A-21)] \pm\left({ }^{t} 05, N-2\right) \sqrt{\operatorname{var} \log \left(\Delta W_{0}^{\prime \prime}\right)}
$$




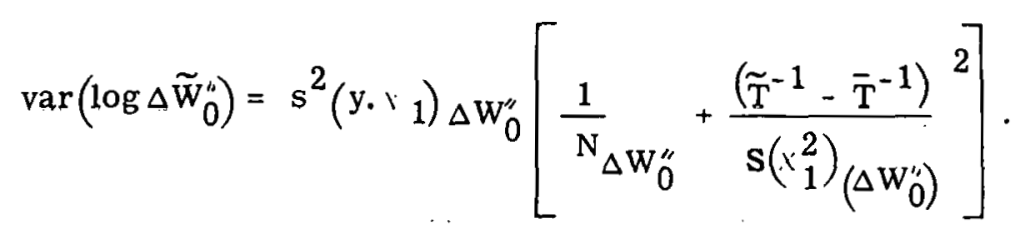

In the case of $\Delta W^{\prime \prime}-\Delta W_{0}^{\prime \prime}$,

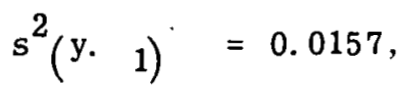

$$
\begin{aligned}
& \mathrm{N}_{\left(\Delta \mathrm{W}^{\prime}-\Delta \mathrm{W}_{0}^{\prime}\right)}=6 \text { and } \\
& \mathrm{t}_{05,4}=2.78 \text {. }
\end{aligned}
$$

In $t_{05, N-2, N}=6$ is only approximate since there are really 3 , twice replicated observations, each pair of replicates establishing the line $\left(\Delta \dot{W}^{\prime \prime}-\Delta W_{0}^{\prime \prime}\right)=k_{(\ell)}$ t. $\widetilde{T}$ and $\bar{T}^{-1}$ have the same meaning as before.

$$
s\left(x_{1}^{2}\right)_{\left(\Delta W^{\prime \prime}-\Delta W_{0}^{\prime \prime}\right)}=8.35 \times 10^{-8}
$$

In the case of $\Delta W_{0}^{\prime \prime}$

$$
\begin{array}{ll}
\mathrm{s}^{2}\left(\mathrm{y}_{1} x_{1}\right) & =0.0135, \\
\mathrm{~N}_{\Delta \mathrm{W}_{0}^{\prime \prime}} & =4, \\
\mathrm{t}_{05,2} & =4.30, \\
\widetilde{\mathrm{T}} \text { and } \overline{\mathrm{T}}^{-1} & =\text { are as before, } \\
\mathrm{s}\left(x_{1}^{2}\right)_{\Delta \mathrm{W}_{0}^{\prime}} & =8.23 \times 10^{-8} .
\end{array}
$$

With these values and the use of expressions (A-20), (A-21), (A-23), and (A-24) the following values of the mean $\Delta W$ in $\Delta W=\Delta W_{0}+k_{(l)} t\left(m g / \mathrm{dm}^{2}\right)$ and its 95 percent confidence limits for 1,2 , and 3 years at 1050,1150 , and $1300^{\circ} \mathrm{F}$ are as follows. 


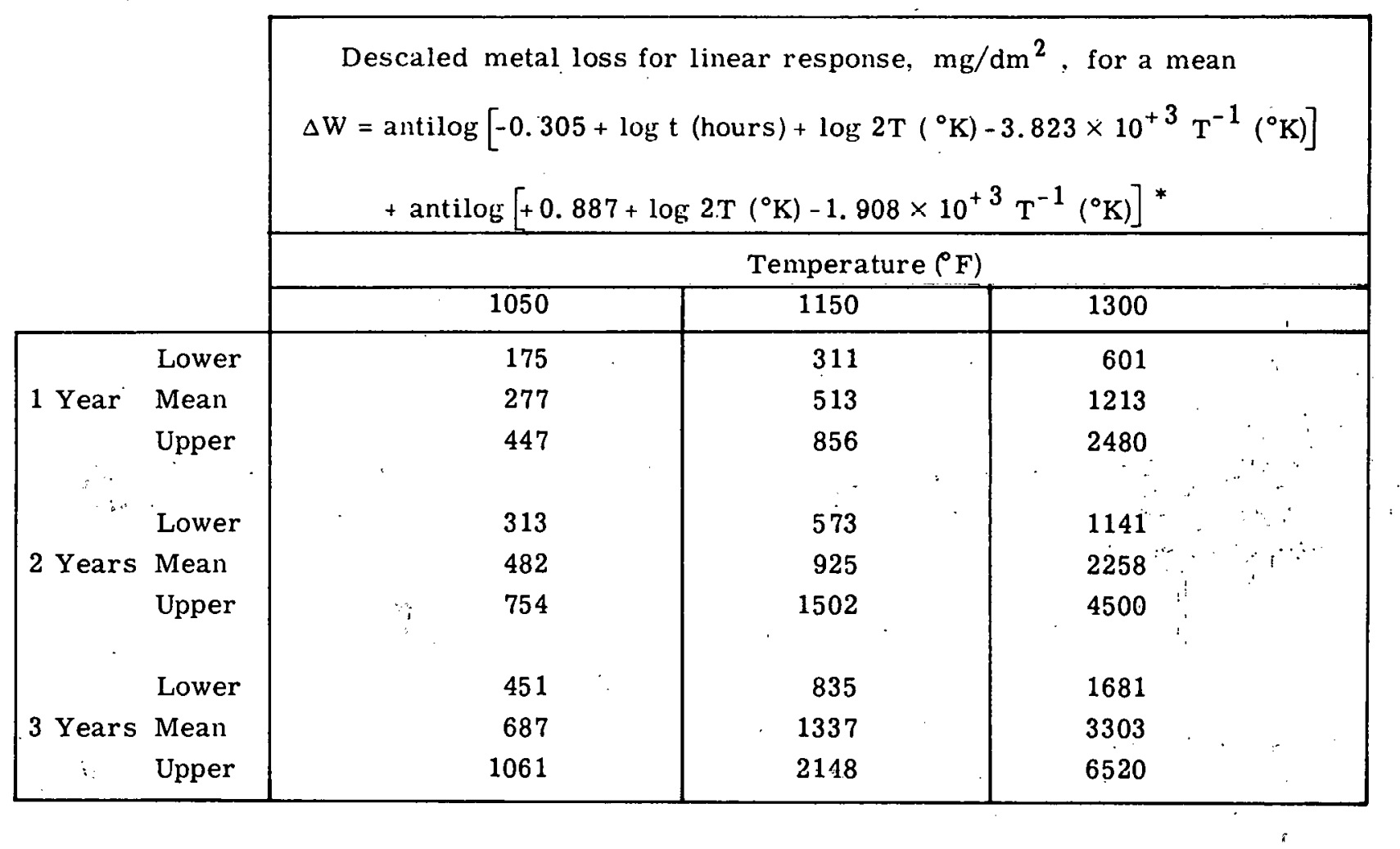

* Equation 5, page 17 
C. A. Pursel, Dir.

Reactor Engineering Div.

Chicago Operations Office

U. S. Atomic Energy Commission 9800 South Cass Avenue

Argonne, Illinois

W: H. Brummett, Jr., Dir.

Contracts Division

U. S. Atomic Energy Commission San Francisco Operations Office

2111 Bancroft Way

Berkeley 4, California

Dr. J. M. West

General Nuclear Engineering Corp.

P. O. Box 245

Dunedin, Florida

Gunnar Johnson

Nuclear Power Dept. - Greendale

P. O. Box 512

Milwaukee 1, Wisconsin

Dr. A. V. Crewe

Argonne National Laboratory

A Box 299

Lemont, Illinois

Arthur F. Miller

Business Manager

Combustion Engineering, Inc.

Pruclear Dlvision

Windsor, Connecticut

E. C. Ward

Northern States Power Co.

Minneapolis, Minnesota

$\mathrm{J}$, Wright.

Atomic Power Department

Westinghouse Electric Corp.

P. O. Box 355

Pittsburgh 30, Pennsylvania

Jules Wise

U. S. Atomic Energy Commission

New York Operations Office

376 Hudson Street

New York 14, N. Y.

W. R. Voigt

Chief, Water Reactors Branch

U. S. Atomic Energy Commission

Washington 25, D. C. 
D. F. Cope

Director, Reactor Div.

Oak Ridge Operations Office

U. S. Atomic Energy Commission

P. O. Box $E$

Oak Ridge, Tennessee

W. S. Dowis

Hanford Atomic Products Operation

Irradiation Processing Department

General Electric Company

Richland, Washington

Nuclear Utilities Services, Inc.

$1730 \mathrm{M}$ Street, NW

Washington, D. C. 20036

ATTN: J. C. Scarborough

Brussels Office - USAEC

U. S. Mission to the European Communities

23 Avenue Des Arts

Brussels. Belgium

ATTN: Scientific Representatives 